\title{
Screen, Simulation, Situation: An Archaeology of Early Film Animation, 1908-1921.
}

\author{
by
}

Daniel McKenna

\begin{abstract}
A thesis submitted to the Faculty of Graduate and Postdoctoral Affairs in partial fulfillment of the requirements for the degree of

Master of Arts

in
\end{abstract}

Film Studies

Carleton University

Ottawa, Ontario

(C) 2014 Daniel McKenna 


\begin{abstract}
Recent film scholarship has turned to the kinetic element of cinema as a way of bridging analog and digital practice, often latching on to animation as the vehicle for describing this relationship. This study thus explores the origins of animation in cinema from 1908-1921 in an attempt to construct a meaningful connection between old and new animated media. Two filmmakers in particular pioneered the first animated films at this time: Winsor McCay and Emile Cohl. These graphic artists illustrated the ability of the animated image, even in its most nascent stages in film history, to negotiate a personalized expression of reality through a myriad of technological and sociocultural shifts which threatened to efface their artistry. Positioned between contemporary and archaic forms of animated media, their work functions as a paradigm of how to understand the animated image through the three cinematic components of screen, simulation, and situation.
\end{abstract}




\section{Table of Contents}

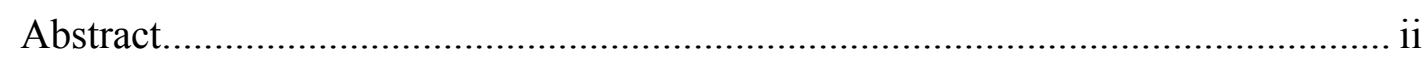

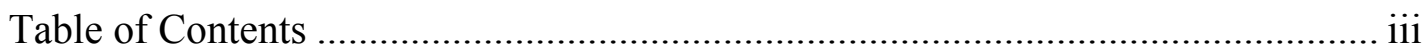

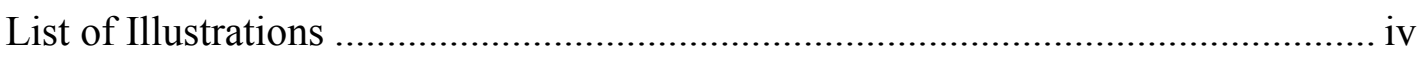

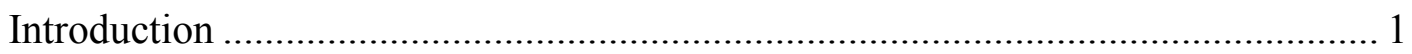

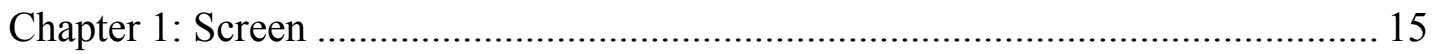

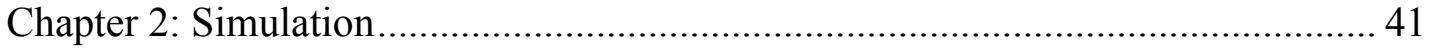

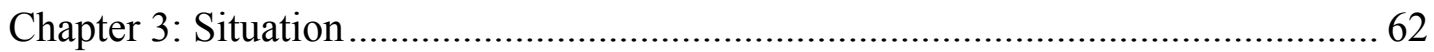

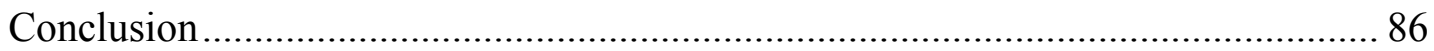

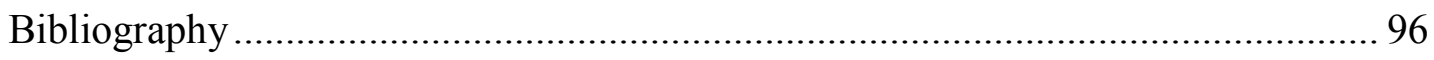




\section{List of Illustrations}

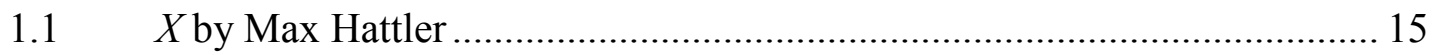

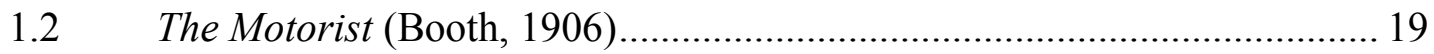

1.3 "Little Nemo in Slumberland" (McCay, 1908) …………………............... 19

$1.4 \quad$ "Little Sammy Sneeze” (McCay, 1905) .................................................... 21

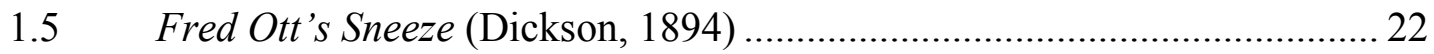

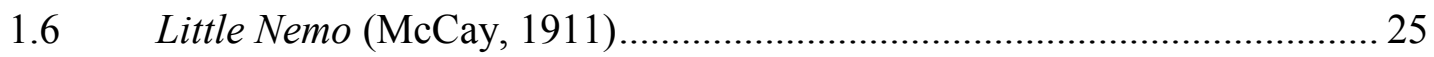

1.7 Little Nemo as McCay's self-figuration...................................................... 27

1.8 Nemo imitates McCay's lightning-sketch performance............................... 27

1.9 Offscreen space and three-dimensional perspective in Little Nemo ........... 27

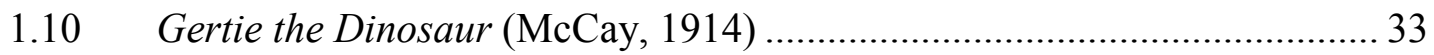

1.11 Historical "record" in The Sinking of the Lusitania (McCay, 1918)........... 35

1.12 Realistic detail and fluid movement in The Sinking of the Lusitania........... 35

1.13 The ship's final "curtain call" in The Sinking of the Lusitania ................... 37

1.14 Framing human wreckage in The Sinking of the Lusitania .......................... 38

1.15 The dream grasps the spectator in Bug Vaudeville (McCay, 1921) ............ 39

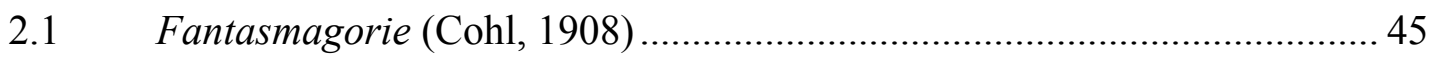

2.2 Illustration of Robertson's Phantasmagoria ................................................ 48

2.3 Phantasmagoria as cinema in Fantasmagorie (1908) ………………........ 56

$2.4 \quad$ The Puppet's Nightmare (Cohl, 1908) ......................................................... 57

2.5 The Mind of a Café Waiter (Cohl, 1910) ................................................... 58

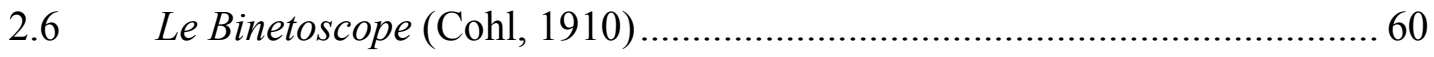

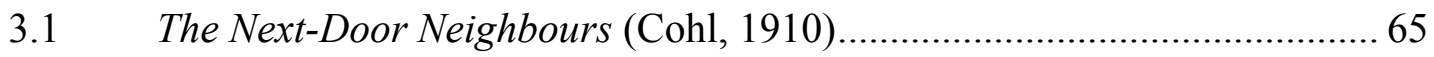

3.2 The Next-Door Neighbours and Robertson's optical schematics................. 66

3.3 En Route (Cohl, 1910), opening and closing images ................................. 82

3.4 Rien n'est impossible à l'homme (Cohl, 1910) ............................................. 83

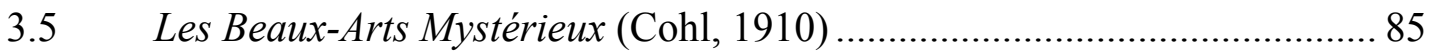

4.1 New York plasticity in "Dream of the Rarebit Fiend" (McCay, 1905) ...... 87

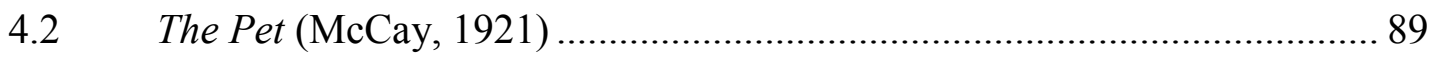

4.3 Inward vision in Rien n'est impossible à l'homme (Cohl, 1910) ................ 95 


\section{Introduction}

In July of 1927, a private exhibition was held in the honour of cartoonist Winsor McCay, featuring his pioneering animated films of the previous decade. Sometime during the event, an increasingly irritated McCay stood up after several drinks and sullenly condemned the state of the animation industry to his fellow animators sitting before him:

Animation is an art. That is how I conceived it. But as I see, what you fellows have done with it, is making it into a trade. Not an art, but a trade. Bad Luck! $!^{1}$

The industrialized production of animation filmmaking, which he had long since retired from, was for McCay the sounding of the death knell of its artistic potential in handing its vivifying power over to mechanized apparatuses. His embittered sentiment dismissed the work of contemporaries such as J.R. Bray and Max Fleischer (the latter being in attendance to introduce McCay's speech), animators who had engineered the industrialization of the animated film and whose early success paved the way for Disney's eventual domination of the film industry. American cartoons circulated freely in mainstream venues on both sides of the Atlantic, while lively formal experiments were undertaken by thriving European avant-garde movements. The following day, a New York Times reviewer lightly commented that McCay had expressed to his audience that "the art of animated cartoons had not progressed, and that its possibilities were unlimited".

McCay's resentful commentary now seems oddly prescient in light of how film scholarship has traditionally marginalized animation as artistic cinema's invisible stepchild. Recently, however, animation has emerged in the digital age as a way of highlighting a decline of

\footnotetext{
${ }^{1}$ John Canemaker, Winsor McCay: His Life and Art (New York: Abbeville Press, 1987), 159.

2 "Winsor McCay gives exhibition." The New York Times July 20, 1927, 29.
} 
photochemical technology in cinema. The moving image has a tendency to be defined by the technology that creates it. For instance, to speak of a digitally animated production as a "film" in the familiar sense is perhaps a fallacy, as these productions do not use celluloid or the analog film camera, but the label persists, stemming from a history of defining cinema through photochemical technologies capable of exact visual reproduction. This historical conjunction which enabled a link between cinema and a pre-existing external reality is often understood as an indexical relationship. This sense of indexicality as essential to cinema has been put in question by the digital turn in moving-image entertainment, which has opened the moving image to all sorts of novel manipulations that seem to undermine the supposed link between filmic representation and the extra-filmic referent. In attempting to resolve this inconsistency, scholars have turned to the kinetic element of cinema as a way of bridging analog and digital practice, often latching on to animation as the vehicle for describing this relationship.

However, as animation historian Donald Crafton has argued, this expanded view of animation is perhaps too conveniently applied:

As a mechanical technique, yes, the practice predated cinema and continues into the putative post-cinema digital era (that is, now). For a long time we have been rapidly replacing images in series to make them appear to move - on wheels, discs, strips of film, video and computer screens. The animation effect, however, doesn't define the medium. Its biomechanical nature is a given. ${ }^{3}$

In other words, the conflation of animation with the digital moving image disregards the complexity of an intricate concept. As such, this study returns to the origins of animation in cinema, investigating its historical intricacies in an attempt to construct a meaningful connection between old and new animated media. Specifically, I return to the moment when early film

${ }^{3}$ Donald Crafton, "The Veiled Genealogies of Animation and Cinema," Animation: An Interdisciplinary Journal, 6.2 (2011): 105. 
animators first confronted cinema's indexical relationship by placing photochemical technology discernibly in the service of projected motion. My analysis focuses on two filmmakers who pioneered the development of the animated film in the late 1900s and early 1910s: American comic strip artist Winsor McCay, and his French contemporary, Emile Cohl. For these pioneer animators, the photographic elements of cinema were primarily a means to achieving illusions and abstractions of moving images. The same could arguably be said for early trick film directors who manipulated staging and editing to produce illusions of physical impossibilities; unlike trick artists, however, whose deception relied on photographed reality, McCay and Cohl filmed hand-produced images in sequence, introducing their training as static imagists into a kinetic medium. Moreover, their "tricks" were not hidden, but put on display as a spectacle of movement. Their images were real in the sense that their movement, or their imbuement with life, as such, was perceived as real, even as their films openly declared and embraced their artifice. Drawing on the idea that the impression of movement amounts to a continuous thread that links early and contemporary film practices, I argue that revisiting the role of animation in early film history provides new perspectives on its contemporary manifestations. Specifically, the cases of Winsor McCay and Emile Cohl demonstrate the ability of the animated image, even in its most nascent stages in film history, to negotiate a personalized impression and expression of reality through a myriad of technological and sociocultural developments which threatened to efface their artistry.

\section{Defining Animation}

What constitutes an animated image? The earliest animated films were not described as such, and were often grouped by exhibitors and trade journals with single-frame cinematographic productions, such as trick films. Many were described in terms equivalent to "moving pictures" 
or "drawings that move", and words like "animation" or "animated" were used in varying ways to describe cartoons and live-action images alike, often to denote a heightened intensity about the movement of the picture. ${ }^{4}$ Only after major animation studios moved towards a streamlined industrial production process, making the individual artisan largely obsolete, did the term acquire its dominant associations with the hand-crafted, non-photographic image. This was reflected in the first manual of animation written by Edwin G. Lutz in 1920, entitled Animated Cartoons: How They are Made, their Origin and Development, which concretized the main principles of the medium at that time. ${ }^{5}$ The first book to be solely devoted to the craft of animation, it described various ways of producing as few drawings as possible for efficient output. It was a process that was, at the time, entirely geared towards the studio production of cartoon characters which looked not unlike those found in comic strips (as evidenced by the book's explanatory illustrations). Most importantly, it provided a simplified aesthetic and technological script for any aspiring animator to follow (one of whom was a young Walt Disney, who familiarized himself with Lutz' basic strategies and applied them to his own work). The influx of animated productions resulting from this optimized process established generic conventions synonymous with "animation", many of which have survived as familiar understandings of the medium. Paul Wells lists some of these genre conventions - anthropomorphic configuration, narrative continuity, stylistic unity, and the effacement of the artist, to name a few - as constituting "orthodox" animation, referring to its iconic Disneyesque form. ${ }^{6}$ Having acquired its own set of "orthodox" conventions, animation was no longer intertwined with its live-action relatives, and was discursively displaced by the photoreal image colonizing conceptualizations of cinema's specificity.

\footnotetext{
${ }^{4}$ Crafton, 2011: 103.

${ }^{5}$ Donald Crafton, Before Mickey: The Animated Film 1898-1928 (Cambridge: MIT Press, 1982), 201.

${ }^{6}$ Paul Wells, Understanding Animation (New York: Routledge, 1998), 36-38.
} 
The discursive authority of "orthodox animation" as a definition of the medium has begun to slip away in a digital environment, where the historical separation of "animation" from "cinema" has produced a contested terrain where each term is understood in varying ways as a subset of the other. The fact that animation, as a concept and a practice, predates the origin of the film camera has given rise to the idea that "animation begat cinema". ${ }^{7}$ This framework has been adopted largely in an attempt to historically account for digitally-produced images, fashioning a convenient genealogical niche for digital animation amidst a heterogeneous lineage of analog moving-image technologies, as Lev Manovich does here:

Manual construction and animation of images gave birth to cinema and slipped into the margins... only to reappear as the foundation of digital cinema. The history of the moving image thus makes a full circle. Born from animation, cinema pushed animation to its periphery, only in the end to become one particular case of animation. ${ }^{8}$

For Manovich, digital cinema is a form of animation in which live-action footage is merely one of its many compositional elements. This definition is grounded in the indexical properties of film and photography, presupposing a link between reality and the photochemical technology that captures it - a link that digital cinema is said to have severed by compromising the immutability of the photograph. Animation is a way of describing contemporary cinema as if it is no longer the "art of the index", or "an attempt to make art out of a footprint".

Manovich's digital model, compelling as it is, tends to broaden animation into a nebulous umbrella term which attempts to reconcile the presupposed tension in the moving image between its mutable digital form and the immutable indexicality of its photochemical form. It has been challenged, most notably by Donald Crafton, on the basis that the supposedly "linear path" traced

${ }^{7}$ Crafton, 2011: 107.

${ }^{8}$ Lev Manovich, "Digital Cinema and the History of a Moving Image", The Film Theory Reader: Debates and Arguments, ed. Marc Furstenau (New York: Routledge, 2010), 252. 
from nineteenth century animation technology to cinema "has been formed by our unreflective familiarity with animation cinema and with cinema, luring us to give a name to what formerly were artifacts and techniques without a classification". Crafton instead argues for historically specific definitions of animation, as searching the past for an "avatar" of a present object can produce a counterintuitive historical account of romanticized causality. For example, it is important to acknowledge that film animation proper (i.e. not trick-film ancestors) only emerged after photoreal cinema as a medium was entrenched as a cultural institution. The cinematograph defied the ephemerality of its nineteenth century antecedents in part because it so vigorously forced them into obsolescence while absorbing their spectacular allure. Animation on film, however, arrived post hoc and was thus unburdened with discarding the shell of novelty status. It assumed the descriptive language of its trick-film predecessors, frequently incorporated live-action into its diegesis, and was exhibited alongside its photoreal counterparts. How, then, to characterize its derivation from nineteenth century modernity and visual culture, as well as its equally palpable connection to the contemporary moving image?

Tom Gunning offers a useful approach here in re-examining the over-privileged status of the index in cinema's relationship to reality:

Cinema has never been one thing. It has always been a point of intersection, a braiding together of diverse strands...the discussion of cinematic realism cannot be allowed to ossify into a dogmatic assertion about the photographic nature of cinema or an assumption about the indexical nature of all photography. ${ }^{9}$

This has resulted, as Manovich also notes, in a marginalization of animation, but Gunning argues that "far from being a product of new media, animation has always been part of cinema and that only the over-emphasis given to the photographic basis of cinema in recent decades can explain the

\footnotetext{
9 Tom Gunning, "Moving Away from the Index: Cinema and the Impression of Reality", The Film Theory Reader: Debates and Arguments, ed. Marc Furstenau (New York: Routledge, 2010), 259-60.
} 
neglect this historical and technological fact has encountered". In this vein, cinematic motion ought to be privileged at least as equally as indexicality. Specifically, it is the synthetic motion of the projected image which triggers a sense of participatory kinesthesia in the spectator and forges an impression of reality.

In light of this, I wish to suggest that the dominant thread in the history of animation, from the nineteenth century to the present, is movement as both the impression and expression of reality. Movement is the key here because it evinces a sense of vitality to the still image that is perceived as "real". This has been called the "illusion of life", a slogan used by both the Lumière brothers and Walt Disney to describe live-action and animation respectively. Consequently, it is a phrase which Alan Cholodenko understands as a "fascination with the way in which an apparatus animates - gives movement and life to - images of people and things". ${ }^{10}$ However, Cholodenko's position questionably attributes life-giving powers to a fundamentally inanimate mechanical object which produces the expression of its operator. As Gunning reminds us, "the apparatus, in itself, can neither lie nor tell the truth"11 - it produces an image which is mediated by the expression of its author and the impression it makes upon the spectator. As such, animation cannot be swept wholesale into the index-as-trace argument, nor can it be discounted solely on the basis of a different form of indexicality. This allows for an expansion of the theory that an impression of reality is forged from the spectator's visceral experience of kinesthesia when perceiving projected motion. If one's impression of reality derives from this interior phenomenological experience, then animation constitutes an expression of reality which both consciously and unconsciously plays to this experience, questioning the primacy of photographic reality in the process.

\footnotetext{
${ }^{10}$ Alan Cholodenko, ed., The Illusion of Life: Essays on Animation (Sydney: Power Publications), $1991,20$.

11 Tom Gunning, "What's the Point of an Index? Or Faking Photographs," Still/Moving: between Cinema and Photography, ed. Karen Beckman and Jean Ma (Durham: Duke University Press), 2008, 28.
} 
This effect has been explained elsewhere without direct reference to animation. Gunning argues that a semiotic view of the index - a sign with a referent - is insufficient in describing the entire effect of the photographic image, an image which "opens up a passageway to its subject, not as a signification but as a world, multiple and complex". He aligns this with André Bazin's view that the photographic image places the spectator in the "presence of something", noting how the critic's ontological musings are often over-associated with the prevailing view of the index as a trace of reality. Bazin himself noted that the expressive power of photography surpassed the boundaries of its basic representative function when he wrote that the photograph "actually contributes something to the natural order of creation instead of providing a substitute for it". ${ }^{12}$

This speaks to the phenomenological approach toward the impression and expression of reality in animation, which attempts to articulate its anchorage in the "real". Vivian Sobchack offers a useful framework for this reality in her discussion of film as embodied vision. Observing major trends in film theory, Sobchack terms realist tendencies as treating film as "perception-in-itself", or "objectivity freed from entailment with the prejudicial investments of human being" - and conversely, formalist tendencies treat film as "expression-in-itself", which is "subjectivity freed from worldly constraint". ${ }^{13}$ Sobchack further argues that neither should necessarily exclude the other, as both are bound up in intentionality, an act of consciousness through which the spectator is brought into the presence of with the film image. Therefore, "the existential and embodied act of viewing becomes the paradigm of this exchange of both perception and expression" in the image. The film experience can be articulated thusly as simultaneously the "perception-of-expression" and the "expression-of-perception". If "perception" here is substituted with "impression", what surfaces might be described as the animation experience.

${ }^{12}$ André Bazin, What is Cinema? Trans. Hugh Gray, Volume 1 (Berkeley: University of California Press, 1967), 15.

${ }^{13}$ Vivian Sobchack, "Phenomenology and the Film Experience", Viewing Positions: Ways of Seeing Film, ed. Linda Williams (New Jersey: Rutgers University Press), 1995, 46. 
The crucial difference between the "perception" and "impression" of reality here is that the latter "does not at all commit us to the nonsensical position that we take the cinema image for reality, that we are involved in a hallucination or 'illusion' of reality that could cause us to contemplate walking into the screen, or interacting physically with the fictional events we see portrayed". Rather, an impression of reality engages spectator fantasy, activated by motion which "need not be realistic to have a 'realistic' effect - that is, to invite the empathetic participation, both imaginative and physiological, of viewers". Animation has historically catered to this effect, often but not always self-reflexively, expressing an impression of the world constantly mediated by screens, simulations, and situational experiences.

This, I believe, helps to account for the animated image in its wide array of technological incarnations, including the digital. It avoids defining cinema as a strictly photographic medium and steps away from doctrinal reiterations of its traceable origins in tangible reality, which discussions of the digital image often tend towards. As animators have generally rejected the desire to approximate photographic reality, animation is in a position to be examined for its awareness of what the moving image does, both for and with its audience. As such, animation is less about recording and representing the sensation of movement as much as it is concerned with producing the sensation of movement, which in turn offers unique insights into phenomenological experience. It is for this reason that, as Crafton suggests, defining the material borders of animation is merely a matter of semantics, as its classification under these terms only serves to further marginalize the study of its phenomenology. This may be an overly polemical suggestion for some, but in any case, it draws our attention to the possibility that outlining the material contours of such a pliable object provides only short-term gain, which makes the historicizing of their transformations all the more essential. If we can't define animation in terms of its 
materiality or differing indexical relationship, how do we then define it? If we define it solely at the level of movement, then what makes it distinct from other forms of moving image?

\section{Archaeology of Animation}

In arguing against a historically-linear genealogy, Crafton suggests that a "meaningful 'archaeology of cinema' would not consist of scanning [nineteenth century optical] objects looking for avatars of future cinema or animation, but in trying to understand the values they delivered to their users and how those consumers and commentators applied them". Similarly, a meaningful connection between the animated films and their contemporary relatives must be drawn with a similar understanding in mind. Anticipating Crafton's logic, Thomas Elsaessar proposes a useful framework for such a connection, rejecting teleological progression in favour of a non-linear, archaeological mode of inquiry:

...the successive phases of the cinema, but also the cinema's relation to other media-forms, such as television, video art and digital media, can be mapped by analysing their different and distinct diegetic worlds, comprising the technical apparatus and mental dispositifs, but also dependent on the temporal, spatial and enunciative locators/activators that together constitute their particular "ontology."14

Elsaessar uses the term "diegesis" here to refer to the "meta-space that enables and regulates the kinds of contact that can be made between audience space and screen space". ${ }^{15}$ The "diegetic worlds" of old and new media-forms, then, can be mapped based on their material, mental, and situational mechanisms which are in conversation with their users and creators.

These mechanisms resonate with three essential cinematic elements highlighted in Esther Leslie's analysis of Emile Cohl, which are central to much of early animation:

\footnotetext{
${ }^{14}$ Thomas Elsaessar, "The New Film History as Media Archaeology”, Cinémas: Journal of Film Studies, 14.2 (2004): 110.

${ }^{15}$ Elsaessar, 93-94.
} 
Animation, the giving of life, battles with annihilation, and always overcomes, always reasserts the principle of motion, of continuation and renewal...Through the intervention of the artist's hand, through the knowing play with surface and depth, and through an acknowledgement of screen, simulation, and situation, Cohl reveals the derivation of the over-lively objects. ${ }^{16}$

Taking these components - screen, simulation, and situation - as a rough guideline of how early animators acknowledged the inner workings of their kinetic medium, animation can be understood as a media-form with a particular ontology. The following chapters will examine in-depth each of these components as they relate to the work of McCay and Cohl.

The first chapter, "Screen", drawing from Winsor McCay's work as an example, examines the treatment of the projection surface by early animators as a physical gateway to imaginary realms, or a medium for the material presence of incorporeal subjects. The first animated films creatively staged their fantastical subject matter to emphasize the spectacle of inanimate figures infused with movement. This often involved foregrounding the conspicuous presence of the artist within the film, a conventional practice for a time when the largely artisanal animation process was mythologized as a laborious triumph. Donald Crafton has elaborated extensively on this practice, known as the "hand of the artist" motif, signifying the animator as the locus of generative agency a common form of authorial self-inscription in pre-cel animation which subsided over time. The emphasis on the animator's performativity, however, tends to overlook the equally performative role of the screen itself, deployed as a self-reflexive strategy to stage the animation. Specifically, the creative manipulation and abstraction of screen space to stage the realistic movement of non-photoreal figures, usually by containing them in screen-like surfaces represented by visually defined frames, was intended to mediate the visible presence of invisible or incorporeal figures.

\footnotetext{
${ }^{16}$ Esther Leslie, Hollywood Flatlands: Animation, Critical Theory and the Avant-Garde (New York: Verso, 2002), 2, emphasis added.
} 
The animator could choose to either re-enforce or abstract the defined spatiality of these frames, often playing with the multiplicity of "screens" present within the singular, overarching frame of the cinematograph projection. Not merely a neutral substrate for content, the multi-layered "screen" in early animation took on a life of its own as a self-reflexive material vehicle for the immaterial or imaginary.

The second chapter, "Simulation", explores the impression of movement perceived in the animated figures on the screen, drawing from the work of McCay's French contemporary Emile Cohl. Both animators employed single frame cinematography and stop-action substitution to construct the transformation of their images, consisting primarily of drawings, layered paper cut-outs, and occasionally puppets (as in the case of Cohl). How did these inanimate figures, when projected in sequence, perform a realistic simulation of lifelike fantasy? Here, the early nineteenth century projection display known as the "Phantasmagoria" is a useful paradigm of this simulative process, establishing a tension that these animators would negotiate between animation, the individual's power to effect transformation, and automation, which gave this power to a mechanized apparatus.

The early animated film demonstrated how synthetic cinematic motion concretized the realistic impression of an image through movement primarily through the manipulation of graphic lines. McCay and Cohl were skilled illustrators who were both partial to the fluid transformations of the graphic line, a quality of animation which Sergei Eisenstein would later term “plasmaticness". Vivian Sobchack contends that the graphic line foregrounds animation's ontological difference from photoreal cinema: unlike the photograph, the line is a conceptual object having no material existence outside its formal representation, and as such is particularly suited for magical thinking and representing the immaterial. In extending the kinesthetic 
properties of the autonomous graphic line to other forms of animation, it becomes evident that the animated medium has an instinctual ability to appeal to a sense of lifelike presence usually attributed to the indexical or iconic, eschewing the photoreal across photochemical and digital platforms and frequently re-invoking the tension created by the presence of automated processes within a highly personalized art form.

The third chapter, "Situation", locates and further explores this tension within the historical intersection of the early animated film and the modern environment that fostered its nascency. The title here refers not just to these films' acknowledgement of the cinematic spectator's unique position before a screen, but also their historical situatedness in an industrialized modern environment, and the slippage that visibly occurs between these two situations. This chapter attempts to understand the early animated film as a product of an urban visual culture which encouraged spectators to see, en masse, mediated forms of reality - characterized by the proliferation and ubiquity of the mass press, museums, and optical toys, to name a few. It was within this spectacular milieu that Winsor McCay and Emile Cohl produced the first fully animated films, replete with fantastic imagery mediated by the hand of the artist. The acknowledgement of formal manipulation in the animated film was equally an implicit recognition of the spectator's active perceptual role in a cinematic setting. As such, animation freely experimented with spatial organization and perspective ("Screen") while rejecting the photoreal as a "window" upon the world in favour of depicting fluid movement ("Simulation"). In essence, early animation internalized the perceptual experience of the fin-de-siècle urban spectator and re-presented it as spectacle. Specifically, sensing the industrialization of their art which threatened to efface the artist, these animators emphasized their status as the conjurers of this spectacle, reconstituting themselves as the agents of vision which could vivify that which was 
previously inanimate. Furthermore, this reconstitution of the animator's power of vision was not just a turn-of-the-century phenomenon; it was the culmination of a much longer process in which this privileged position, originally held by mystifying figures of power, was gradually given over to the individual amongst the anonymous collective of newly-enlightened spectators.

The historical sweep of this analysis, vast as it might appear, is necessary to reconnect contemporary understandings of animation with what it meant to those who first brought it into the filmic medium. The value of this connection derives from the period in which McCay and Cohl worked, pre-“orthodox" animation (to borrow Wells' term for post-industrialized studio animation). Being further removed from the constraints of generic conventions and assembly-line aesthetics allows the work of these individual artisans to better reflect the profound influence of nineteenth century spectacular entertainment, which was gradually veiled by the time animation-devoted studios began to thrive and which continues to live on primarily in contemporary digital experimental art. Their ambiguous attitude towards the modern moment which both enabled and hindered their personal artistry and visionary power remains a constant thread in animation history, from the early Phantasmagoria to current digitally-automated manifestations. Situating "animation" as both concept and practice at the heart of this formative experience thus recasts its historical separation from cinema as a relationship where both concepts engage with each other in a mutual negotiation of critical theory and aesthetic form. In doing so, we might be able to interrogate the contemporary manifestations of this separation in a similar vein. 


\section{Chapter One: Screen}

Visitors venturing to London's King’s Cross Filling Station in the summer of 2012 were greeted by an extraordinary sight. Simple geometric shapes, animated in Flash on a black background, were projected upon a giant screen of water; the black became imperceptible, while the bright figures were caught in the mist and appeared to hover over the canal, transforming into increasingly complex abstract compositions (Figure 1.1).

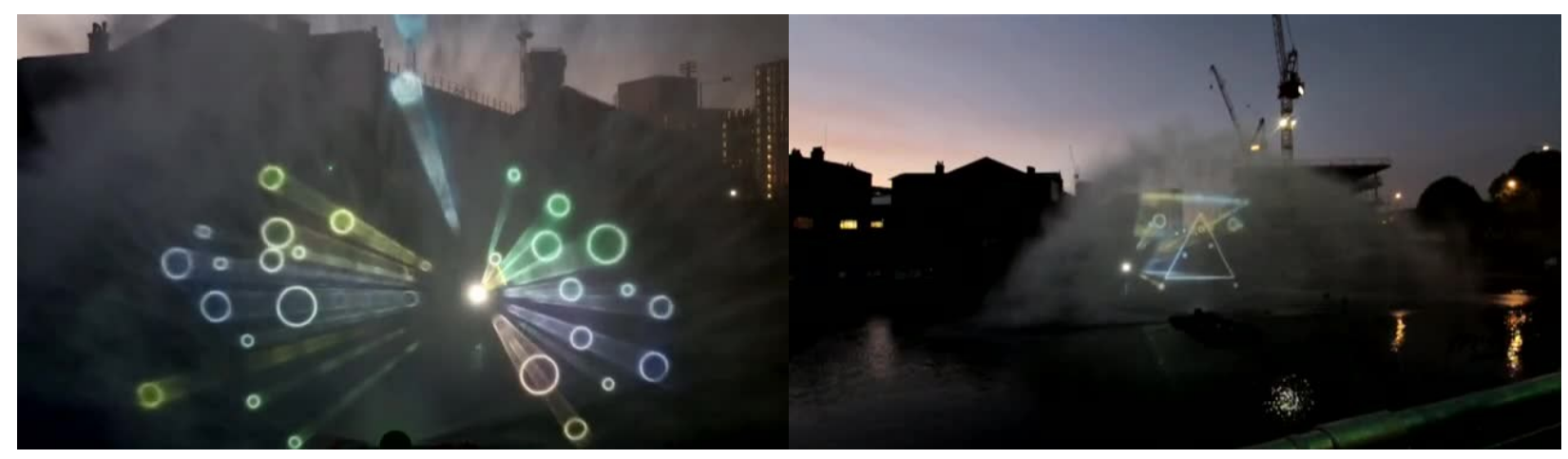

Figure 1.1. $X$ by Max Hattler. Images taken from Vimeo presentation. $<$ http://vimeo.com/49029399>

This display, modestly entitled $X$ in reference to a mutable algebraic variable, was designed by German moving-image artist Max Hattler. His animated exhibition is symptomatic of a growing fascination with the formal capabilities of digital projection found in contemporary experimental installations. One can observe this innovative spirit at work in public galleries and museums, as well as other areas outside these traditional exhibition spaces. Artists like Hattler are responding to the omnipresent glowing electronic rectangle, characterized here by Mitchell Whitelaw as an ubiquitous "neutral substrate":

For all the diversity of the contemporary media ecology - network, broadcast, games, mobile - one technical form is entirely dominant. Screens are everywhere, at every scale, 
in every context. As well as the archetypal "big" and "small" screens of cinema and television we are now familiar with pocket- and book-sized screens, public screens as advertising or signage, urban screens at architectural scales...the ubiquitous digital screen is characterised by both generality - an ability to display any content at all - and self-effacing slightness - it tries to make itself disappear as a neutral substrate for content. ${ }^{1}$

Whitelaw further suggests that digital animation which departs from the content neutrality of the screen and becomes site-specific - such as immersive light themed art installations, for example is reflective of "post-screen" practice. ${ }^{2}$ These experimental projection displays are designed with a high degree of specificity, both in and of the screen, exploring creative alternatives to the portentous uniformity of digital media. Moreover, not all of them are strictly limited to the avant-garde realm - for instance, many of these artists work with mainstream musicians on stage displays for live performances (Hattler is one such artist who frequently collaborates with musicians in his work, channeling an obvious Oskar Fischinger influence).

As an investigation into early animation demonstrates, however, the screen has not always been so self-effacing as to warrant a "post" prefix to describe a departure from the familiar "glowing rectangle". ${ }^{3}$ The performative space of this luminous surface negates its neutrality, transforming it into a lively space negotiating what Anne Friedberg terms "twin paradoxes" of spectatorship:

Facing a screen, the spectator/user/viewer is caught in a phenomenological triangle - twin paradoxes - of mobility and immobility (the mobility of images; the immobility of the spectator) and of materiality and immateriality (the material space of the theater, domicile, or office and the immateriality of the cinematic, televisual, or computer image). The screen functions as an architectonic element, opening the materiality of built space to

\footnotetext{
${ }^{1}$ Mitchell Whitelaw, “After the Screen: Array Aesthetics and Transmateriality”, Column, 7 (2011): 50-57.

2 Whitelaw, 57.

3 Whitelaw does acknowledge that 'this 'post' is nothing like a conscious critique, let alone a revolutionary break...the inescapable irony is that the outcomes of this work are entirely bound up in screenful images". Whitelaw, 56.
} 
virtual apertures in an 'architecture of spectatorship'.

The screen thus virtually accesses the immaterial for the spectator, making it especially essential for exhibiting the imaginary worlds animation has generally been tasked with representing. Early animators were all too aware of the film screen's function as a virtual keyhole, and their work reflected this awareness. Their films often foregrounded the animator's presence by depicting the animator interacting with his moving creations, displayed with inventive framing choices. The screen architecturally participates in the performance as the manipulation of its inner and outer space becomes central to the staging of the animated material. Crucially, this performance was not isolated in animated cinema; animators borrowed as much from early films as they did from various other media they had experience in, such as vaudeville "lightning sketching," comic strips, and caricature. In each case, their films looked ahead to future screen-centric experiments while invoking earlier visual practices concerned with visualizing expressions of invisible realities. In what follows, I will examine Winsor McCay's career as an early paradigm of animation's self-reflexive capabilities, and as an important synthesis of old and new media which laid the foundations for a distinct emergent medium.

\section{Winsor McCay}

Prior to his filmmaking career, Winsor McCay had established himself as the most prolific American illustrator of the early 20th century. His early drawings for dime-museum posters and Cincinnati newspapers, as well as his vaudeville lightning-sketch performances, demonstrated an unmatched skill for drafting photorealistic detail from memory. In 1903 McCay's talent brought him to New York, where his impressive skill at quickly producing complex comic strips made him

${ }^{4}$ Anne Friedberg, The Virtual Window: From Alberti to Microsoft (Cambridge: MIT Press), 2006, 150. 
the most coveted cartoon artist in the newspaper business. He pioneered the development of the comic strip with his immensely popular Sunday cartoon series, especially "The Dream of the Rarebit Fiend" and "Little Nemo in Slumberland". In these series, McCay combined comical gags with the unbounded freedom of dream logic and its physical and perceptual impossibilities, expressed through highly detailed drawings that transformed themselves from panel to panel. The popularity of the strips eventually attracted the patronage of William Randolph Hearst, who hired McCay to illustrate the inflammatory editorials of American editor Arthur Brisbane.

Though he enjoyed a lucrative career under Hearst's employ, the magnate's tyrannical demand for output eventually began to hinder the cartoonist's creativity; but not before McCay, in 1911, at the height of "Little Nemo's" popularity, released the groundbreaking animated film of the same name. Showcasing his lightning-quick sketching ability, his eye for realistic perspective, and awareness of cinematic movement, the film set McCay on a unique direction in filmmaking and cemented his place in cinema animation history.

Much has been made about McCay's transition from comics to film, inspiring extensive work on how the cartoon strip, as the elder medium, directly influenced film form. ${ }^{5}$ This influence, which has been overstated, has had the unfortunate effect of exaggerating the immediate aesthetic similarities between comics and film animation (often simply their hand-drawn nature) and thus encouraging claims of causation with little empirical evidence. ${ }^{6}$ It is more accurate to view these media as influencing each other in a common negotiation of aesthetic form. This is especially true of McCay, who, prior to experimenting with animated motion pictures, likely frequented the cinematograph displays commonly found at vaudeville exhibitions during his early

\footnotetext{
5 See John Fell, Pascal Lefebvre, and Francois Lacassin for notable examples of this work.

${ }^{6}$ Crafton, 1982: 47.
} 
career as a lightning-sketcher. ${ }^{7}$ From the early cinema of his time McCay would have been able to glean the technical knowledge required to bring his cartoon characters to life on screen and also an acute awareness of how this screen functioned in an increasingly popular and ever-present entertainment medium.

Evidence for cinema's influence on McCay is scattered throughout his comic strips. An example concerns the extent to which his comic strips directly lift their fantastical narratives from famous films. Rather than simply ape the filmic material, however, McCay's illustrations visually expanded on the original premise. One not-so-subtle example of this is found in a 1908 "Little Nemo in Slumberland" strip in which Nemo and mischievous companion Flip drive a car up the side of a building, in a scene reminiscent of W.R. Booth's famous trick film from 1906, The Motorist (Figures 1.2 and 1.3).
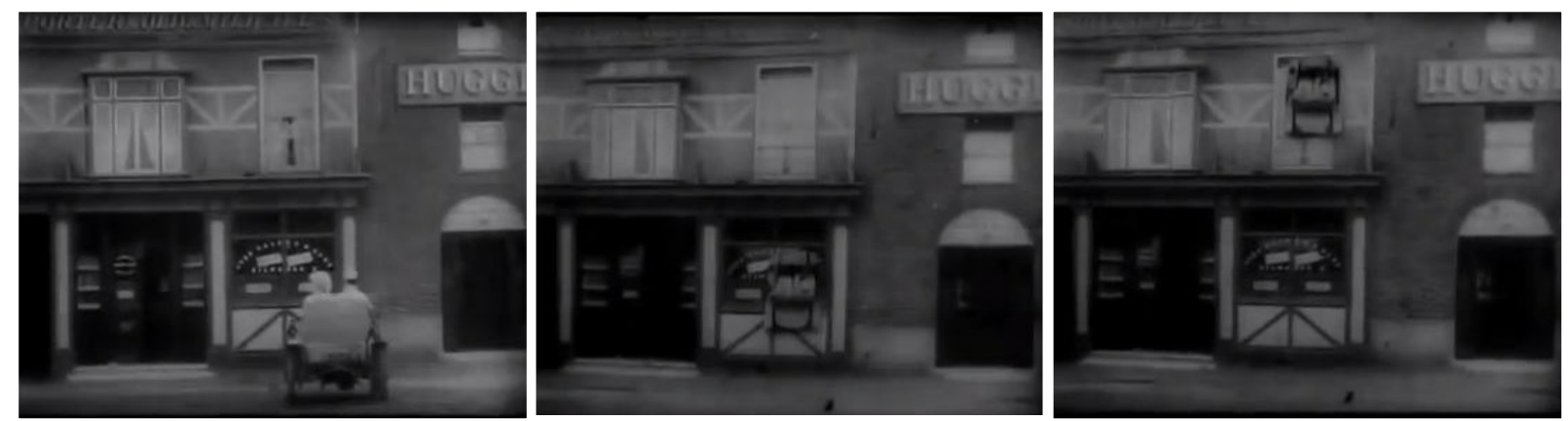

Figure 1.2. The Motorist (Booth, 1906). Images taken from British Film Institute Screenonline entry. $<$ http://www.screenonline.org.uk/film/id/1018840/>

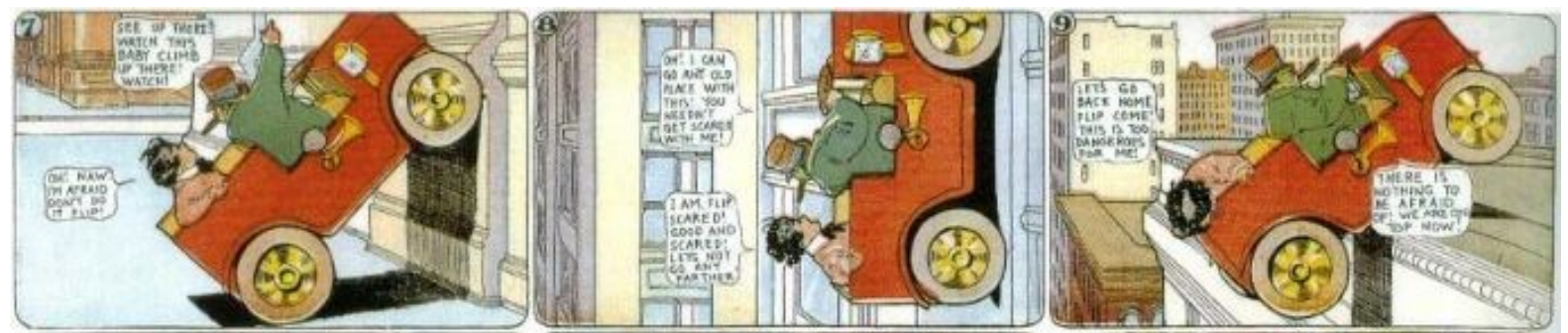

Figure 1.3. "Little Nemo in Slumberland" (McCay, 1908). Image taken from The Comic Strip Library archive. $<$ http://comicstriplibrary.org/display/521>

\footnotetext{
7 Drew Morton, "Sketching Under the Influence? Winsor McCay and the Question of Aesthetic Convergence
} Between Comic Strips and Film," Animation: An Interdisciplinary Journal, 5.3 (2010): 302-303. 
The similarity in visuals involves an importance difference in effect. Booth's trickery is creatively accomplished through blatant cinematic manipulations; but in the dream-space of Slumberland, the physically impossible act of driving a car up a vertical face is more realistically achieved. The trick-film genre invited viewers to imagine (and hopefully marvel at, upon befuddlement) how the trick was done, how the scene was staged; whereas the same tricks performed in McCay's panels invited viewers to imagine how the scene might actually unfold in an alternate reality. The former reinforced the immutability of a tangible reality, while the latter expressed a subversive impression of its real-world logic and physics.

The "Slumberland" series was by no means the first instance of cinema's influence on the illustrator. McCay demonstrated his cinematic literacy in his comic strips as early as 1904, when "Little Sammy Sneeze" first appeared in New York dailies. In this series, the titular character builds up a destructive sneeze in six rigid equi-dimensional panels. In the penultimate panel, the child's violent sneeze climaxes and wreaks havoc on his surroundings, followed by a frame depicting Sammy being booted away for his crass behaviour. The "Sammy" series stands out as a particularly cinematic early comic strip; as Crafton notes, the peculiar size of the black panel borders emulated the square aspect ratio of early films, and the characters within the panels are usually staged in tableau-fashion from the knees-up, a framing choice that was known in film circles as the "American shot". ${ }^{8}$ Some Sammy cartoons, on occasion, even appear to have borrowed their staging from specific instances in early film. One cartoon from January 1905, for example, featuring Sammy sitting down to eat with his parents, mirrors the Lumières' staging of the family in Le Repas de Bébé (1895). ${ }^{9}$

A particularly striking instance of McCay's borrowing from cinematic antecedents appears

\footnotetext{
${ }^{8}$ Crafton, 1982: 93-94.

${ }^{9}$ Crafton, 1982: 94.
} 
in a later strip from September 1905, in which Sammy's signature sneeze breaks the surrounding panel (Figure 1.4). Here, McCay appears to be approximating the first filmic record of a sneeze, captured ten years earlier by W.K.L. Dickson with his assistant Fred Ott before the camera (Figure 1.5). The film's individual frames were then published in a magazine as a sequence of images analyzing the anatomy of the sneeze. McCay breaks away from the typical Sammy formula by omitting background action in the frame, situating the child's trademark routine in a blank white space. Devoid of discernible surroundings, the cartoon's self-reflexive gesture recalls Fred Ott's sneeze which is similarly performed directly for the viewer with a notable absence of background detail.

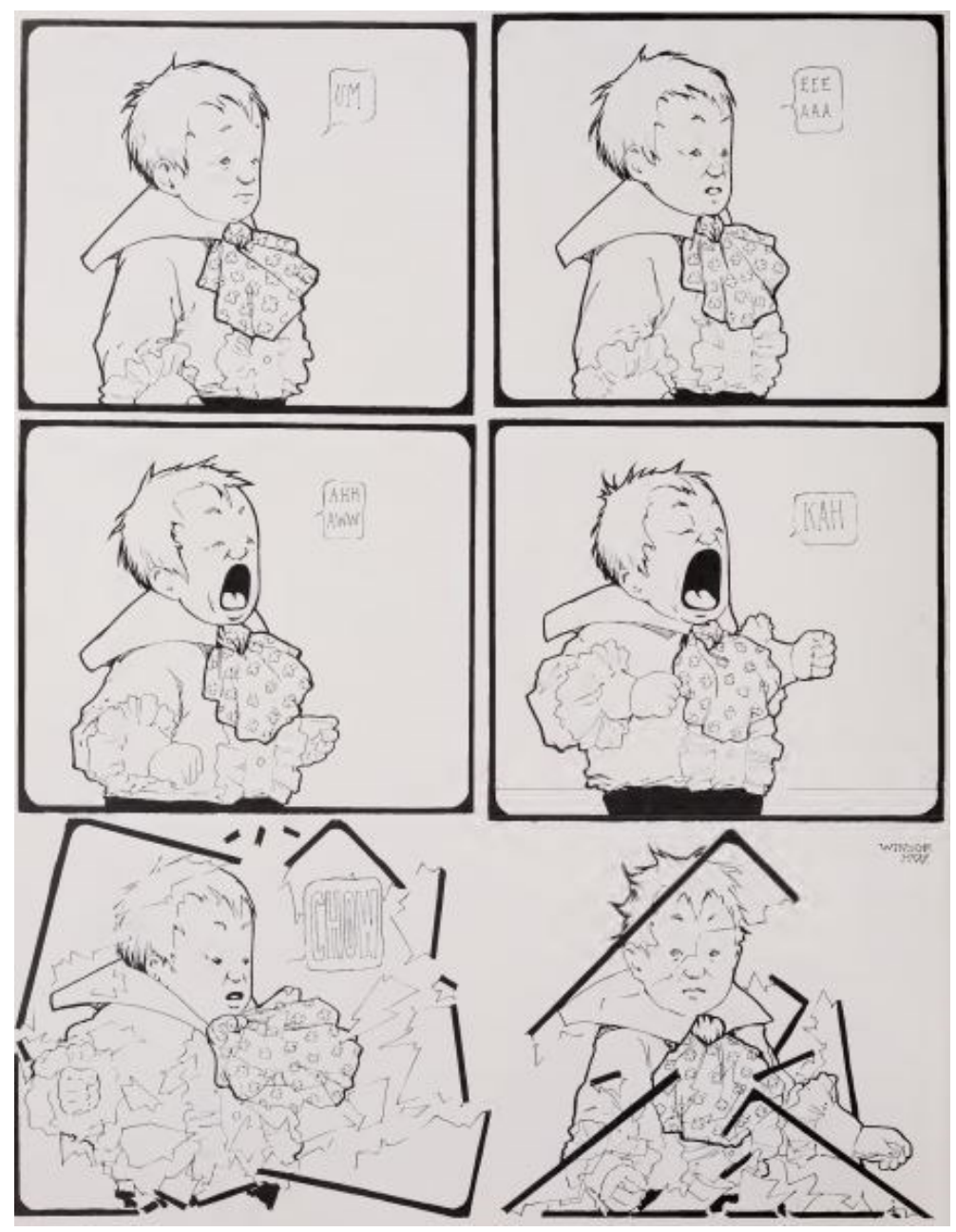

Figure 1.4. "Little Sammy Sneeze" (McCay, 1905). Image taken from Canemaker, 65. 
McKenna 22

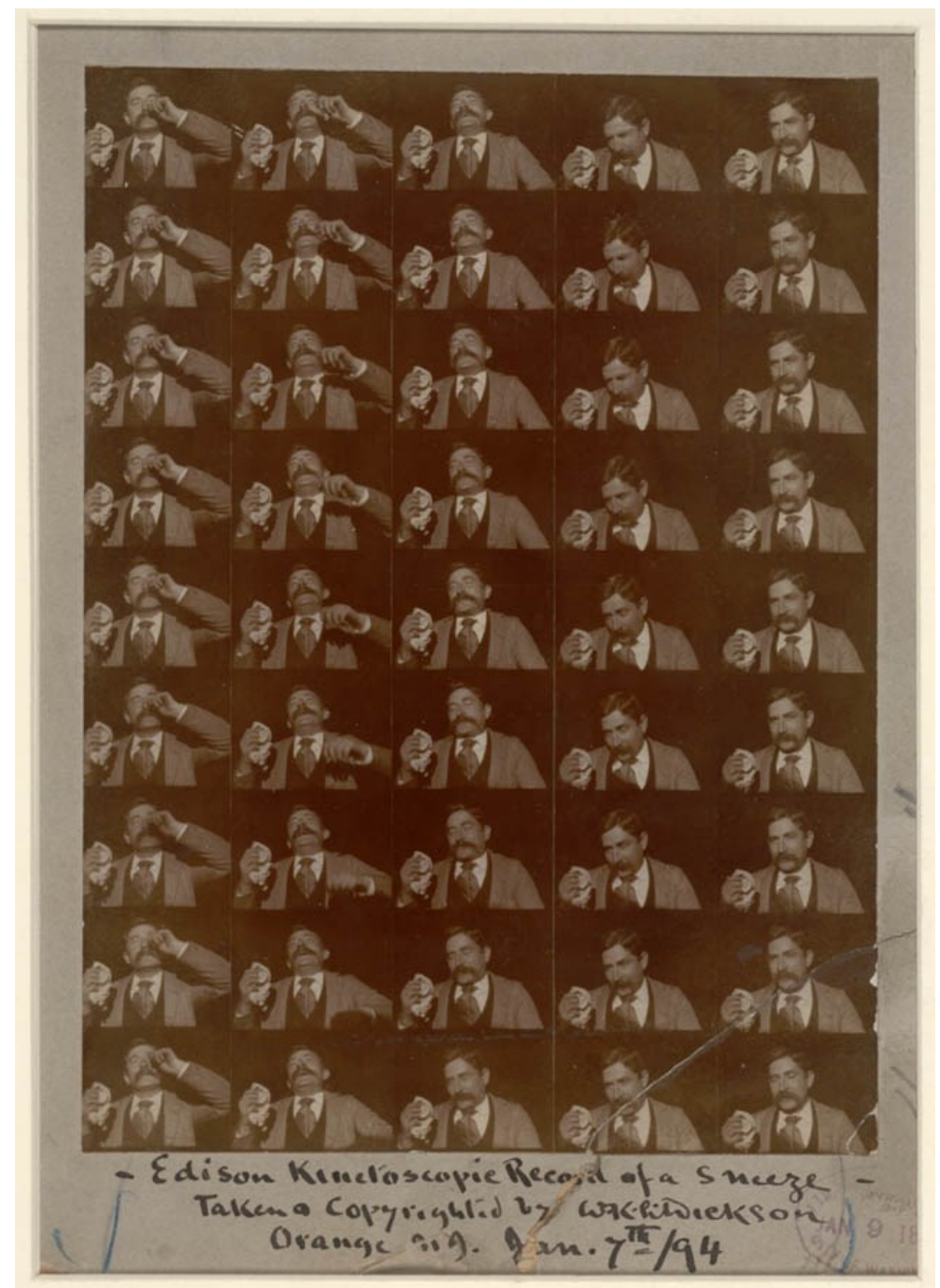

Figure 1.5. Fred Ott's Sneeze (Dickson, 1894). Image taken from Morton, 300.

Both cartoon and film thus draw attention to the frame as a performative object. Dickson's film foregrounds the camera's capacity for capturing and framing real movement; McCay enacts a reflexive spin on this by adapting the frame's capacity for staging reality to his illustrations. Then, Sammy shatters that frame while staring obstinately at his viewers, reminding them of his construction.

At the same time, an important difference is in play. In McCay's cartoon, the debris of the frame appears to be composed of broken window fragments, as if to suggest the capacity of an 
illustration to offer a transparent view upon a world not governed by the laws of external, physical reality (as in Dickson's cinematic analysis of motion) but by an internal dream logic visually expressed by the animator. Each panel presents a frozen moment from the cartoon characters' diegesis, visually narrated by McCay's penstrokes - both invoking and contrasting the exaggerated mimesis of animated photography, from Muybridge's and Marey's iconic 1870s motion experiments to Dickson's kinetoscopic record of a sneeze. In each of these photographic experiments, the subject is extracted from its normal surroundings and deposited into a neutral, "pseudo-scientific abstraction of space", a realm to which the photographic apparatus is given privileged access. ${ }^{10}$ Though McCay's sequential illustrations recall this spatial void, it becomes apparent that there are no "normal surroundings" for the cartoon subjects to be abstracted from; as Sammy (and, later, multiple "Rarebit Fiend" frame-breaking characters) ${ }^{11}$ pointedly demonstrate, their natural environment exists within the illustrator's mind as an imaginary subversion of reality, reconstructed on the static page as a series of sequential snapshots. Thus McCay's flawlessly-rendered anatomy of a sneeze in six stages (the six frame sequence characterized every Sammy cartoon) anticipated the principles of sequentially-constructed motion that he would later deploy in his animated films by collapsing these frames into the single performative proscenium of the film screen. McCay's films almost always acknowledged this screen, as well as the role of motion in collapsing the separate static illustrated units into one frame. Animation for McCay was characterized by the ability of the animator to engage the performative potential of the film screen as a self-reflexive vehicle for the immaterial or imaginary.

\footnotetext{
${ }^{10}$ Nick Jones, “Quantification and Substitution: The Abstract Space of Virtual Cinematography”, Animation: An Interdisciplinary Journal, 8.3 (2013): 256.

11 For notable examples, see Merkl: 2007, DVD image entries 340, 349, 396, 416, 560.
} 


\section{Little Nemo (1911)}

Around 1909, McCay began to develop his Little Nemo cartoon strip for the film screen. He was likely inspired by James Stuart Blackton, whose films were an early prototype of frame-by-frame animation, combining lightning-sketching with trick photography. He also likely saw some of Emile Cohl's first animated films from the French Gaumont studio, which by 1909 had reached the United States. In his own motion-picture work McCay borrowed Blackton's practice of placing the artist before the camera and Cohl's rapidly moving lines, but added his signature complexity of penetrating detail, and fine-tuned the fluidity of movement so that it could look and feel intensely realistic. ${ }^{12}$ McCay debuted Little Nemo in 1911. The first half of the film is a live-action prologue featuring McCay wagering his skeptical friends that he can make his drawings move, and then going about the process of drawing several thousand pictures to be photographed in sequence. The prologue smoothly transitions into animation when a drawing of Nemo's friend Flip is inserted into a stabilizing frame to be photographed - the camera moves in, the framed drawing of Flip fills the frame of the screen. Lettering appears above, announcing his ability to move, and the animation begins (Figure 1.6).

When the camera moves in on the drawing, allowing it to fill the frame and begin to move, a connection is forged between the disparate surfaces of the sketchpad and film screen. The performative role imbued by the drawing surface, which alludes to McCay's lightning-sketching, is consumed by a projection surface occupying the real-world space of the spectator. Two significant markers of the sketch's materiality - stasis and a visible frame - are effaced in the

process. The screen effectively becomes what Friedberg calls a "transitional surface", where

12 Canemaker, 131-132. 
"light becomes a building element in a newly immaterial architecture". ${ }^{33}$ But it is also a performative surface, as the film draws attention to its role as a conduit for the immateriality of McCay's imaginary characters to colonize the material space of the spectator's perceptual sphere.

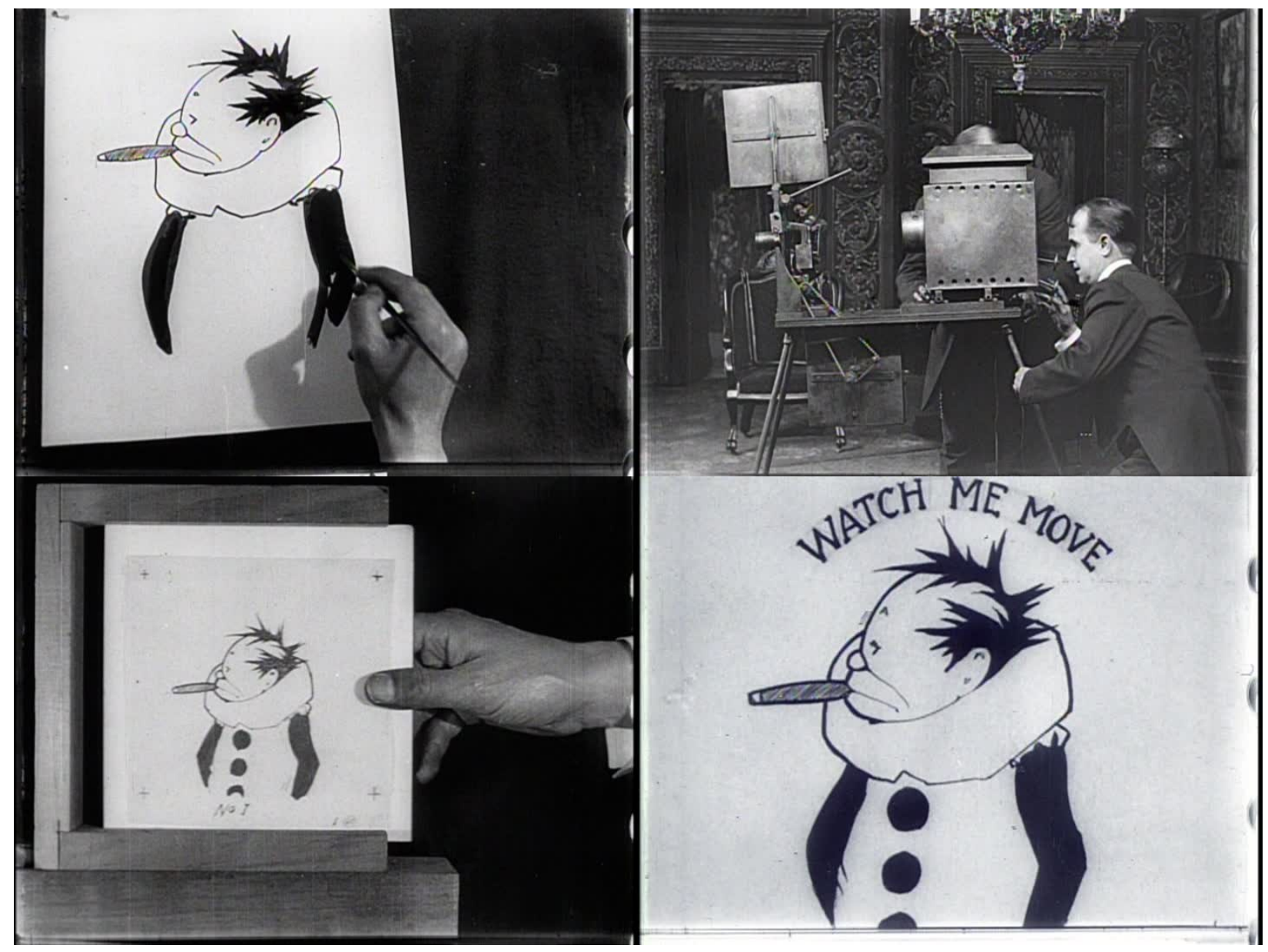

Figure 1.6. Little Nemo (McCay, 1911). Images (and all others in this chapter hereafter) taken from Winsor McCay: The Master Edition (DVD, Milestone Cinematheque, 2004).

This connection is reinforced by the foregrounding of the artist in the film. Crafton has elaborated extensively on this practice, known as the "hand of the artist" motif, signifying the animator as the locus of generative agency - a common form of authorial self-inscription in pre-cel animation which subsided over time as spectators learned to presuppose the artist's creative

\footnotetext{
13 Friedberg, 151.
} 
manipulation. ${ }^{14}$ The animator's presence in Little Nemo constitutes an "extraordinarily materialist conception of animation", basing the film in the laborious reality of physically creating each drawing. ${ }^{15}$ McCay's presence is on full display here, as the live-action prologue highlights his lightning-sketch talent and the laborious process of creating thousands of drawings for the animation to follow. This performance bleeds into the animation after the live-action sequence yields the floor. Following the introduction of Flip and companion Impie, Nemo enters and asserts control over his roughhousing friends, separating the two and using his arms to telekinetically distort them within the frame (Figure 1.7). As John Canemaker observes, Nemo is "McCay's self-figuration, his alter ego, proving his mastery over the actions of his creations". ${ }^{16}$ The following sequence confirms this figuration, as Nemo acquires a pen and draws a Princess who comes to life beside him, in an uncanny impression of McCay's lightning sketches performed only a few minutes earlier in the prologue (Figure 1.8).

Assuming the role of a life-giver in both the live-action and animated sequences, McCay undermines a presupposed gap between the real and the imaginary. This divide is constituted by the film frame, which "forms a tableau-like proscenium, forcing our vision to center its gaze, while implying a continuum of space lingering just offscreen/off-frame". ${ }^{17}$ This "continuum" of space beyond the frame is generally envisaged as an extension of what exists within the frame, following the assumption that an apparatus is placed before the world to capture a part of it. McCay's comics functioned in similar fashion, fashioning the panel frame as a window to an imaginary world which extended beyond what was drawn. This enabled him to experiment with the frame's evocation of off-frame space as an extension of in-frame space.

\footnotetext{
${ }^{14}$ Crafton, 1982: 12.

15 Crafton, 1982: 129.

16 Canemaker, 133.

17 Friedberg, 165.
} 


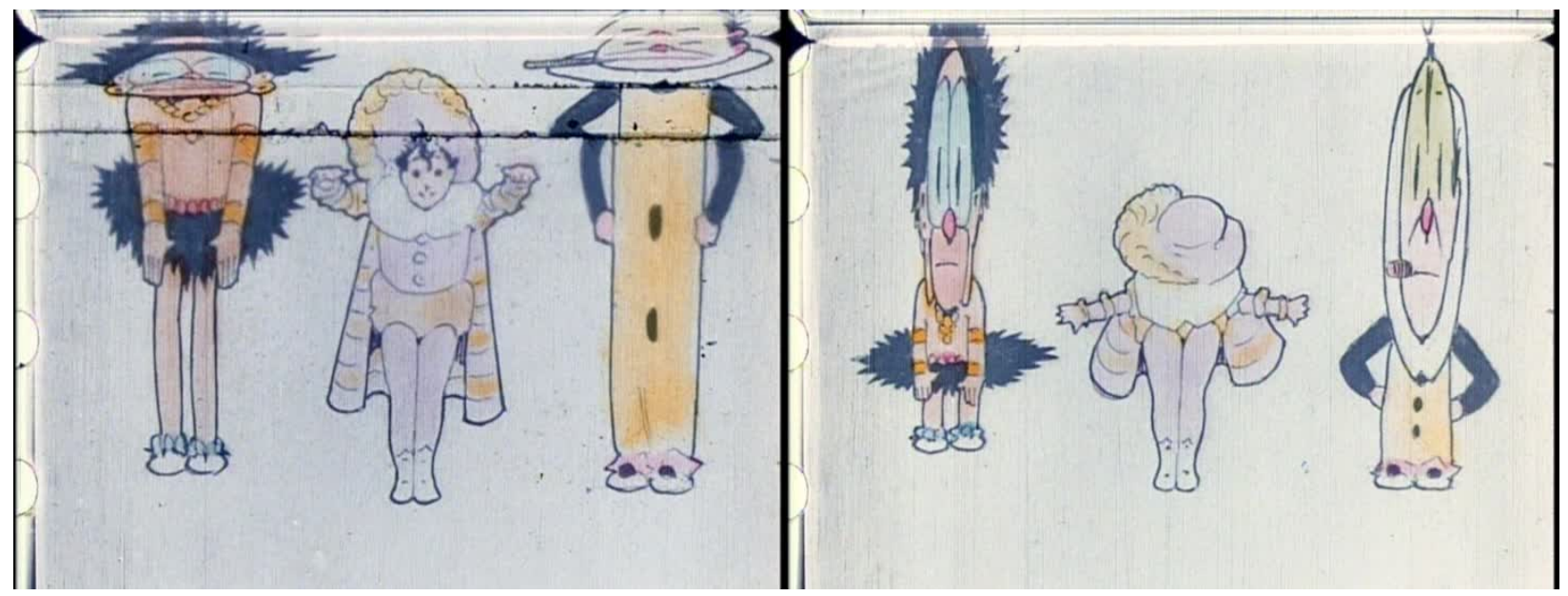

Figure 1.7. Little Nemo as McCay's self-figuration.

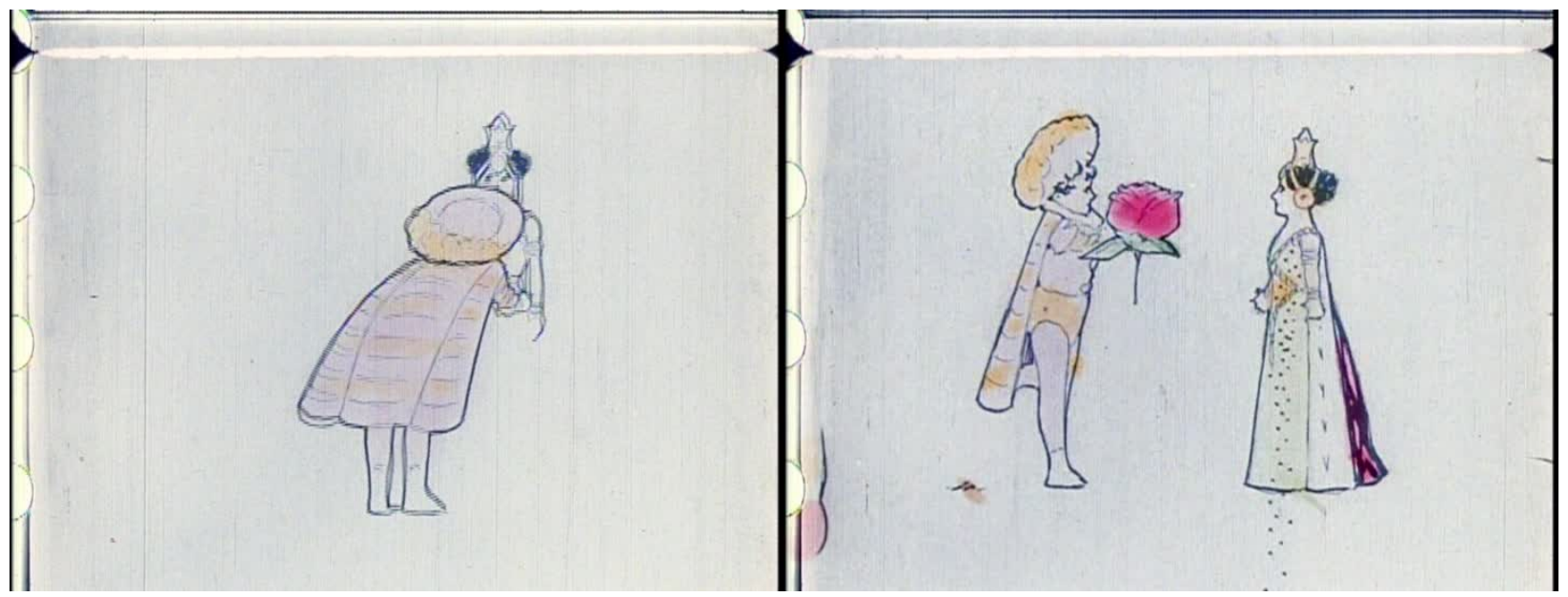

Figure 1.8. Nemo imitates McCay’s lightning-sketch performance.

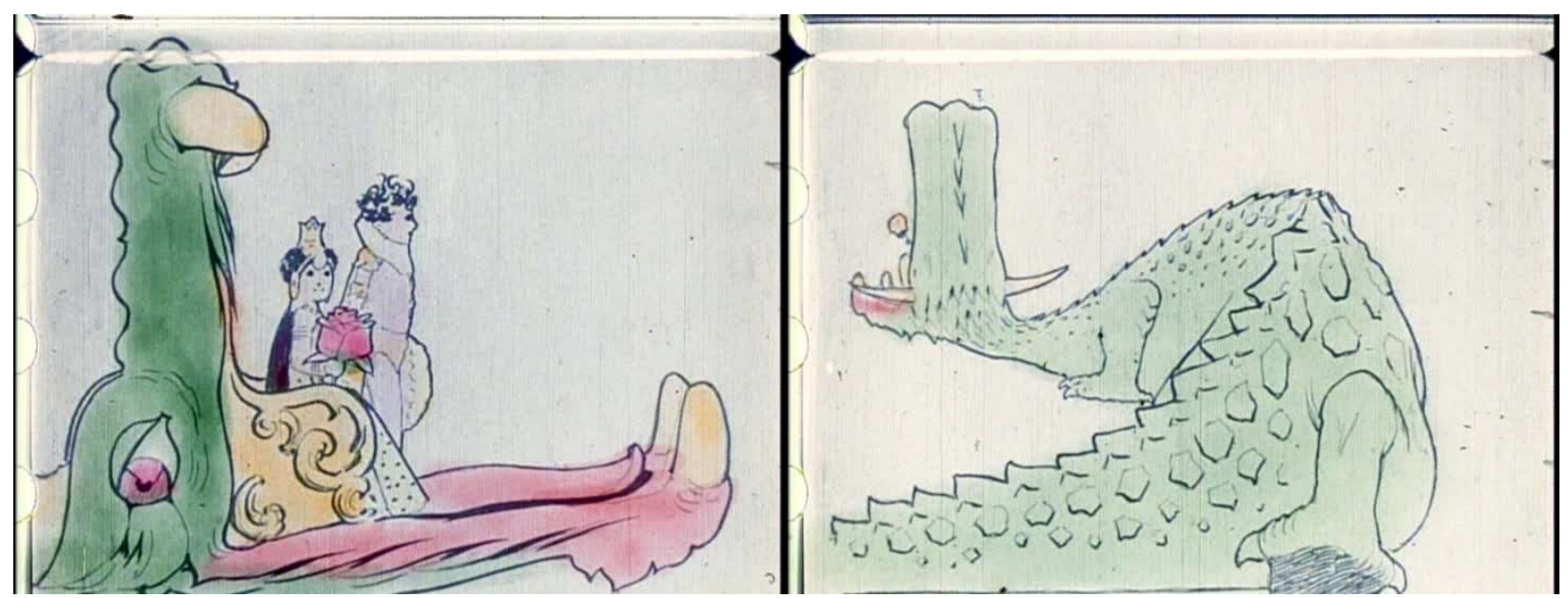

Figure 1.9. McCay insinuates offscreen space and three-dimensional perspective in Little Nemo. 
Little Nemo performs a similar experiment through McCay's refusal to use backgrounds, so that the film frame alone delimits the characters' animated world. This is a practice that Drew Morton terms "re-enforced framing", which is on display in the sequence where Nemo assumes control of his companions:

Re-enforced framing, like the frame and the gutter of the comic panel and the framing articulated in the cinema of attractions, asserts itself as a physical boundary. In the case of the film adaptation, it acts as a barrier between on-screen and off-screen space. Much like the comic panel and the cinema of attractions, the frame of McCay's film allows the duo a space to perform, stretching their bodies to the edge of the frame, but limits the space of that performance at the same time. Specifically, as the exercise continues, the duo's stretching is stopped and squashed by the assertion of a physical boundary between on-screen and off-screen space. ${ }^{18}$

The assertion of the frame as a "physical boundary" speaks to the perceived physicality of the cartoon characters. Their movement alone does not make them "alive," as such; it is the physical confinement of their bodily expansions and contractions which marks the perceptually realistic vitality of their movement. And yet, it is this corporeal plasticity which paradoxically locates them in an imaginary realm, beyond the spectator's immediate physical surroundings where the body is incapable of such magical contortion. The physical limits of corporeality are literally and figuratively stretched out, so that the animator's imaginary world can be mapped onto the spectator's perceptual experience. This is achieved, as Morton explains, by initially denying, and then insinuating the possibility of an off-screen reality, playing with the spectator's perception of screen space:

Re-enforced framing is one of the formal characteristics that turns the spatiality of a composition inwards. By denying the existence of an off-screen, diegetic space, re-enforced framing essentially projects the traditional comic strip framing of McCay's

18 Morton, 304. 
earlier work on to the screen. This form of aesthetic adaptation channels the viewer's gaze inwards rather than outwards towards off-screen space. In this sense, it takes on the classic compositional style of "Little Sammy Sneeze", rigidly formal in its denial of external space. However, as the film progresses, McCay shifts his compositional tendencies, also pushing the viewer's gaze outward toward off-screen spaces. ${ }^{19}$

This gaze is pushed outward when a dragon pushes inward from the left of the frame, in the first strong indication of off-screen space (Figure 1.9). Nemo and the Princess board the dragon, which transports them off into the distance, in an impressive rendering of three-dimensional perspective. Initially staged as a two-dimensional tableau drawing on a blank background, Little Nemo's animation creates the illusion of depth and off-screen space merely by playing with the boundary of the screen and the centered gaze that boundary inhibits. After several minutes more of playful animated scenarios, the characters' movements are halted and the camera moves back out again, revealing the hand holding a static drawing. The viewer is pulled out of the animated reverie and reminded of the film's construction.

\section{Gertie the Dinosaur (1914)}

McCay repeated many of Little Nemo's formal strategies in his best-known film, Gertie the Dinosaur (1914). In Gertie, just as it did in Nemo, the screen functioned as a vehicle for the animated reality of the film's characters. Once again, the film opens with a live-action prologue featuring a wager narrative, as McCay bets a friend that he can make an illustrated dinosaur come to life. This occurs after a trip to a museum, where McCay and his companions observe a reconstructed dinosaur skeleton. The wager is made, and McCay is shown preparing his drawings, which are clearly framed before the camera as they were in Little Nemo. Then, an intertitle announces that McCay will "show us what he thinks a Dinosaur looked like in real life".

\footnotetext{
19 Morton, 304-305.
} 
The prologue thus develops a narrative that situates the animation as deeply indebted to its live-action counterpart; McCay will literally express in visual terms his impression of a dinosaur. As the animation begins, it demonstrates how Gertie generally expands on the synthesis of real and imaginary initiated by Little Nemo. As the film moves through animated segments of Gertie being directed by McCay (represented by quotations in intertitles) to perform various visual gags, it is clear that the animator's physical presence is inextricable from that of his dinosaur's. This presence was not-so-subtly hinted at in Little Nemo, where the titular character served as the metaphorical self-figuration of the animator. Gertie takes this premise further, as McCay vocally asserts his control of the dinosaur's animated realm throughout the film, punctuated at the end when he enters the scene himself as an illustrated figure. The gap between the materiality of live-action and the immateriality of animation is noticeably reduced here. In Nemo, McCay's persona entered the film through one of his animated figures; though he asserted metaphorical control over the animation, he did not physically interact with his characters while they were moving. In Gertie, McCay interacts with his animated character in his own skin, and physically enters the animated space without the guise of an imaginary cartoon being. The animator and his dinosaur occupy the same physical space, blurring the perceptual divide between live-action and animation.

This is not to say that the spectator confuses the animation for live-action. Rather, this is to say that the animated image is encompassed within the perceptual experience of live-action, and Gertie draws attention to this fact. Where Nemo displayed the unbounded oneiric potential of the animated film, Gertie attempts to rein this in by tying it more closely to live-action reality. Unlike its predecessor, Gertie features a background for its performing subject, with prehistoric cave scenery that extends beyond the confines of the frame. Nemo's re-enforced framing gives way to 
Gertie's consistent evocation of off-screen space, which the dinosaur is made aware of by McCay, who points out various other animals entering the frame (Gertie subsequently terrorizes these intruders, protecting her in-frame territory). In sum, the perceptual gap between live-action and animation, though it is cleverly bridged, is more pronounced in Nemo. Gertie also acknowledges this divide, but more subtly effaces it via constant intercutting between the animation and intertitles, as well as its consistent use of a background extending beyond the frame. It is also significant that Gertie doesn't bookend its animation with stasis as in Nemo; instead it displays its propensity for integrating the perceptual experience of live-action into its animation.

Still, Gertie assumes Nemo's self-reflexivity, prominently featuring the screen as the vehicle for immaterial animated creations to occupy the viewer's material perceptual space. J.P. Telotte notes how Gertie played with the perceptual implications of on-screen and off-screen space, arguing that one of the fundamental properties of early animation is:

...the space that the animator or cartoonist must fill up or leave empty, the space that through his or her own creative efforts the animator must, like McCay in Gertie the Dinosaur, almost literally enter...when we look more closely at how McCay's films engage with space, we can see another dimension of that modernist spirit at work, for we find that his work implicates an assault not simply on the social status quo, but also on what we might term the phenomenological status quo, that is, on both the organization of, and the audience's experience of, space itself. ${ }^{20}$

Furthermore, McCay's "assault" on the audience's traditional experience of space, or the "phenomenological status quo", is founded on a tension between real and imaginary space built into traditional assumptions of on- and off-screen boundaries:

...McCay's films almost invariably proceed from an oneiric impulse, one that, as with all dreaming, always seems to be negotiating between our sense of real space and imaginary space, and thus is always speaking to the sort of spatial negotiation that, as I have suggested, seems fundamental to much early animation. ${ }^{21}$

\footnotetext{
20 J.P. Telotte, “Winsor McCay's warped spaces," Screen, 48.4 (2007): 464.

21 Telotte, 468.
} 
As Telotte also points out, McCay's dream-like animation almost always builds itself on a rational foundation which grounds its fantastical subject matter. ${ }^{22}$ In most cases, this is achieved through the live-action display of McCay himself. His onscreen presence signals himself as the creator, a form of authorial self-inscription that denotes his work as both real and constructed. The film's conclusion, in which McCay punctuates this transition by entering Gertie's animated world himself, was also a fundamental part of its main form of exhibition at the time, as a live vaudeville-style performance. $^{23}$ In these live shows, McCay appeared on-stage next to a screen onto which the animated portions of the film, sans intertitles, were projected. He proceeded to interact with the screen, synchronizing his performance with Gertie's actions projected next to him. When he ordered Gertie to catch a pumpkin, he would throw a real one behind the screen, timing his throw so that it appeared to enter the film frame as an animated object. When he entered the frame himself, he simply walked behind the screen as his animated self-figuration was about to appear in that area of the frame (Figure 1.10).

Gertie, then, assumed the principles of spatial awareness set out by Nemo, while modifying them slightly. The performative potential of the animated screen was elevated, as evidenced by its vaudeville integration, but was also marginally masked, as the film took for granted that an immaterial character could freely interact with its creator from within its animated world, and vice versa. The significance of Gertie thus lies in its attempt at the seamless perceptual transition between live-action and animation, appealing to the sense of animated realism that most of McCay’s later work would further tend toward.

\footnotetext{
22 Telotte, 468.

23 Crafton, 1982: 112.
} 


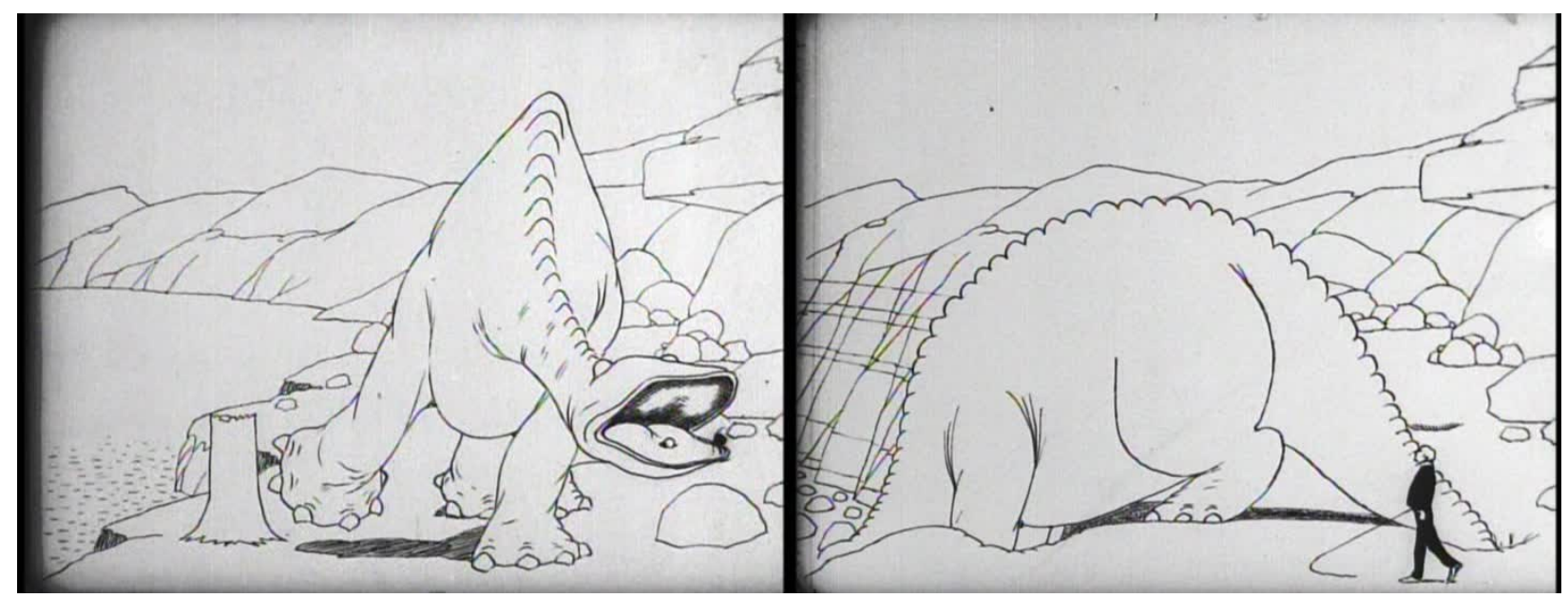

Figure 1.10. Gertie the Dinosaur (McCay, 1914).

\section{The Sinking of the Lusitania (1918)}

It took McCay several years to complete his next film, an animated re-enactment of the sinking of the British passenger liner Lusitania by a German submarine in 1915. Enraged by the attack, which included hundreds of American casualties, McCay was moved to create The Sinking of the Lusitania to drum up support for the United States' entry into the war against Germany. He was further motivated by the creative stifling he endured at the hands of his employer Hearst, who staunchly supported American isolationism and forbade McCay to draw any editorials to the contrary. ${ }^{24}$ This was already in addition to Hearst's demanding editorial quota for McCay, who had been forced by the magnate to cease his Gertie the Dinosaur performance tours to focus on his newspaper work. Hearst's interference, along with the general decline of vaudeville at the time, triggered a schism in McCay's animation, which would no longer be conceived as live performance material; according to Crafton, this live interaction with the audience was the "spark of excitement" that McCay's inner showman craved, which led to the more subdued tone of his

24 Canemaker, 104. 
later films. ${ }^{25}$ As such, The Sinking of the Lusitania - likely the earliest example of the animated documentary - plays an important role in his canon because it shows how the animator's bridging of physical and animated reality could go both ways - just as he crossed into Gertie's animated realm, animation could cross the other way in representing the physical realm.

The unfortunate irony of the film is that it was not the first time McCay had drawn the ship. The Lusitania was previously the subject of a 1907 "Rarebit Fiend" strip, in which it is comically struck and torn in two by an out-of-control steamship. ${ }^{26}$ The tone of the film is appropriately much darker, emphatically displaying its inclination for a truthful depiction of tragedy. This is emphasized in the film's live-action prologue, in which McCay uses a portrait of the ship as a visual reference for his drawings (Figure 1.11). The animated re-enactment follows suit, characterized by its strikingly detailed images and fluid movement (Figure 1.12), which was drawn based on survivors' recollections of the event. ${ }^{27}$ A title card even announces that the film represents the first visual "record" of the sinking. The film thus stakes a deep claim in reality despite the absence of live-action or archival images of its subject, demonstrating that even early on, "animation was seen to have a unique representational function for the non-fictional moving image, one that could not be fulfilled by the conventional live-action, photographic alternative". ${ }^{28}$ The power of its representational truth claim is reinforced by its emulation of propagandistic newsreel footage of the time, weaving together images of the ship with dramatic intertitles calling Americans to join the fight against Germany. ${ }^{29}$

${ }^{25}$ Crafton, 1982: 122.

${ }^{26}$ Ulrich Merkl, The Complete Dream of the Rarebit Fiend by Winsor McCay (Merkl: 2007), DVD episode 328.

27 Annabelle Honess Roe, "Absence, Excess and Epistemological Expansion: Towards a Framework for the Study of Animated Documentary," Animation: An Interdisciplinary Journal, 6.3 (2011): 218.

28 Honess Roe, 218.

${ }^{29}$ Crafton, 1982: 116. 

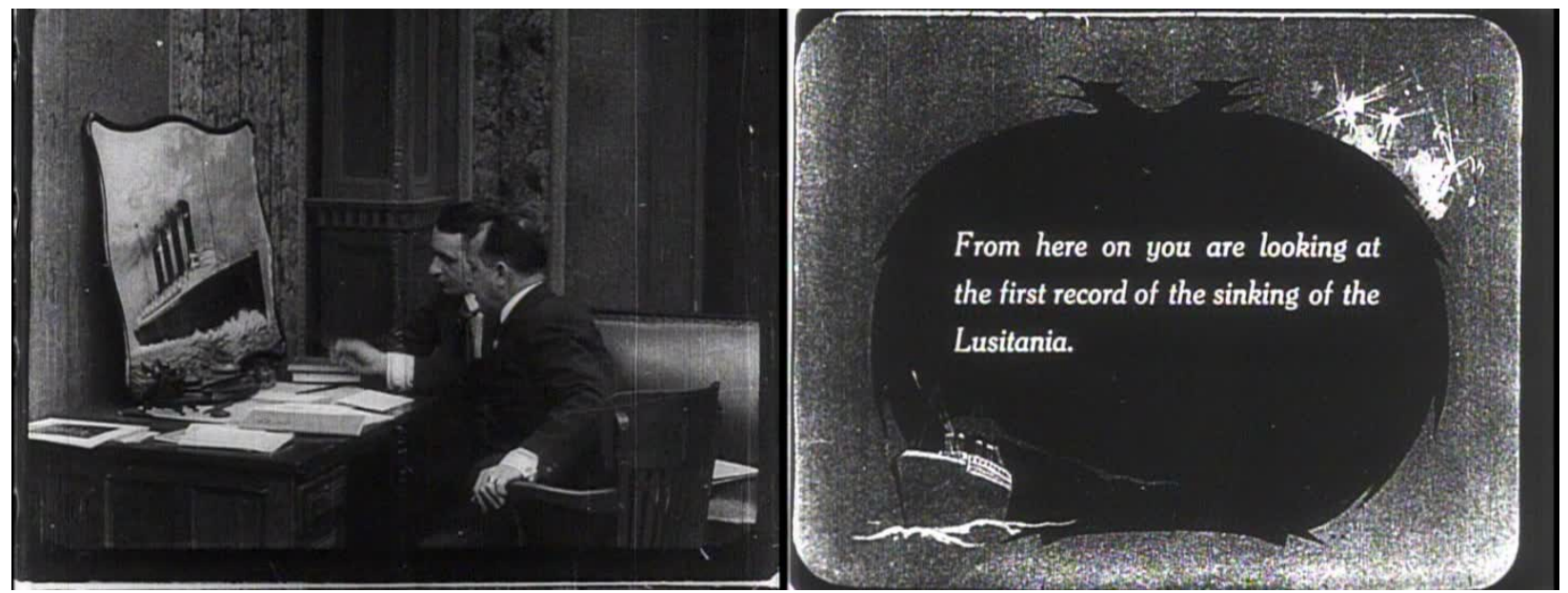

Figure 1.11. McCay drawing a historical "record" in The Sinking of the Lusitania (1918).
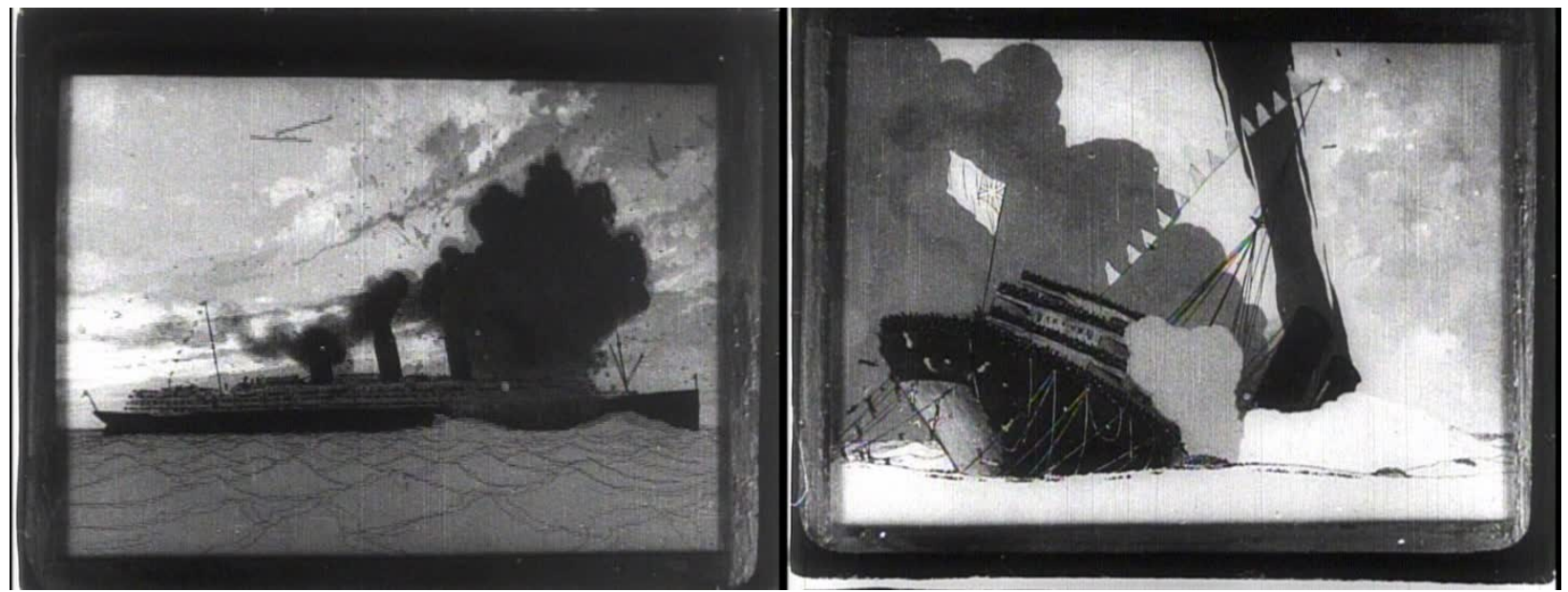

Figure 1.12. Realistic detail and fluid movement in The Sinking of the Lusitania.

These images thus function as a form of "mimetic substitution", in which the animation stands in for the live-action image, assuming its privileged position in representing reality. ${ }^{30}$ Moreover, this mimesis is not merely a reproduction of images that already exist in photographic form, but rather a reflection of the artist's impression of what visible form those images might take. Thus, the film is an instance of animation which "goes beyond just visualizing unfilmable events", instead inviting the viewer "to imagine, to put something of ourselves into what we see on

30 Honess Roe, 226. 
screen, to make connections between non-realist images and reality". ${ }^{31}$ McCay achieves this by foregrounding his presence again, acting as a mediating presence for the film's reality, compensating for the fact that the hand-drawn representations of the event cannot act as photographic evidence. McCay must act as a different form of evidence: he is a witness who testifies to the veracity of his images. As the life-giver to these images, he endows them with movement and heightens the film's ability to compel belief in its claim to truth, dispensing with the need for the discrete physical reality of photography.

The Sinking of the Lusitania is notable for its amalgamation of McCay's formal strategies developed up to that point - the live-action prologue, foregrounding the artist, married to the fluid animation - which are brought here into the arena of more conventional visual storytelling. By 1918, narrative-based feature films were more common as short, attraction-based novelty works fell by the wayside. McCay's previous films bore resemblance to these attraction-based works, as evidenced by the lack of editing in the animation, which was allowed to perform in a stage-like setting defined by the film frame. As in Gertie the Dinosaur, when a cut did occur in the animation, it was simply to introduce an intertitle containing dialogue. Before Lusitania, McCay only used one brief instance of screen direction, at a time when the technique was still young, in his 1912 film How a Mosquito Operates - but in that film it quickly gave way to his usual practice of allowing the animation to run its course in the frame without interruption from another shot's perspective. The Lusitania marks the first instance of McCay's creation of a world through editing, in addition to drawing objects which extended past the confines of the frame. A powerful narrative is created through cutting from scene to scene, from the introduction of the torpedo attack to the tragic aftermath, with explanatory intertitles and a lengthy diversion to a series of

31 Honess Roe, 217. 
photographed portraits of famous people who perished on the ship. The sinking scene is long and drawn out, cutting between various vantage points of the smoking ship and the passengers floating in the water, presumably to reinforce the catastrophic nature of the spectacle and draw the ire of the viewer towards the Germans held responsible.

Still, The Sinking of the Lusitania presents some interesting framing choices which recall McCay's previous fascination with how the screen acted as the intermediary for his imaginary creations. When the drawings are completed in the prologue and the ship is introduced, it is depicted leaving a New York harbour. As it departs, an illustrated curtain enters the screen from the right, and is drawn across the entirety of the frame (Figure 1.13). A dire foreshadowing of the events to follow, this is also nod to the constructed performance of the animation, even as it attempts to realistically portray an actual event. As the film continues, much of the animation is contained in a frame-within-a-frame, as if to visualize on-screen the experience of watching these events through a window (Figure 1.14). The ship itself is never framed like this, giving it the effect of refocusing the viewer's attention on the cause of the attack and its heartrending aftermath. It also refocuses attention on the screen itself as the vehicle for the animator's creations, still rooted here in his internal imagination but shot through with the sobriety of nonfictional reality.

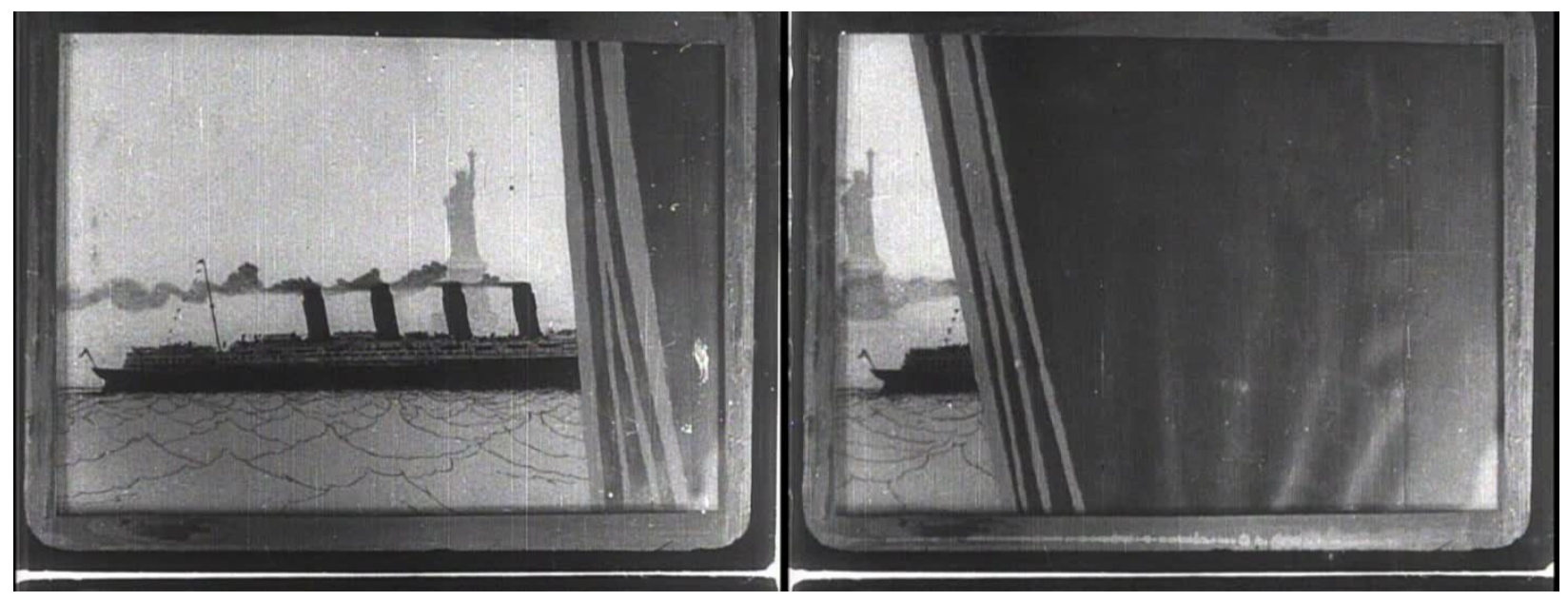

Figure 1.13. The ship's final "curtain call” in The Sinking of the Lusitania. 


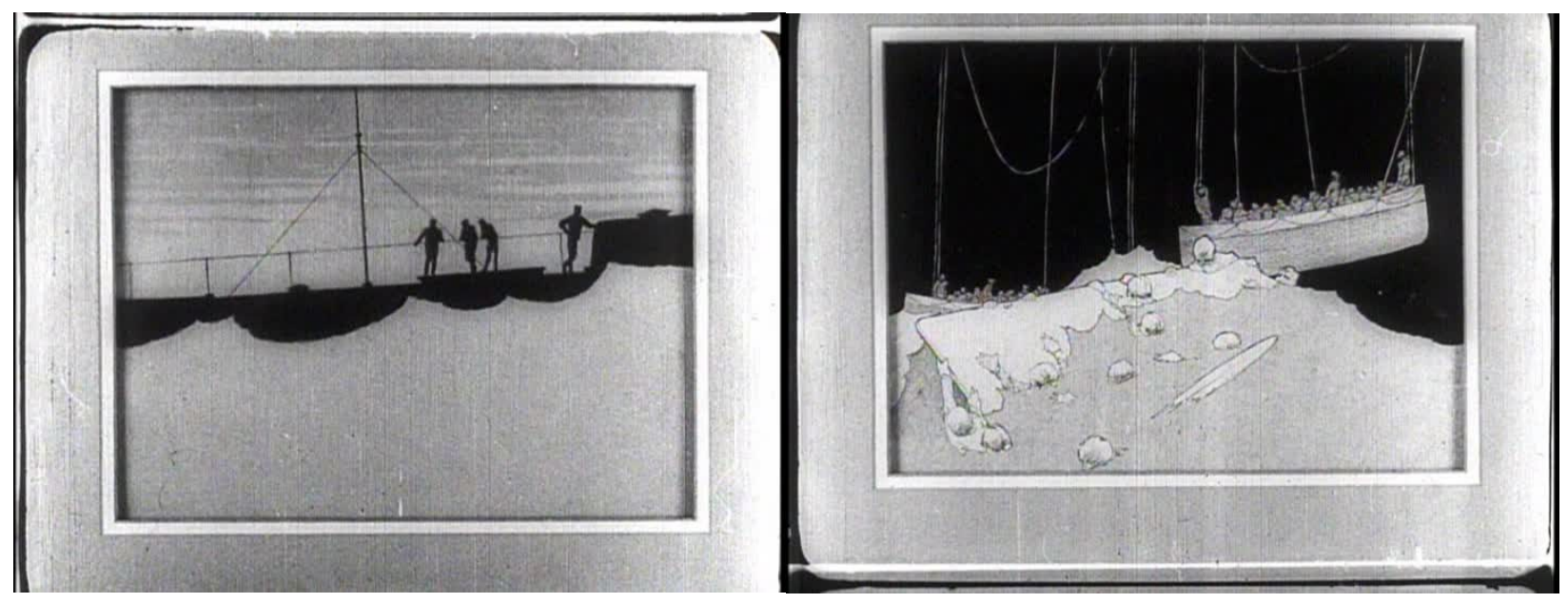

Figure 1.14. Intense framing of the submarine and human wreckage in The Sinking of the Lusitania.

\section{Conclusion}

The Sinking of the Lusitania demonstrated the extent to which McCay's animation evolved from Little Nemo eight years earlier. Imagined but not imaginary, realistic but not photoreal, the film represents McCay's uncompromising individual expression of an historical actuality, conditioned by the oneiric vision which pervaded all of his work. Where the screen once functioned as a blank canvas to be filled with the wild performances of fictional impossibilities, as in Nemo, it eventually demonstrated its ability to act as a stage which sieved the sobering reality of real-life events through the animator's imaginary filter. McCay's post-Lusitania work never approximated historical reality that closely again, frequently returning instead to the playfulness of his vaudeville work and the fantastical tropes of his "Rarebit Fiend" cartoon series. He dispensed with the customary live-action prologue and began to draw on layered cels, which had become much more common as a labour-saving device. His fascination with the cinema screen as a performative stage was dissolved into his adoption of the basic principles of continuity, where he applied simple editing and screen direction to quasi-coherent dream narratives taken from his 
cartoons. He also replaced intertitles with cartoon-styled captions, using speech bubbles with text to convey dialogue instead. There are even brief instances of actual photography used for backgrounds in place of painstakingly detailed drawings. All of this points to his ability to seamlessly integrate disparate aesthetic forms into the space of one frame, but also to his increasing exhaustion with the medium, which he always maintained should avoid labour-saving vices to uphold its artistry. After 1921, he quit filmmaking altogether and returned exclusively to cartooning.

Occasionally, however, this later work overtly echoed his earlier, more experimental repertoire. Bug Vaudeville (1921) features one brief intertitle in place of the live-action prologue stating to the viewer that the film is entirely hand-drawn. It then depicts a man's dream (caused by the ever-potent rarebit), in which he watches a series of bugs performing on a stage in front of him. He sits complacently and applauds, detached from the stage before him, until he is attacked by a trick-performing spider and wakes up from the nightmare (Figure 1.15).

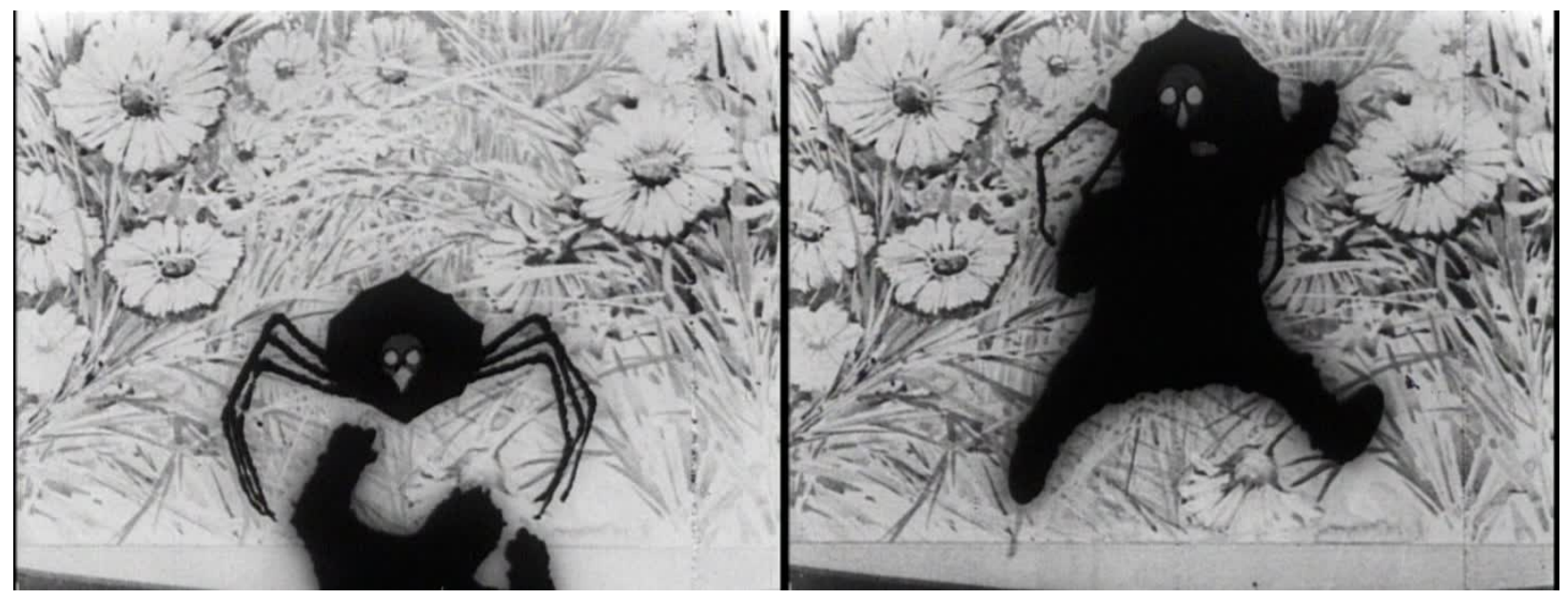

Figure 1.15. The dream physically grasps the spectator in Bug Vaudeville (McCay, 1921). 
The film is a meta-narrative of cinema that McCay so sharply portrayed in Nemo and Gertie: initially a mere spectator to his dreams, the man is violently reminded of his physical implication in that performative space. ${ }^{32}$ Each time the curtain draws back from the stage, there is nothing separating him from the imaginary bugs. As in the pathbreaking motion pictures from earlier in McCay's remarkable career, the spectator once again occupies the same perceptual space as the lively phantasmagoria of moving images.

32 Bug Vaudeville is reminiscent here of Emile Cohl's Mind of a Cafe Waiter (1910), discussed in the following chapter. 


\section{Chapter Two: Simulation}

The previous chapter explored the film screen as a performative medium for the materialization of immaterial beings for the spectator's perception. This chapter expands on the analysis of the material within the screen, exploring the intricacies of how the movement of various types of animated media performed an externalized simulation of the animator's imagination.

\section{Simulation and/as Performance}

The concept of "simulation" resonates well with the emphasis placed thus far on the "performativity" of animation; to simulate something insinuates an executive process or intentional act, hinting at the looming presence of a governing entity conditioning the performance at hand. The process is one which Crafton has historically located in the early nineteenth century history of animation, where the French term "animer" or the English "to animate" were employed in a diverse assortment of contexts underpinned by a shared sense of performativity:

They are statements that execute an action, cause something to be done or status to change. To animate effects a dramatic transformation from one state to one much different, from sleeping dogs to baying hunt-ready hounds, from non-life (fetus, phantom) to living thing, from nonchalant to excited, from death to life or a semblance of life, from the static to the moving. There was a glissando in the 19th century between this semantic use of animation as performative to animation as actual performance. ${ }^{1}$

Crafton refers here to the transition from the user-based performance of optical toys such as the zoetrope and phenakistoscope to the public performance of cinematograph, which took the performative device out of the viewer's hands but was still synonymous with "animated pictures".

\footnotetext{
${ }^{1}$ Crafton, 2011: 98.
} 
The "animator", or purveyor of moving images, was no longer predominantly the viewer-user, but the vivifying figure hidden behind the projection device, as it previously had been during the days of haunted magic-lantern displays. In consistently testifying to the artist's vivifying abilities, early film animation invoked these nineteenth century spectral expressions of invisible reality, which required the mediating presence of an apparatus and its operator as the animator. Here, French caricature artist Emile Cohl is suitably positioned as a paradigm of this self-reflexive mediation. Cohl's body of work consistently reflected the previous century's obsession with visualizing the invisible, often through a carnivalesque lens. As such, his work resonates strongly with the concept of the performative screen developed in the previous chapter with reference to Winsor McCay's animation, but expands on it through his interest in abstraction, as well as his broader use of materials, opening up the scope of this analysis to animation that goes beyond pen and ink.

\section{Emile Cohl: Visualizing the Invisible}

As Crafton observes, the comparison of Cohl and McCay presents, at least on the surface, a "study in contrasts". ${ }^{2}$ Cohl was significantly older when he entered filmmaking, and his vast output - the result of working for a studio, which McCay never did - far outstrips that of his American counterpart. Unlike McCay, whose showmanship required live performance, Cohl kept his presence in his films more subdued, never revealing more than his hands. Finally, though both artists had previous illustration careers, McCay's comics were continuous in important respects with his films while Cohl deserted much of the style of his comics for a more minimalist aesthetic conducive to the labour-intensive demands of his work in motion pictures. However, the two animators inextricably occupy the same historical arena, and their differences listed here are belied

\footnotetext{
${ }^{2}$ Crafton, 1982: 89.
} 
by their shared interest in conjuring the incorporeal or immaterial into the material perceptual realm of the spectator viewing their films. The significance of Cohl is his aforementioned use of abstraction and broader use of materials; he also presents a more palpable connection to nineteenth century media by virtue of his age and Parisian background, which incidentally provides a useful French complement to McCay's representation of American animation. From the very outset, Cohl's films exposed the most elemental components of animation in cinema, by way of his interest in abstracted graphic lines, puppets, and paper cut-outs - all while frequently caricaturing nineteenth century positivism with the internal reality of dream logic. Several years before McCay's Little Nemo, it was Cohl who first broke apart the gearbox of his medium to view its most rudimentary units at work, demonstrating how it could simulate the imaginative processes of the mind.

Though Winsor McCay often claimed to be the inventor of the animated film, it was in fact his French counterpart who deserved that title. Cohl's inaugural effort, Fantasmagorie (1908), is most often recognized as the first "true animated cartoon". ${ }^{3}$ For a long time it was categorized as a trick film, and even Cohl himself viewed his first effort as "trick kinematography". ${ }^{4}$ At this point, "animation" as a codified, systematic film practice had yet to take hold in the cinematic lexicon. By 1912, the trick film as a category had all but disappeared, representing a mere one percent of film giant Pathé's output that year; it appears that animation, which continued to thrive, had matured in the public eye to the point where it was simply no longer viewed as part of the trick film genre, but as its own distinct medium. ${ }^{5}$ This is clear in Fantasmagorie, which shares far more in common with its animated descendants than its trick-based predecessors, for whom animation was

\footnotetext{
${ }^{3}$ Crafton, 1982: 60.

${ }^{4}$ Philippe Gauthier, “A Trick Question: Are Early Animated Drawings a Film Genre or Special Effect?” Animation: An Interdisciplinary Journal, 6.2 (2011): 165.

${ }^{5}$ Gauthier, 168-169.
} 
only a "whimsical divertissement". ${ }^{6}$ These trick films either used crude, short-lived snippets of animated drawings to supplement its live-action footage (Blackton's Humourous Phases of Funny Faces, 1906), or used the stop-action substitution technique with static live-action images to set a photoreal sequence in motion (Blackton's The Haunted Hotel, 1907). Fantasmagorie, on the other hand, entirely consisted of moving drawings, with the brief exception of Cohl's hands appearing in live-action to manipulate the drawings within the frame, and anticipated McCay's work in negotiating the same screen-aware spatial tension. These drawings only seem to be a few inches tall, an indication that his figures are "drawn for the camera's lens, not on large paper pads or blackboards imitating a theatrical audience's perspective". ${ }^{7}$ In other words, Cohl's cinematic animation was its raison d'être, the product of a more painstakingly refined experiment with drawn movement than had ever previously been attempted.

Like much of McCay's early oeuvre, Fantasmagorie displays a propensity for putting the cinema screen on display as a performative space for immaterial entities. Cohl drew the film with black ink on a white background, but printed the animated footage in negative, creating a white-on-black effect that Crafton claims "was probably motivated by a desire to simulate Blackton's chalk-line effect". ${ }^{8}$ However, it also likely served the purpose of creating a background that doubled as a darkened cinema theatre, in which the film appears to open, featuring a frustrated cinema-goer trying to view the screen before him over another female spectator's obnoxiously oversized hat. This setting quickly gives way to a series of fantasies in which a clown materializes out of nowhere above the two patrons and is promptly subjected to nightmarish physical distortion and dismemberment. Like Little Nemo, the clown's corporeal plasticity maps

\footnotetext{
6 Crafton: 1982, 59.

7 Richard Neupert, French Animation History (Malden, Oxford: Wiley-Blackwell), 2011, 27.

${ }^{8}$ Donald Crafton, Emile Cohl, Caricature, and Film (Princeton: Princeton University Press), $1990,137$.
} 
the animator's imagination onto notions of tangible physicality graspable within the spectator's perceptual sphere. The animation is also performed in a blank free-floating space, which Cohl aligns with the dark, imagination-spurring exhibition space of the cinema. Cohl's hands also make a brief appearance, putting his clown back together after his illustrated dismemberment (Figure 2.1).
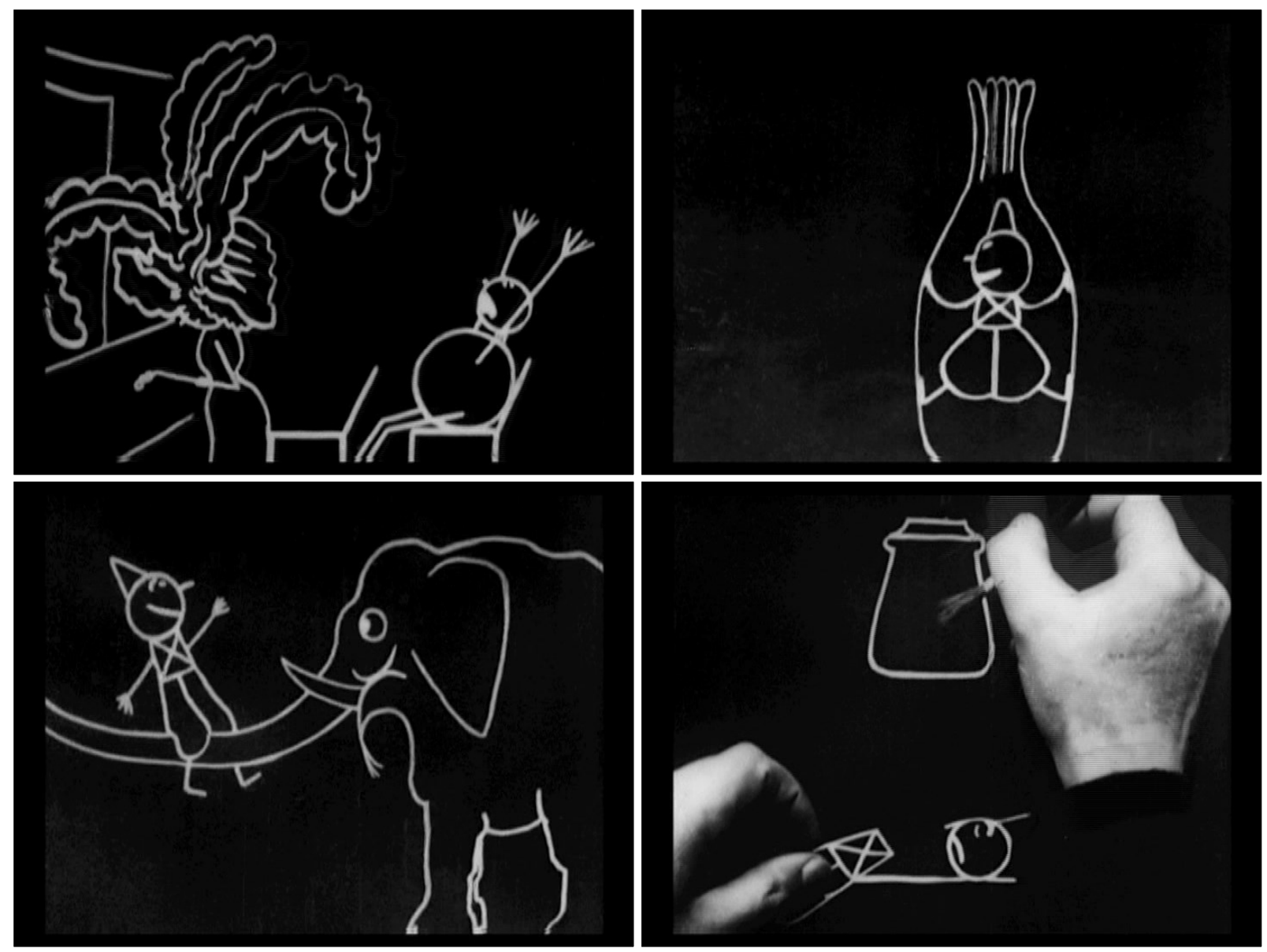

Figure 2.1. Fantasmagorie (Cohl, 1908). Images (and all other film images in this chapter hereafter) taken from Gaumont Treasures Vol. 2: 1908-1916 (DVD, Kino International, 2011).

But Fantasmagorie, more so than any of McCay's work, foregrounds the inner workings of the animated material within the screen. Where McCay favoured realistic perspective and verisimilitude in his graphic compositions even in his most fantastic creations, Cohl preferred 
abstract illustrations to call attention to the movement of individual lines and their interplay with the screen:

The tendency toward abstraction contributes to the ever-present sense of ambiguity between readings of the screen space as a two-dimensional plane and as a three-dimensional illusionistic space. Cohl often used this ambiguity to playfully confuse the viewer...he preferred to remind the viewer that he or she was watching a moving drawing on a surface, with an artist hovering just off camera. ${ }^{9}$

In addition to its playful "confusion" of the viewer's screen experience, the ambiguous space of Fantasmagorie makes a decided statement on the ability of animation to simulate the invisible process of the mind. Its dark background, aligned with cinematic exhibition, ostensibly creates a non-space in which the animator's imagination can run amok - and the appearance of Cohl's hands in positive print on black background, as opposed to the negative of the rest of the film, testifies to his determination to create and maintain that imaginative setting. ${ }^{10}$ Moreover, in addition to merely recreating the stuff of nightmares on screen, the film invokes a specific set of historical circumstances under which animation became associated with these invisible processes. This is found in the film's title which marks its self-reflexivity, referencing the famous "Phantasmagoria", a magic lantern display developed by Belgian showman Étienne-Gaspard Robertson at the turn of the nineteenth century. Aligning his film with this haunted spectacle, in which incorporeal spectres seemingly materialized before an audience, Cohl "alerted his viewers to the strangeness of the images they were about to see". ${ }^{11}$ A closer analysis of the Phantasmagoria as a late spectacle of the Enlightenment can illuminate the origins of animation's performance of simulation.

\footnotetext{
${ }^{9}$ Crafton, 1990: 299-300.

10 To elaborate: in order to do this, Cohl had to draw new, positive-print, white-on-black drawings and coordinate them not just with the location of his hands, but the previous black-on-white drawings he produced in negative - all while rejecting the simpler process of merely producing the whole film in positive print. This also suggests that Cohl may not have initially planned the sequence involving his hands, but in the improvisational spirit of the film, implemented this trick when the idea arrived to him. For more on this process, see Crafton, 1990: 121.

1 Crafton, 1990: 258.
} 


\section{Phantasmagoria}

Robertson premiered the Phantasmagoria in Paris in 1798, and the first international imitations appeared in England only three years later. By 1803, the show had crossed the Atlantic and taken hold in the United States, thriving as a popular attraction for another three decades. ${ }^{12}$ The Phantasmagoria's popularity was such that it was acknowledged as a cinematic forerunner in a 1936 issue of International Photographer:

The audience is leaning forward, tingling with fright. Amid a backstage clatter and a steady thump-thump, a devil on a smoky cloud is approaching. As he gets larger, the boldest of the audience become less bold and the timid ones look to the nearby exit. It is a new experience to them. It is magic! Yes, magic to them; but to us the medieval slideshow. ${ }^{13}$

The article goes on to describe the techniques behind Robertson's various spectral illusions. In a dark chamber, using a combination of rear-projected lanterns and glass slides, Robertson projected ghosts, demons, and deceased historical figures upon a luminous waxen sheet, giving them a haunting translucent glow. He also occasionally projected his images upwards onto clouds of smoke, so that they appeared to hover ominously above the spectator's eyes (Figure 2.2). Fixing his lantern (which he dubbed the "fantascope") to wheels on a track allowed him to shrink or swell the size of his spectres, creating the impression of three-dimensional perspective on a flat surface. Though Robertson himself did not invent the Phantasmagoria, it was his version of the display that so thoroughly perfected its petrifying effects, thereby initiating its worldwide popularity. "Such was this antecedent of today's cinematic presentation", the article's author declared, committing it to his genealogy of motion pictures.

\footnotetext{
${ }^{12}$ X. Theodore Barber, "Phantasmagorical Wonders: The Magic Lantern Ghost Show in Nineteenth-Century America", Film History, 3.2 (1989): 78.

13 Earl Theisen, "The Archaeology of the Motion Picture in Three Parts - Part II", International Photographer, January 1936, Vol. 8: 4.
} 


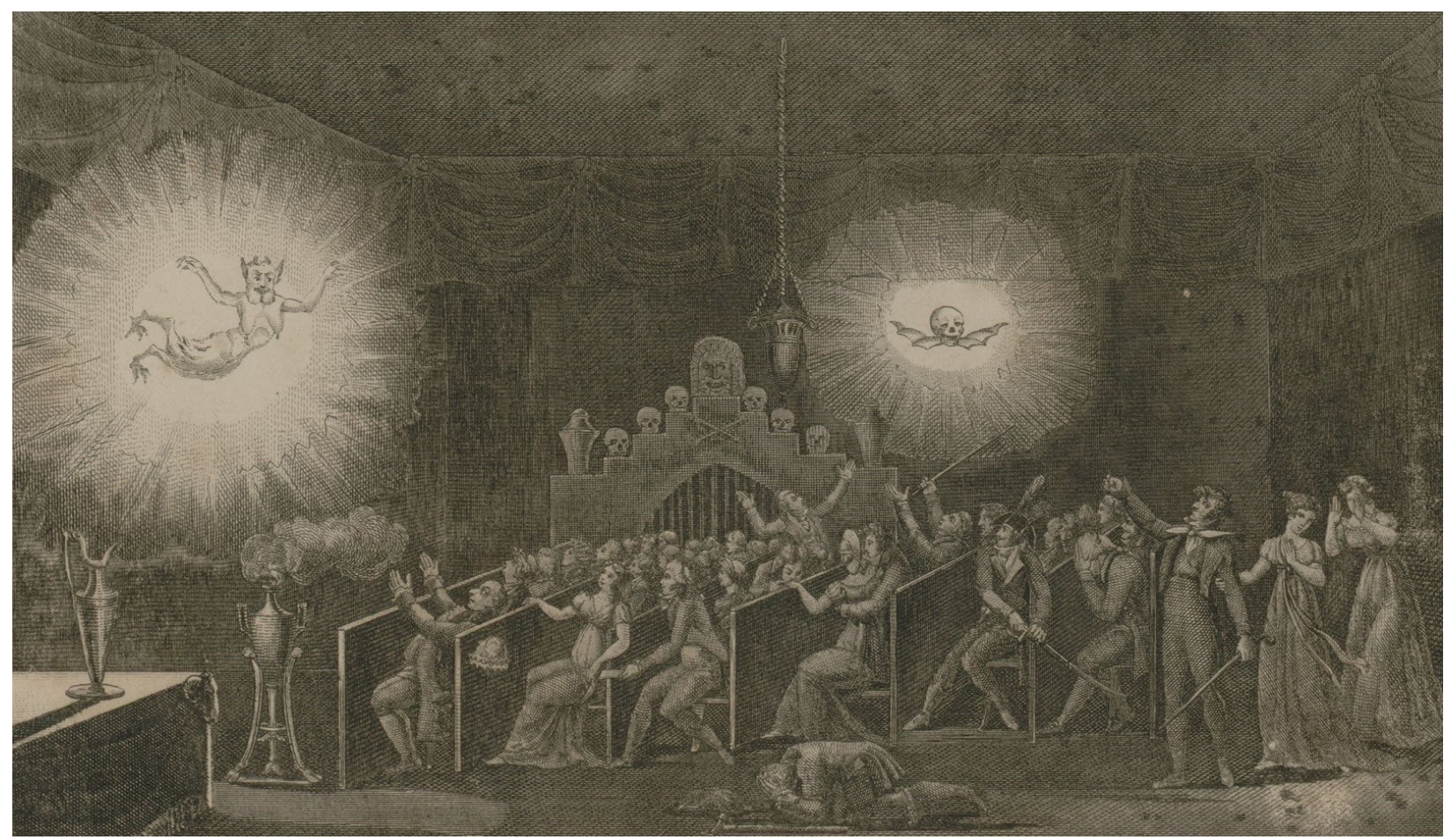

Figure 2.2. Illustration of Robertson's Phantasmagoria. Image taken from Robertson's "Memoires", Vol.1, 1831.

Though its popularity can be credited to Robertson's technological refinements, it can also be attributed in large part to the sociocultural environment in which it emerged. The Phantasmagoria was invented in the mid-eighteenth century, "at a crucial epoch in the history of Western ghost belief - at precisely the moment when traditional credulity had begun to give way, more or less definitively, to the arguments of scientific rationalism". ${ }^{14}$ Image projection engaging with the supernatural was thus coded as a convergence of empirical observation and spiritual belief. This logic was anticipated in the previous century by mathematician Johannes Kepler, who developed the dual concepts of imago and pictura. Using the camera obscura as a metaphor for the human eye, Kepler conceived of a distinction between images visible within the mind - the imago - and images which could be viewed and measured externally, outside the mind, much like the image on the obscura wall - the pictura. Significantly, Kepler did not view imago and pictura

\footnotetext{
14 Terry Castle, "Phantasmagoria: Spectral Technology and the Metaphorics of Modern Reverie", Critical Inquiry, 15.1 (1988): 52.
} 
as wholly distinct entities, but saw elements of both in image projection, and opticians following his work freely used both terms to describe the projected image. ${ }^{15}$

Anne Friedberg translates Kepler's optical duality as an early distinction between "real" and "virtual" images, positing that the "virtual" in that moment came to be known as "a substitute - 'acting without agency of matter' - an immaterial proxy for the material". ${ }^{16}$ But what if the reverse of this is also true? That is, if this definition of the virtual is inverted - to say that the real is a material proxy for the immaterial - a fitting summation of the Phantasmagoria emerges. Robertson effectively demonstrated the transition of an image from imago to pictura: conceived within the mind, the spectres were rendered externally visible in a material reality, forcing audiences to confront in the flesh what was only previously visible as imagination. The show capitalized on this duality, staging the terrifying projections in a highly aestheticized environment which was nonetheless underpinned with positivist pretension, to create "a rational exhibition in order to expose the mechanism behind such spectres of the mind". ${ }^{17}$ Acting within the show as a scientific figure conducting a necromantic experiment, Robertson disabused any supernatural credulity lingering amongst the audience — they were to perceive the spectres as real, but only in the sense that their minds, having been reminded of the naivety of ghostly mythology, had really created such beings without any referent to an external reality. ${ }^{18}$ "Is it not known that these shadows and ghosts are only visions," Robertson in his memoirs mused rhetorically, "which art is able to easily reproduce; wouldn't one understand more in seeing with his own eyes that which

\footnotetext{
15 Alan Shapiro, "Images: Real and Virtual, Projected and Perceived, from Kepler to Dechales", Inside the Camera Obscura: Optics and art under the spell of the projected image, ed. Wolfgang Lefevre, 2007, 82.

16 Friedberg, 8

17 Marina Warner, Phantasmagoria: Spirit Visions, Metaphors, and Media into the Twenty-first Century (New York: Oxford University Press), 2006, 153.

18 Castle, 49.
} 
simple men have viewed with terror for thousands of years?"19

As Terry Castle explains, however, Robertson only partially realized his utopian endeavor of secular enlightenment:

Ghosts were unreal, according to the skeptics, in the sense that they were artificial - the product of certain internal mechanistic processes. The magic lantern was the obvious mechanical analogue of the human brain, in that it 'made' illusionary forms and projected them outward. But in another highly paradoxical sense, ghosts now seemed more real than ever before - in that they now occupied (indeed preoccupied) the intimate space of the mind itself. The paradox was exactly like that achieved at the real phantasmagoria: ghosts did not exist, but one saw them anyway. Indeed, one could hardly escape them, for they were one's own thoughts bizarrely externalized. ${ }^{20}$

In other words, the Phantasmagoria succeeded in fuelling, not dispelling, the spiritual imagination of its spectators. Its proto-cinematic exhibition method, in which "the projections formed luminous shadows in a dark room, a non-space", demonstrated how the "space of the imagination could be occupied by abandoning a natural decor". ${ }^{21}$ Just as early film animators played with the presence of the screen and animator as material vehicles for the immaterial, so did Robertson, first appearing before the audience to force them to acknowledge the workings of his apparatus, then disappearing in the dark and allowing his spectres to take over the spectators' imagination. Like Cohl's Fantasmagorie he drew his images on black backgrounds to enhance their "free-floating" quality in the dark, and saturated his thin gauze-screens with wax "so that his phantoms were further dematerialized by the diaphanousness and translucency of the material on which they appeared". ${ }^{22}$ Robertson thus confronted the same spatial negotiation that challenged the first film animators, faced with filling a luminous void with images of the incorporeal which, when

${ }^{19}$ Etienne-Gaspard Robertson, Mémoires Récréatifs, Scientifiques et Anecdotiques Vol.1, Paris: Librairie de Wurtz, 1831, 147. Accessed from the Internet Archive, Jan 3, 2014. <https://archive.org/details/mmoiresrcratifss01 robe >. ${ }^{20}$ Castle, 58

${ }^{21}$ Koen Vermeir, "The Magic of the Magic Lantern (1660-1700): On Analogical Demonstration and the Visualization of the Invisible", The British Journal for the History of Science, 38.2 (2005): 133.

${ }^{22}$ Warner, 148. 
endowed with movement, ostensibly created "an illusion that they possessed that quality of conscious life: animation". ${ }^{23}$

\section{Phantasmagoria to Fantasmagorie}

How does animation then specifically embody that quality of conscious life? Movement is a starting point, but not nearly enough to describe the vitality of animation in full. The Phantasmagoria created moving images, but this movement was crude at best - a series of visibly hand-painted images that could only swell and shrink, which was not enough to convince of the illusion those rationalist audience members who were disinclined to ghost belief. Indeed, one of the occasional criticisms of the show from this scientific perspective was that it wasn't realistic enough to achieve its enlightening goals. One such critic was British scientist Sir David Brewster, who wrote that the show needed better technology to create more lifelike images, leading him to invent the "catadioptrical phantasmagoria", which used mirrors and lenses to reflect onto a screen a living human performing as a spectre; this set-up was later used successfully in the popular mid-nineteenth century show known as "Pepper's Ghost". ${ }^{24}$

For those who were lulled into paranormal credulity, however, something in the movement of the spectres affected them profoundly. As one reviewer of the show put it, the combination of the ghostly summonings with darkness and tinkling cymbals caused him to sense within himself "l'accord du monde visible et invisible"; the motion perceived within the shadows provided "la clef d'un autre monde". ${ }^{25}$ It appears, then, that it was not merely the phantasms' movement, but their apparent ability to move of their own volition, which gave the Phantasmagoria its power. In

\footnotetext{
${ }^{23}$ Warner, 148.

24 Castle, 39.

25 Robertson, 305.
} 
the dark behind a screen and accompanied with haunting music, Robertson achieved this effect by hiding the conjuring apparatus more completely than any magic lantern showman before him. The Phantasmagoria's self-acting spectres thus engendered the intertwining of animation with the concept of automation, which Vivian Sobchack notes was characterized in the early 1800s as "conflating movement and anima through the use of the word 'self". ${ }^{26}$ Animation's simulation of lifelike movement, then, may be articulated as employing "movement [as] the linchpin, but spontaneous agency (or anima) [as] the true sign of "life". 27

Where does Cohl's film animation fit into this equation? The connection may be made by jumping ahead briefly to the 1930s, when Soviet montage pioneer Sergei Eisenstein became obsessed with Mickey Mouse. He saw the anthropomorphic rodent as a "plasmatic" figure, able to assume any shape whatever, which for him displayed a certain omnipotence embodying pleasurable viewing for an audience shackled by the inflexible chains of capitalist ideology. ${ }^{28}$ Eisenstein's importance here lies in his distinction between the mind's pre-logical (or sensuous) and logical (or knowing) consciousness, a divide straddled by animation. The fundamentals of this distinction form the perfect description of the spectator's experience at Robertson's

Phantasmagoria:

We know that they are...drawings, and not living beings.

We know that they are... projections of drawings on a screen.

We know that they are... 'miracles' and tricks of technology, that such beings do not really exist.

But at the same time:

We sense them as alive.

We sense them as moving, as active.

We sense them as existing and even thinking! $!^{29}$

${ }^{26}$ Vivian Sobchack, "Animation and automation, or, the incredible effortfulness of being", Screen, 50.4 (2009): 383.

27 Sobchack, 2009: 383.

28 Vivian Sobchack, "The Line and Animorph or "Travel is More than Just A to B", Animation, 3.3 (2008): 254.

${ }^{29}$ Sergei Eisenstein, “On Disney”, The Eisenstein Collection, ed. Richard Taylor (New York: Seagull Books), 2006, 139. 
This duality of sensing versus knowing is taken up in Fantasmagorie so that the sensuous becomes a self-reflexive strategy: Cohl, via his brief cameo, acknowledges the spectator's logical consciousness without disavowing the pre-logical immediacy of kinesthetic perception. Far from being mystified by an Uncle Josh-like sense of delusion, the 1908 viewer knew of the hand-worked mechanisms behind the projected images but, as with the Phantasmagoria, sensed self-acting fantasy in spite of themselves. Thus the seemingly autonomous "plasmatic" figures of Cohl's film are, by Sobchack's logic, “also phantasmatic - the viewer's knowledge of its very laborious production sublimated in the pleasure of "magical thinking"'. ${ }^{30}$

\section{The Performing Line}

Though Cohl's Fantasmagorie took up the perceptual experience of the Phantasmagoria, the film is more congruous with illustrator's prior involvement with the Incoherent movement of the 1880 s, which skewered serious intellectual subjects like science and politics with humourous caricature and comically subversive art displays. Crafton summarizes the animator's motives accordingly:

Cohl's graphic works had little in common with the nineteenth-century positivist view of reality as finite, mensurate, and orderly. Instead he was more interested in expressing the inner reality of the Symbolists, which was delineated only by the imagination...Often his subjects, his fantasies, were reflections of the darker regions of consciousness, untempered by any rational pretensions. ${ }^{31}$

So how did Cohl succeed in visually representing the immateriality of an internalized reality? It was his use of moving graphic lines, more than any other formal strategy, which best allowed him

\footnotetext{
30 Sobchack, 2009: 384.

${ }^{31}$ Crafton, 1990: 296.
} 
to literally delineate visualizations of an inner consciousness. The graphic line, according to

Sobchack, is what foregrounds animation's ontological difference from photoreal cinema:

...the line is ontologically a conceptual and structural object, a formal abstraction that has no substantial existence outside its two-dimensional, planar, graphic representation...[it] is a meta-object that can be conceived, drawn, and rendered but does not substantially exist 'as such'. Rather, like a diacritical mark (a comma or a period or an emoticon), it functions to point to (and sometimes bound) something that matters but is not itself matter: a disequilibrium or discontinuity or difference. Existentially speaking, then, the line is not a substantial 'thing, ${ }^{32}$

As such, having no real material or corporeal existence in itself, the graphic line is ideally suited to the animator's visualization of the immaterial or incorporeal. When set in motion, the line assumes Eisenstein's notion of "plasmaticness", defined as "a rejection of once-and-forever allotted form, freedom from ossification, the ability to assume dynamically any form". ${ }^{33}$ Here, the newly kinetic illustration acquires its vitality, as movement "transforms the quantitatively abstract and geometric essence of the line into its provisional existence as qualitatively particular and lived" ${ }^{34}$ In other words, where a static illustration was once describable in measurable, material terms - e.g. as a chalk-line, circular drawing - it also becomes describable as a living, moving object, as movement effected its transformation from a state of static lifelessness to kinetic vitality, recalling Crafton's "glissando" of "animation as performative to animation as actual performance". ${ }^{35}$

And just as the screen functioned as a performative object, so too does the animated line, uncannily simulating analog motion so that the viewer senses the animator's vicarious presence. Eisenstein acknowledged the artist's performance in hand-drawn animation when he wrote that the

32 Sobchack, 2008: 253.

33 Eisenstein, 101.

34 Sobchack, 2008: 253.

35 Crafton, 2011: 98. 
"tremor of contour - is a tremor of the author, like the tremor of the visible in a pure aspect". ${ }^{36}$ Essentially, this formulation establishes the abstraction that occurs between two images transitioning from one to the other, that space between figuration, as a pure trace of the author's imagination. This logic is exhibited to some degree in the animation of Winsor McCay, who rejected the use of transparent cels so that even supposedly static backgrounds pulsated with human imperfection ("Unless all the live figures vibrate", he once said, "the picture isn't really animated"). ${ }^{37}$ Eisenstein also applied the same reasoning to his own abstracted, incoherent drawings, which he claimed were "elemental because they capture the process between the primal protoplasm and formed man". ${ }^{38}$ Abstraction thus functions as an elemental unit of animation upon which figuration is built, with the animator visibly positioned as the architect constructing the animation's performance.

Cohl's films are reflective of this, as they consistently staged carnivalesque performances of dream narratives which made use of the graphic interplay between abstraction and figuration. The opening of Fantasmagorie, taking place in a theatre and displaying a male patron reacting wildly to the images on the screen before him, first signifies the film's self-reflexive performance. This gives way to the performance of incoherent dream logic when a hole opens up within the female patron's head and a clown emerges, frightening the man behind her in a humourous imitation of the Phantasmagoria (Figure 2.3). The circular hole then engulfs the screen, the theatre and its patrons disappear, and the clown, who first appeared to the cinema audience as an apparition, endures a fleeting nightmarish series of physically-torturous vignettes, which pause only when he finally breaks in two and Cohl's hands enter the frame to put him back together. In a

\footnotetext{
36 Sobchack, 2008: 261.

37 Canemaker, 139.

38 Sergei Eisenstein, "Notes on Drawing”, The Eisenstein Collection, ed. Richard Taylor (New York: Seagull Books), 2006, 186.
} 
way, the clown's treatment anticipates Little Nemo's merciless stretching and squashing of its main characters, bending to the will of the animator's self-figuration. Fantasmagorie, with its crude minimalist graphic style and more incoherent stream of transformations, demonstrates more strikingly than Nemo how, as Paul Wells puts it, the "figurative aspects of the body substantially collapse into the abstract", becoming mere "forms subject to manipulation, exaggeration and reconfiguration". 39 The abstraction of the animated body works to draw out the film's oneiric potential; as Crafton summarizes, all aspects of the film, including "the illogical narrative, images of cruelty and revenge, evocations of claustrophobia and paranoia, the act of floating in an undefined spatial void, painless violence - substantiate the analogy to dreams". ${ }^{40}$
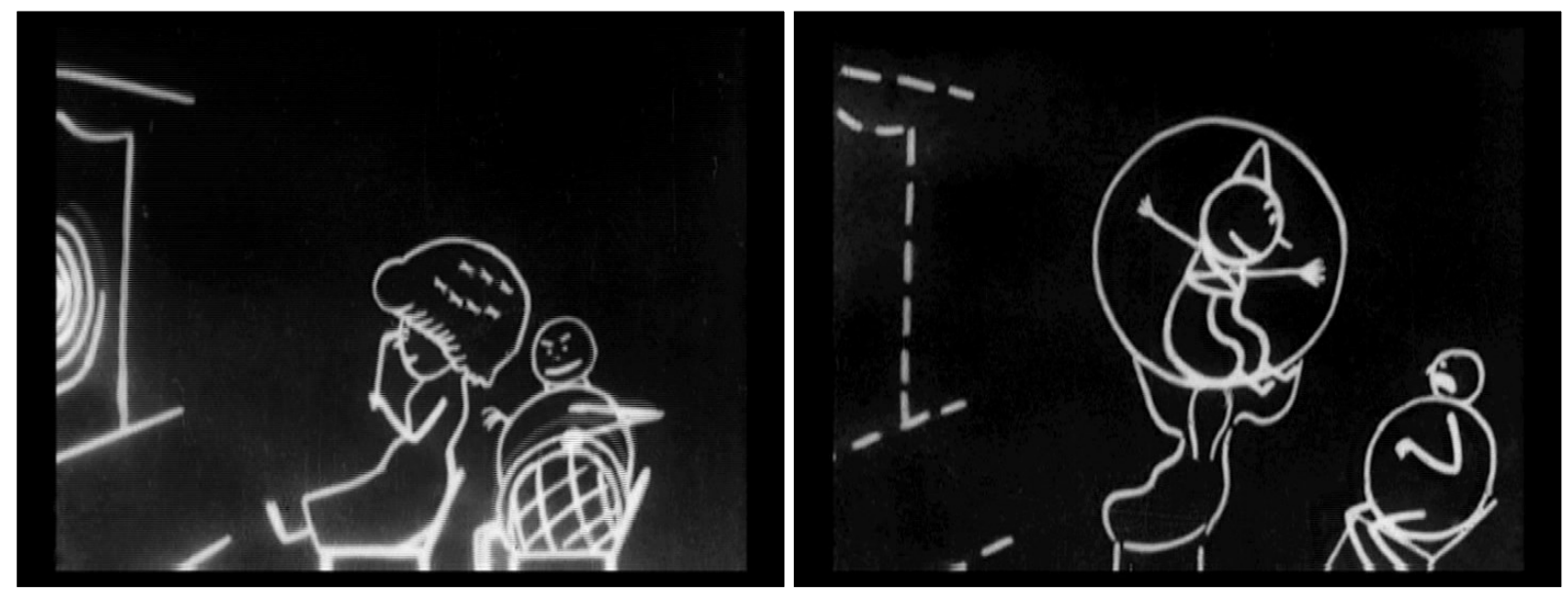

Figure 2.3. Phantasmagoria as cinema in Fantasmagorie (1908).

Fantasmagorie, of course, does not stand alone in Cohl's repertoire as a film exhibiting these traits. He immediately followed his first effort with The Puppet's Nightmare (1908), another white-on-black collage of bizarre visions openly proceeding from the twisted internal reality of dreams. Its self-reflexivity is more subdued, as the animator's hands make no

\footnotetext{
39 Wells, 188.

40 Crafton, 1990: 266.
} 
appearance, and no theatre or screen is present within the film. However, it retains the exact minimalist, rapid-fire stream of consciousness visual style of its forerunner, and again forces its crudely-drawn cartoon figure to watch his dreams materialize before him, then physically involve him in a fleeting series of mind-bending scenarios (Figure 2.4).
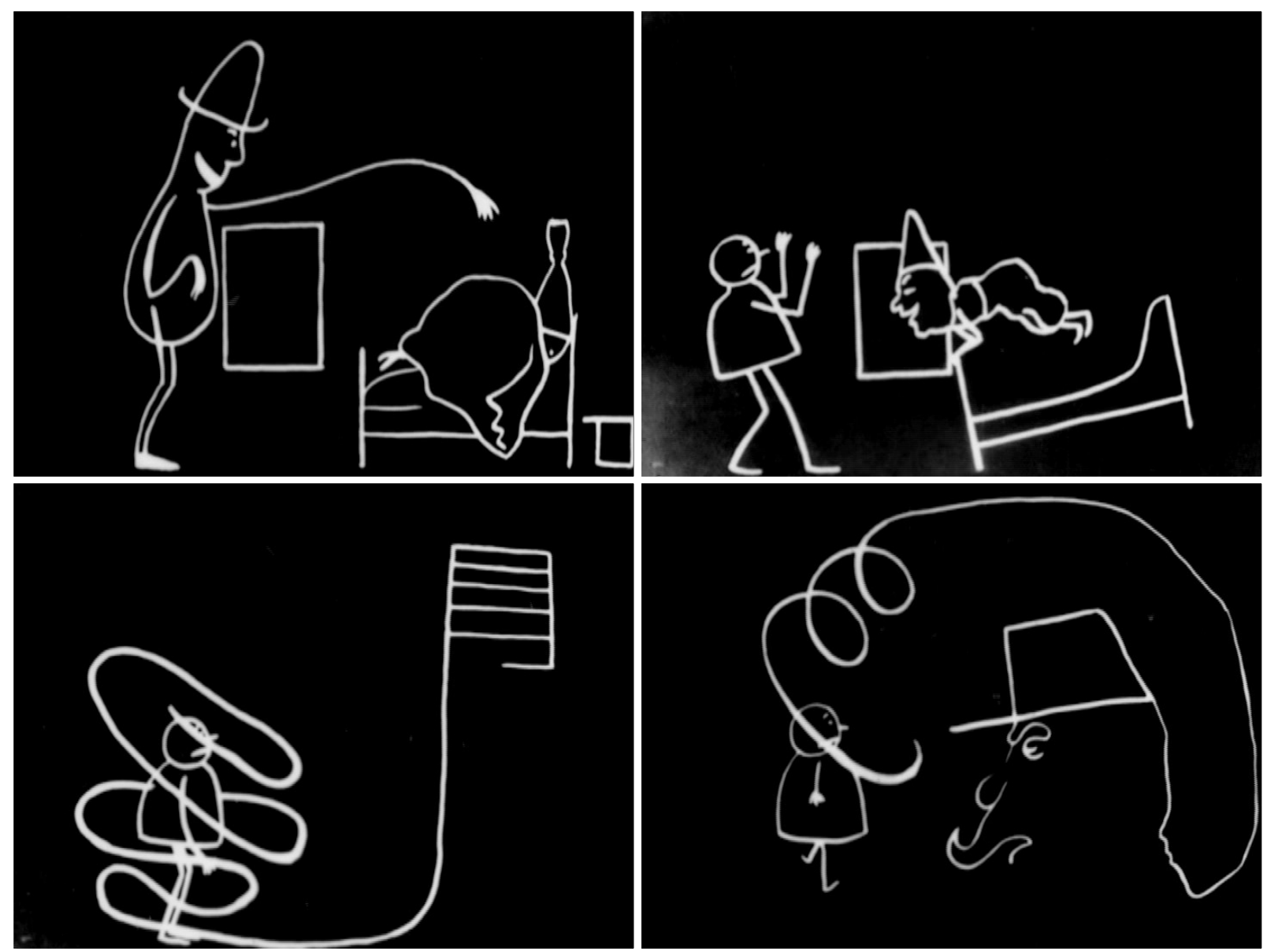

Figure 2.4. The Puppet's Nightmare (Cohl, 1908).

Cohl consistently repeated this loose narrative of the cartoon subject's transition from a distanced, passive spectator of abnormal terrors to an unwillingly active participant, foreshadowing McCay's lighter-spirited Bug Vaudeville. The Mind of a Cafe Waiter (1910) is another notable example, featuring live-action bracketing the animation, which by then was a 
device commonly used by Cohl to set up his dream narratives, something that McCay likely borrowed for himself. $^{41}$ In this film, the titular live-action character falls asleep, becomes animated, and experiences a series of nightmares. They first take the form of paper cut-outs, which aren't as amorphous and mobile as his usual lines, but then Cohl darkens the screen and the waiter begins to witness these hallucinations, now in drawn form, projected above him in a circular visual field. Cohl's evocation of the Phantasmagoria is even more pronounced in this film, as the waiter's visions appears to leap out at him, each triggered by his imagination of a different alcoholic beverage (Figure 2.5). Additionally, Cohl's hands once again make a brief appearance.
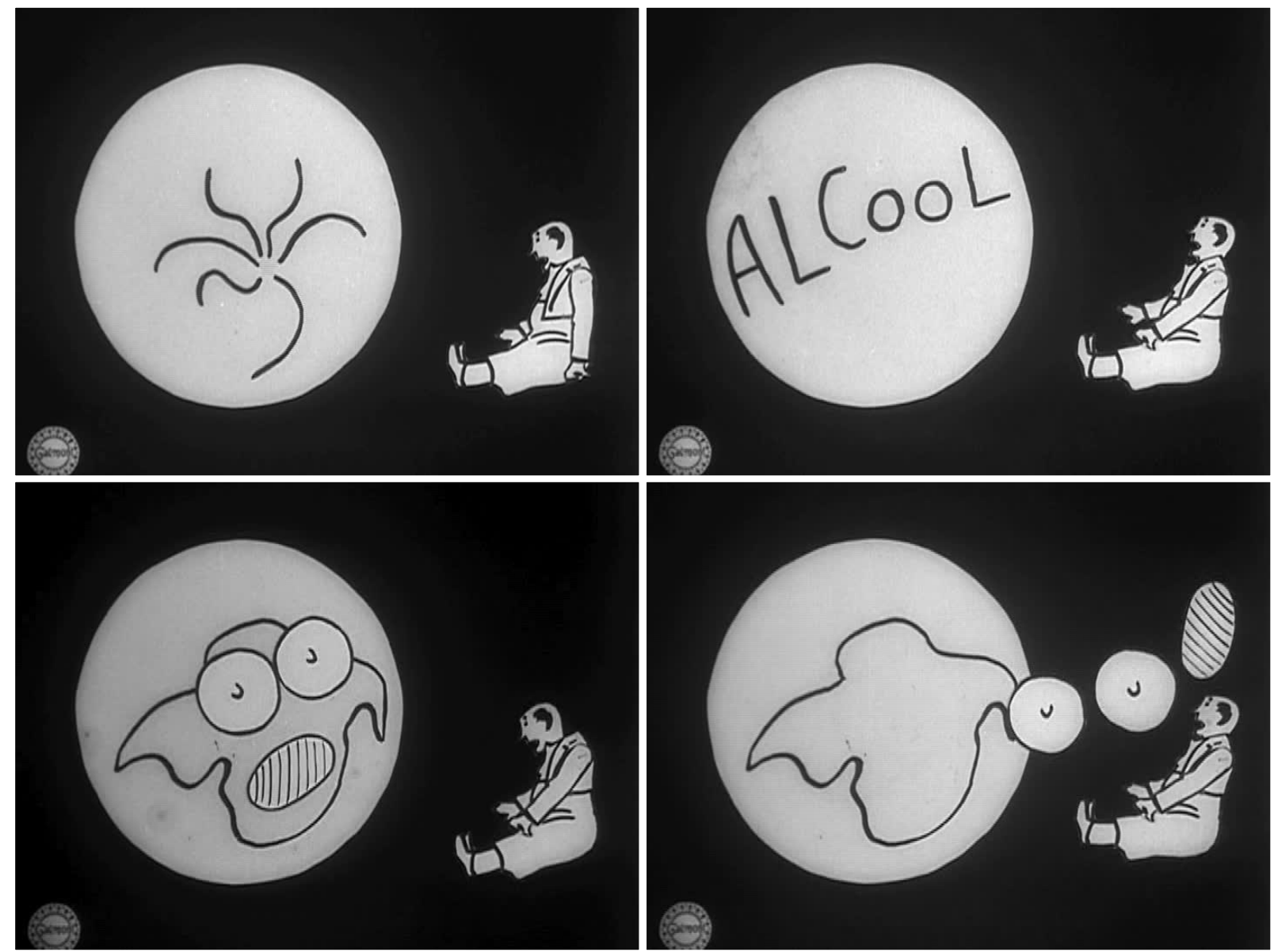

Figure 2.5. The Mind of a Café Waiter (Cohl, 1910).

\footnotetext{
41 Neupert, 35.
} 
Other films in Cohl's repertoire established this performative visual field via the live-action setup of an optical device, through which a character could see their thoughts externalized as animation. A typical example of this film is Transfigurations (1909), in which a showman invites patrons to look into his magical machine, a large device resembling a strange amalgamation of a stereoscope and kinetoscope. As each patron looks into the device, they witness their future foretold through humourously animated transfigurations taking place in a static visual field representing the spectator's point of view; one patron, for instance, witnesses his wife become an angry bird. The laughing showman, likely a self-figuration of the animator, mocks the patron's irritated and dumbfounded reaction.

Cohl repeats this strategy in The Happy Microbes (1909), in which a doctor tells his patient to look into the microscope and observe the bacteria that ails him. The patient sees these illustrated amoebas in the same white circular mask as Transfigurations, which transform into a caricature of a money-hoarding politician; the doctor (again, likely Cohl's metaphoric self-figuration) then informs the patient that he has the "politician's disease". Cohl thus repurposes devices intended for the enhancement of a spectator's vision ${ }^{42}$ as a humourous vehicle for the same type of magical transformations achieved with the unspecified devices in Transfigurations or Le Binetoscope (1910). In the latter film, a clown presents a device that gathers the exuberance of his audience and projects it on the screen. The clown's theatrical stage is first removed from view as moving lines outline the various smiles captured by the toy, and disappears completely when he returns in a darkened scene to further emphasize the conjuring power of his device (Figure 2.6). Crafton also aligns this film closely with the Phantasmagoria, writing that "the clown accomplishes with his binettoscope what Robertson claimed to have done

\footnotetext{
${ }^{42}$ Also see The Enchanted Spectacles (Cohl, 1909) for a similar use of "enhanced vision".
} 
with his Fantascope, vivifying fantasmagorical images of nonexistent beings". 43
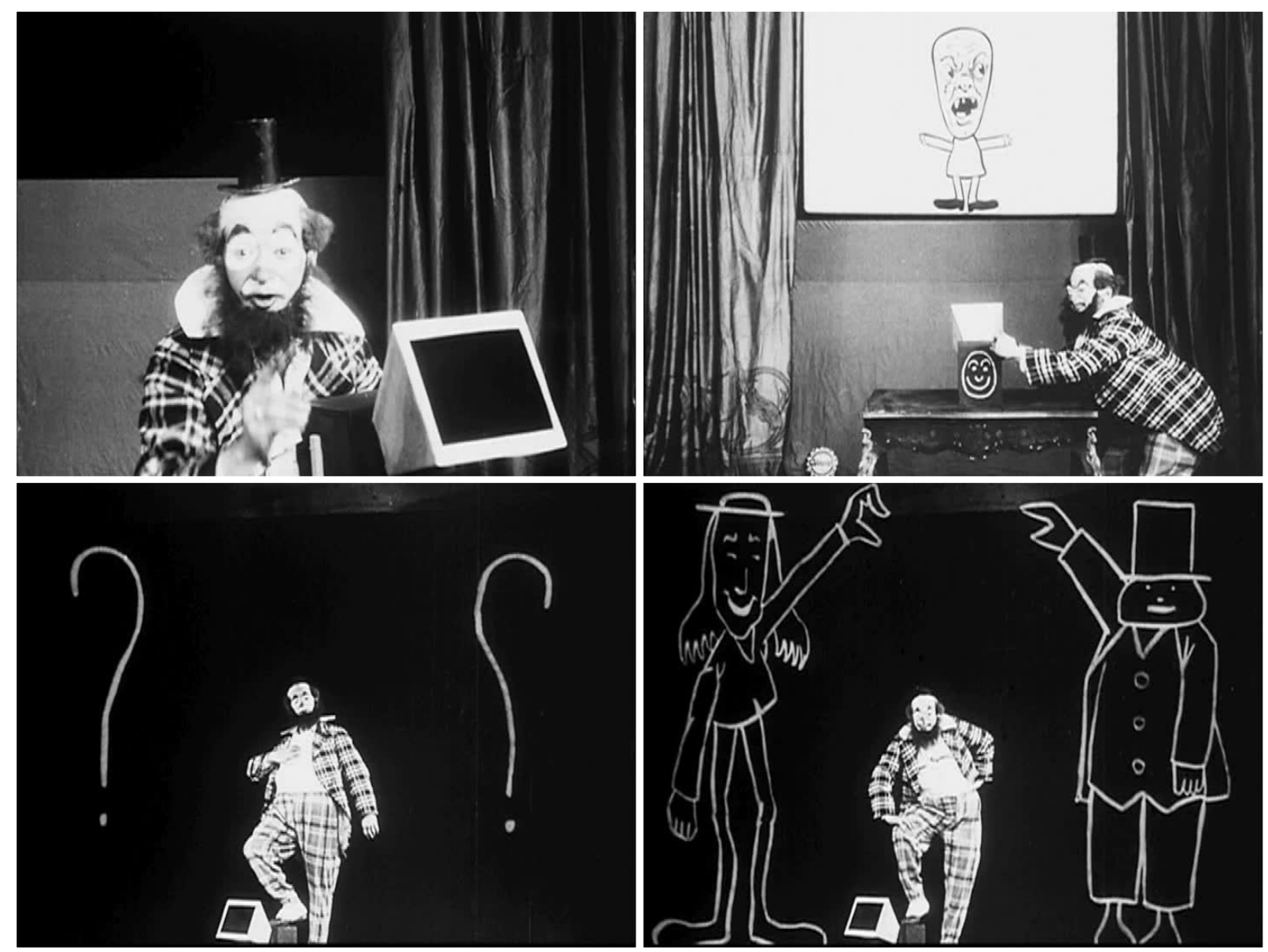

Figure 2.6. Le Binetoscope (Cohl, 1910).

\section{Conclusion}

Films such as Fantasmagorie and The Puppet's Nightmare are actually rare instances of Cohl films which are entirely hand-drawn (save for his photographed hands in the former); The Mind of a Cafe Waiter is much more typical of his output, combining live-action and cut-out shapes with illustrations. Unfortunately, just as Winsor McCay's output was eventually hindered by his workload, the heroic effort required to retrace drawing after drawing for an entire

\footnotetext{
43 Crafton, 1990: 303.
} 
production was unsustainable for Cohl once his superiors at Gaumont began to demand an unreasonable quota of films from their animator. He resorted to using combinations of paper figurines, puppets, and other materials which were quicker to manipulate into new shapes and positions for each photographed frame. However, like McCay, he still preferred the fluid malleability of the graphic line and used it whenever he could, usually saving it for the most fantastical or illogical sequences of his films. Cohl made sure that these sequences were treated as the primary spectacle, manipulating screen space to stage his drawn animation within circular masks or irises. ${ }^{44}$ Thus in his work, Cohl exhibits the complete synthesis of two performative objects - the self-reflexive screen and simulative animated material within it - in order to conjure the immaterial into the spectator's material realm. The following chapter will explore the origins of this synthesized performance by situating it within turn-of-the-century modernity, when mechanized automation threatened to overwhelm artisanal animation.

\footnotetext{
${ }^{44}$ Neupert, 32.
} 


\section{Chapter Three: Situation}

What is the "situation" of early animation? I would like to preface this question here by returning to Esther Leslie's summation of Emile Cohl and his contribution to the history of animated motion pictures:

Animation, the giving of life, battles with annihilation, and always overcomes, always reasserts the principle of motion, of continuation and renewal...Through the intervention of the artist's hand, through the knowing play with surface and depth, and through an acknowledgement of screen, simulation, and situation, Cohl reveals the derivation of the over-lively objects. ${ }^{1}$

The recognition of these essential cinematic components, in both Cohl's and McCay's work, has been elaborated on in the preceding chapters as a self-reflexive practice concerned with performing the invisible processes of the mind as externalized incorporeal beings, engaging the spectator's kinesthetic perception. In addition, attention has been directed to how each animator took their cues from their artistic pasts in earlier spectacular mediums in ways that signaled a self-awareness regarding the workings of their cinematic medium, which was complemented by the filmmakers' physical presence within their films. This self-reflexivity describes one aspect of their acknowledgment of "situation", referring to their recognition of the film spectator's active perceptual position as well as the animator's position as a vivifying figure conjuring images for the spectator.

However, it was not for self-reflexivity's sake that these acknowledgments took place. There existed a historically-specific set of circumstances, pertaining to a rapidly changing modern visual culture, which molded early animation into the metatextual practice that it was. As such, this

\footnotetext{
${ }^{1}$ Leslie, 2, emphasis added.
} 
chapter investigates the historical situatedness of the early animated film within the modern environment that fostered its nascent form. What one finds here is a palpable tension between mystification and enlightenment, a holdover from the previous century's obsession with the power of vision. There is also an ambiguous attitude exhibited towards the increasingly mechanized world, of which these animators were a part and which they (often reluctantly) relied upon in their craft. Thus what underpinned their work was a precarious balance of animation, the artist's mystical vivifying power, with automation, the machinic stuff of enlightening technological progress. When this bubbling tension boiled over, it took the form of the acknowledgement of artifice, a nod to the viewer's knowledge of the cinematic mechanism clashing with their sensation of fantasy. To portray this, early animators freely experimented with spatial organization and perspective ("Screen") while rejecting the photoreal as a "window" upon the world in favour of depicting the fluid movement of life ("Simulation").

What does this ambivalence towards fin-de-siècle modernity reveal about early animation's historical "situation"? The aforementioned tensions point to an uncertainty in turn of the century image-making as to where the powers of vision and performance were located - i.e., in the human observer or the machine. I will argue here that early film animation, in this moment, emerged as the cinematic reconstitution of the animator as the authorial agent of vision. Photochemical cinema had largely effaced the filmmaker in this regard - audiences and early critics were spellbound instead by the unparalleled mimetic capability of the film camera, and the way its images seemed to move of their own volition. Film animation's unmasking of the artist self-reflexively reconfigured the animator's position from an invisible conditioning force to a visible conjurer of moving images. 


\section{The Power of Vision and Performance}

A clear example of this reconfiguration is uncannily articulated in Emile Cohl's The Next-Door Neighbours (1909). In this comical mix of live-action and animation, a nosy couple drills a hole in their wall to spy on the adjacent apartment. Their unsubtle efforts are noticed by the magician residing there, who promptly turns his apartment into an animated phantasmagoria that terrorizes his meddlesome neighbours watching through their makeshift aperture. In this scenario, the spectatorial gaze is inscribed in the two neighbours watching the animated performances of the magician's conjurings. Similar to later films such as McCay's Bug Vaudeville and Cohl's Mind of a Cafe Waiter, they are physically implicated in the performance, as the animated figures cross the split-screen border to physically assault the spectators with rain and fireworks. The magician here acts as Cohl's self-figuration (he even bears a physical resemblance to the animator) who toys with his spectators' laughable paranormal credulity (Figure 3.1).

The neighbours' improvised aperture in their wall recalls the period immediately preceding the public performances of the cinematograph, when moving images and optical illusions were seen with individually operated devices, such as those viewed through peepholes or the thin slots of hand-cranked toys. Crafton notes that the smaller scale of viewership on which these devices operated corresponded to their limited immersive engagement with the spectator:

The optical toys targeted an individual who pays for the apparatus as well as for the 'software'. While a few observers could view the weak images that the projecting praxinoscope might throw on the wall, these devices were designed to be viewed by a limited audience, usually the operator and family members. There was no attempt to 'exhibit' the scenes to numerous people at once, except perhaps, to augment an occasional magic lantern show. The beguiling images created by the optical toys tended to be small, jewel-like things, hypnotic perhaps, but not something that something that one might project oneself into. ${ }^{2}$

\footnotetext{
${ }^{2}$ Crafton, 2011: 100 .
} 

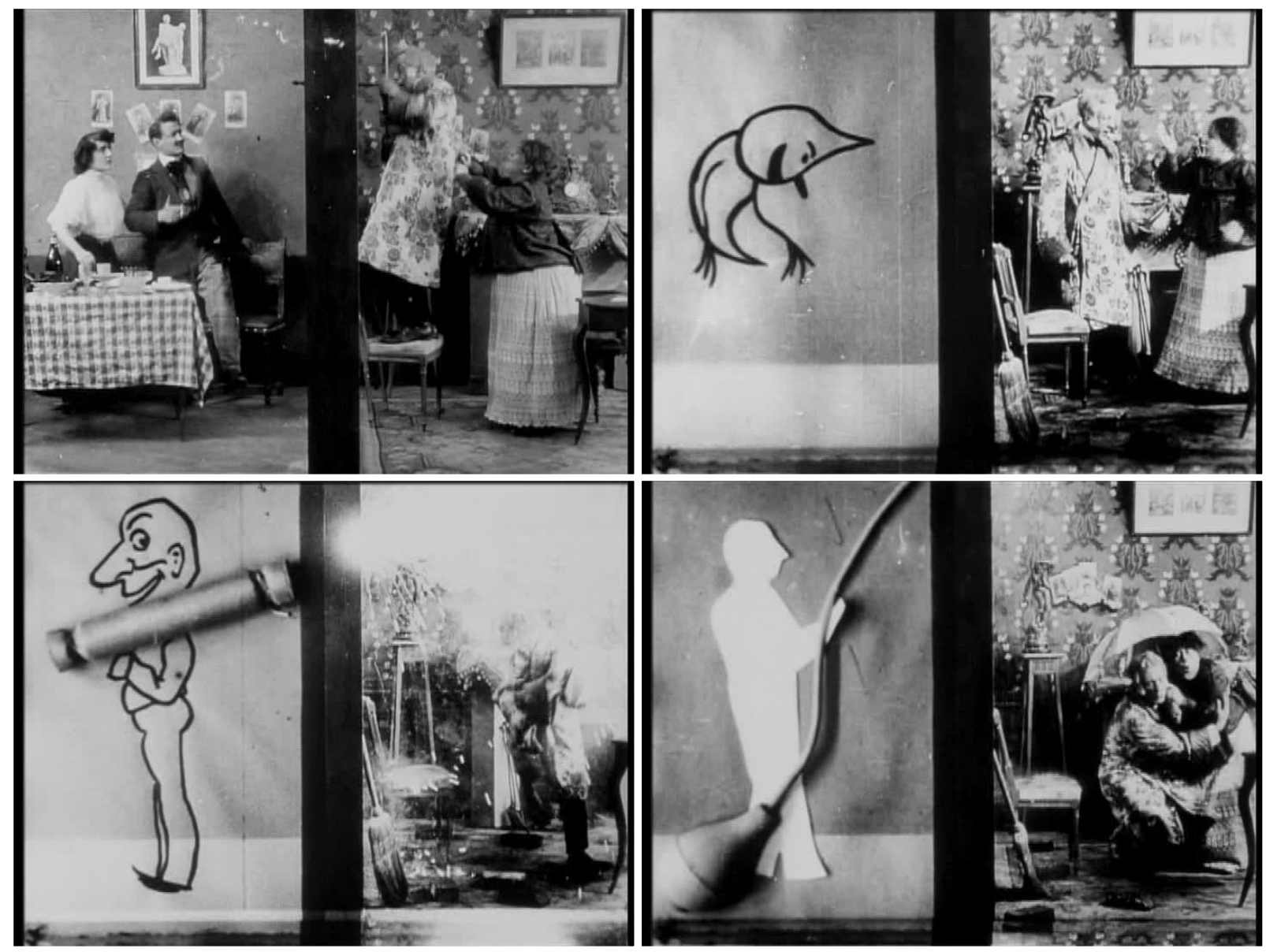

Figure 3.1. The Next-Door Neighbours (Cohl, 1910). Images (and all other film images in this chapter hereafter) taken from Gaumont Treasures Vol. 2: 1908-1916 (DVD, Kino International, 2011).

It was only when these devices began to be developed for public spectacle, such as Emile Reynaud's praxinoscope-based projection in his "Theatre Optique", that the power of the performing image-conjurer began to be reasserted. As Crafton concludes, "[in] their performativity, both the Optical Theatre and the cinema broke with the optical toys of the nineteenth century". 3

In this regard, the film's most significant image appears when the animation briefly takes the form of a giant eye which looks intently back through the peephole at the neighbours. This image, in addition to its self-reflexive gesturing, bears a striking resemblance to nineteenth century

\footnotetext{
${ }^{3}$ Crafton, 2011: 99.
} 
diagrams illustrating the inner workings of optical devices. Some examples of these drawings are found in Étienne-Gaspard Robertson's 1831 memoirs, as the Phantasmagoria showman was also an avid designer of smaller, mechanically-produced illusions for the individual viewer (Figure $3.2)$.
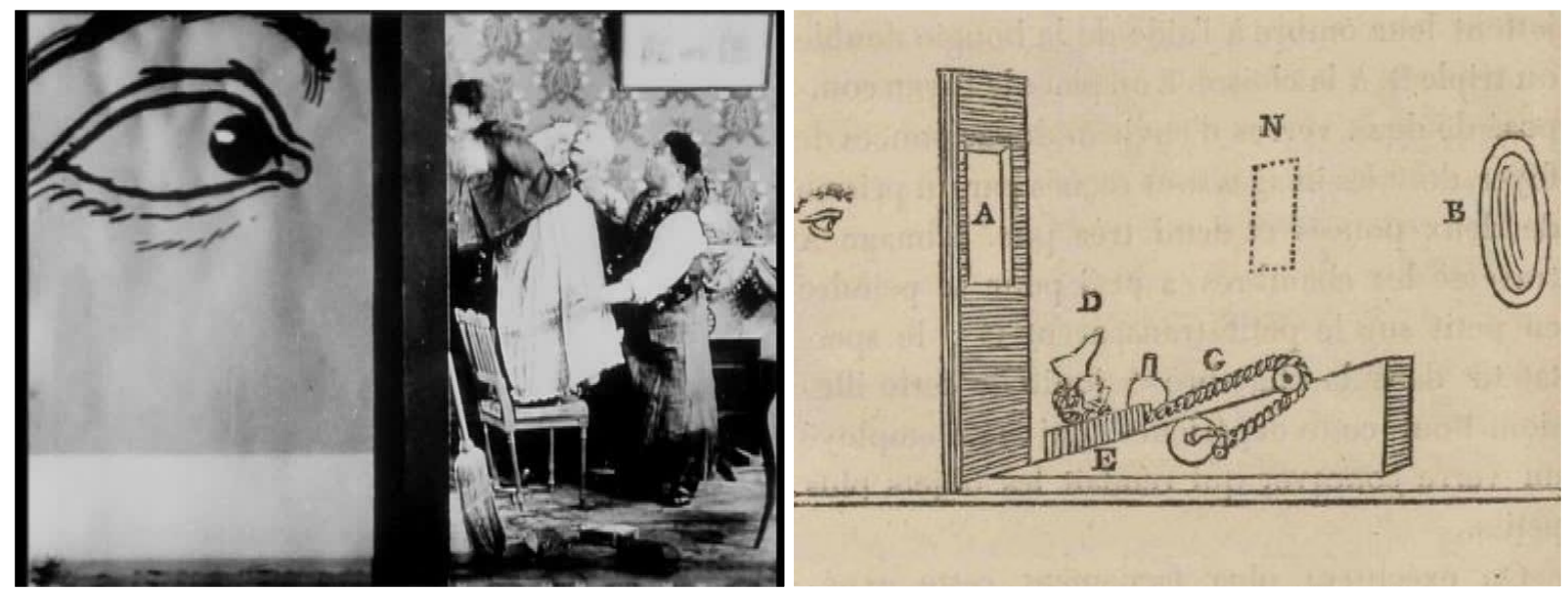

Figure 3.2. The Next-Door Neighbours and Robertson's optical schematics. Second image taken from Robertson, Vol. 1: 412 .

In Robertson's diagrams, the eye represents the spectator, a disembodied voyeur observing images mediated by a machinic apparatus, its internal mechanisms hidden from view. The spectator effectively animates the images of the device, having the agency to alter their own perception through the act of observation. Neighbours inverts this structure so that the gaze, the power of vision, is inscribed in the magician-animator, looking back at the stupefied voyeurs whose bodies are suddenly physically vulnerable. Perceptual change is effected not by an automated machine operated by the voyeuristic spectator, but by a mystical force beyond their control. The film's comedy is a result of the viewing audience's power to see both sides of the dividing wall between reality and fantasy, sharing in the animator's omniscience. Additionally, the magician's pantomimed laughter in the film mirrors this reaction and signifies him as a 
surrogate for both the animator and the audience. Thus The Next-Door Neighbours essentially summarizes early film animation's situation at a tense modern moment when individually-operated optical technology was sublimated by a vivifying figure's enigmatic vision, which restored the animator's previous privileged position as a shamanic conjurer of enchanted images - but this time the animator's secrets were shared with the spectator at the moment of performance.

\section{From Spectator to Animator}

The tensions of this modern moment were rooted in some specific events and sociocultural shifts of the previous century. To explain them, we might look again to Robertson's Phantasmagoria as an early paradigm of the animator's balancing act of delightful bewilderment with scientific illumination. Initially situated as the show's central generative agent, the magical power of the Phantasmagoria animator diminished over time as imitators devised their own versions of the display, and the secrets of this public spectacle were disseminated amongst its previously mystified audience so that any individual could perform it privately with their own lantern or optical device. At the same time, the term "Phantasmagoria" began to dissolve into the era's cultural lexicon as a metaphorical descriptor of an individual's capacity for heightened consciousness and inward vision. Each of these authorial reconfigurations coincided with an epistemological shift that saw the metaphorical power of vision transferred from the transcendental "Hero" or "Great Man" to the anonymous individual amongst a collective of spectators driven to "see and sense everything"" by the influx of visual spectacle instantiated by urban modernity. The spectator was thus able to assume the role of the animator, a hybridized

\footnotetext{
${ }^{4}$ Etienne-Gaspard Robertson, Mémoires Récréatifs, Scientifiques et Anecdotiques Vol.1, Paris: Librairie de Wurtz, 1831, 386. Accessed from the Internet Archive, Jan 3, 2014. <https://archive.org/details/mmoiresrcratifss01 robe>.
} 
figure of mystification and illumination. Leslie's description of the early viewer of film animation thus also fittingly describes this individual of the nineteenth century, who was not "simply seduced by the magic" - rather, they "wanted to know how the magic was done; that is to say, they were spellbound and wanted, at the same time, to break the spell through enlightenment". 5

The Phantasmagoria, as discussed in the previous chapter, was invented at a time when traditional ghost belief had begun to give way to scientific rationalism. As Koen Vermeir writes, the "magic" of the seventeenth and eighteenth century magic lantern show had relied heavily on this belief, which drew from the ancient theory of pneuma and lent imaginary beings their corporeality:

Older and more popular theories fuelled the people's imagination, rather more than did the opinions of contemporary theology or demonology. Neoplatonism and theurgy posited the pneuma as a sphere between the realms of the objective, the subjective and the intersubjective. The pneuma was semi-spiritual and semi-material and was directly affected by the imagination. It was the substance of dreams and visions, of apparitions of the dead, and the mode of activity of demons. The imagination of men and demons could be exteriorized. Our most intimate dreams and horrors could be projected, forming visible shapes on this ectoplasm...The magic lantern brought to the fore this widely disseminated cultural image of demons that could imprint and shape subtle matter. ${ }^{6}$

As such, the magic lantern show cultivated a collective of spectators whose conceptions of incorporeal beings like ghosts and demons took on material appearances in their imagination. The Phantasmagoria, popularized at the tail-end of this epoch, thus tapped into a well of spiritual imagination motivated by an oneiric impulse which would, at the very least, entertain the notion of incorporeal beings. Part of the show's attraction was, therefore, a desire to partake in this shared fascination, and to witness one's individual conceptions of these beings materializing in front of

\footnotetext{
${ }^{5}$ Leslie, 10.

${ }^{6}$ Vermeir, 133.
} 
oneself, as if a personal vision were being played out as a public spectacle. The animator was the shamanic medium for the procurement of these visions, the subject matter of which deviated little from their lantern-show origins; as Vermeir explains, "[long] after people ceased to believe in demonic interventions, monsters and devils remained a prominent theme... and the operator was often represented as a wizard". ${ }^{7}$

Robertson sought to dispel this wizard-label along with the belief in apparitions, but the sublime terror his show effected was such that his rational persona became imbued with these shamanic qualities anyway, forging a hybrid figuration of the scientist-magician. It was this hybrid persona which, in addition to his technological refinements, contributed to the Phantasmagoria's popularity and critical success; though his display quickly spawned many imitations attempting to cash in on the lucrative vogue of the paranormal, most were seen as inferior to the original, likely because these imitators omitted Robertson's secular intentions. This is suggested in one review of a rival exhibit which praises Robertson's display and criticizes the knock-off: as the latter's show is not "animé par les sciences", it is nothing more than a silly amusement. ${ }^{8}$ In contrast, the most successful imitation by a showman named Paul de Philipsthal appeared in London in 1801, selling itself as an exercise in "Spectrology" and mimicking Robertson's rational approach by explicitly stating the non-existence of apparitions. ${ }^{9}$ From there, the show spread to North America when New York museums began to host various incarnations of the display, and the subject matter expanded beyond ghosts and demons so that the term "Phantasmagoria" could refer to a display with "any slides of any topic, so long as they were projected by Robertson's methods". ${ }^{10}$

\footnotetext{
${ }^{7}$ Vermeir, 133.

${ }^{8}$ Robertson, Vol. 1: 147.

${ }^{9}$ Barber, 78.

${ }^{10}$ Barber, 81.
} 
After much prolonged success, the Phantasmagoria gradually declined in popularity until the 1840 s when it was no longer regularly performed by public showmen. It continued, however, as a private performance by individuals who could purchase their own magic lanterns and read instructions on how to recreate the Phantasmagoria themselves on a smaller scale. ${ }^{11}$ With its mystifying secrets exposed, its larger-than-life spectres detached from their Gothic exhibition space and shrunk to fit the confines of an individual's living room, the Phantasmagoria presumably lost much of its terrifying aura as a public display. That did not stop lantern proprietors from marketing their devices as "Phantasmagoria lanterns", complete with descriptions in their catalogs of how to produce the proper Phantasmagoria effect. One such advertisement from 1867, along with this description, also advises consumers to purchase slides with black backgrounds, so that "[the] screen not being seen, the image appears to be suspended in the air, and the deception is complete, even to those accustomed to the exhibition". ${ }^{12}$ Thus there existed a significant market for the secrets of the Phantasmagoria, long after its public decline, as individuals sought to privately delight small audiences of acquaintances by performing the illusion themselves, assuming the role of the visionary animator.

The parceling-out of the animator's conjuring power to the spectator is consistent with a broader shift in the nineteenth century in the relationship between optical devices and vision. As explained by Jonathan Crary, these individually-performed devices:

....are part of a nineteenth century modulation in the relation between eye and optical apparatus. During the seventeenth and eighteenth centuries that relationship had essentially been metaphoric: the eye and camera obscura or the eye and the telescope or microscope were allied by a conceptual similarity, in which the authority of an ideal eye remained unchallenged. Beginning in the nineteenth century, the relation between eye

\footnotetext{
11 Barber, 83.

12 T.H. McAllister, Catalogue of stereopticons, dissolving view apparatus, magic lanterns: and list of over 3000 carefully selected views for the illustration of subjects of popular interest (New York: McAllister Company), 1867, 11, Accessed January 10, 2014. https://archive.org/details/catalogueofstere00thmc
} 
and optical apparatus becomes one of metonymy: both were now contiguous instruments on the same plane of operation, with varying capabilities and features. ${ }^{13}$

Though Crary limits this shift to "nonprojective" devices like the phenakistoscope and stereoscope, the capabilities of the Phantasmagoria were also equivalent to those of the spectator's vision, by way of the dissemination of its secrets through consumer lanterns. The withdrawal of mystification, however, was not necessarily synonymous with total enlightenment, since, as Castle argues, "the demystifying project was compromised from the start. The rationalists did not so much negate the traditional spirit world as displace it into the realm of psychology". ${ }^{14}$ David Brewster's inventions of the kaleidoscope and stereoscope are significant examples of the rationalists' utopian failure. Brewster had criticized the Phantasmagoria for engendering the same sort of mystification which religious and political tyrants used to spellbind their powerless subjects, and his inventions were meant to put these mystifying devices in the hands of the public. But as Crary explains, "his implied program, the democratization and mass dissemination of techniques of illusion, simply collapsed that older model of power onto a single human subject, transforming each observer into simultaneously the magician and the deceived". ${ }^{15}$ In spite of these devices' unconcealed mechanical workings, their operators/observers were susceptible to magical thinking, able to embrace the notion of aliveness in visibly artificial images which they conjured themselves in conjunction with an apparatus. The dissemination of Robertson's methods to the public bore a significant responsibility for this way of thinking, as the "epistemologically unstable, potentially fantastic metaphor of the phantasmagoria simply condensed the historical paradox: by relocating the world of ghosts in the closed space of the

\footnotetext{
${ }^{13}$ Jonathan Crary, Techniques of the Observer: on vision and modernity in the nineteenth century (MIT Press, 1996), 129.

${ }^{14}$ Castle, 52.

${ }^{15}$ Crary, 133.
} 
imagination, one ended up supernaturalizing the mind itself". ${ }^{16}$

Before long, the metaphor of the phantasmagoria was appropriated by cultural commentators who found varying uses for the term's conceptual affinity with consciousness and vision. Karl Marx, for instance, at times recalled both the camera obscura and the phantasmagoria as models of the unconscious mind, ${ }^{17}$ and made specific reference to the "phantasmagorical powers of the commodity". ${ }^{18}$ Marx's words are an indication of the phantasmagoria's metaphorical role as a powerful conditioning force on modern society, with a figurative ability to see beyond the immediate physical world. Moreover, while Marx's use of the term paints in broad strokes a mechanized commodity culture, the metaphor could also be very specific to certain historical places and events. In this regard, a more notorious usage of the term comes from Thomas Carlyle, the nineteenth century historian who initially used it to describe the violent euphoria of the French Revolution. Carlyle vividly painted the Revolution as a rapturous spectacle, its events verbally depicted as a series of "Phantasmagories" and "loud-gibbering Spectral Realities". ${ }^{19}$ Writing in the 1830 s and 1840s, Carlyle was responding to the "mechanized chaos" of modernity clashing with his conservative and patriarchal views, which

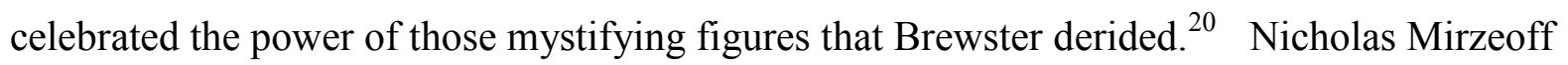
outlines Carlyle's resistance to the age of Enlightenment and revolution:

In counterpoint to this spectral reality of everyday people, with their eternal tendency to amalgamate as Revolution, Carlyle constructed a visualized form of history, dominated by heroes. In his lectures On Heroes, Carlyle argued that only the hero had the vision to see history as it happened, a viewpoint that was obscured for the ordinary person by the specters and phantasmagorias of emancipation. Carlyle imagined the eye of history sweeping across what he called 'clear visuality', 'visualizing' what could not be seen by

\footnotetext{
${ }^{16}$ Castle, 52.

${ }^{17}$ Leslie, 62.

18 Margaret Cohen, “Walter Benjamin's Phantasmagoria,” New German Critique, 48 (1989): 88.

19 Nicholas Mirzeoff, “On Visuality,” Journal of Visual Culture, 5.1 (2006): 56.

20 Mirzeoff, 57.
} 
the minor actors of history themselves...Visuality was, then, the clear picture of history available to the hero as it happens and the historian in retrospect. It was not visible to the ordinary person whose simple observation of events did not constitute visuality. ${ }^{21}$

Thus Carlyle sensed (and attempted to resist) an epistemological shift in which an increasingly modernized and mechanized culture gradually transferred the figurative power of vision, and by extension the agency of historical change, from the enigmatic hero figure to the anonymous collective of individuals, previously the mere "minor actors of history". Carlyle staged the Revolution as a performance, and his lurid, delirious writing was a performance in itself, effectively marking the push/pull between these major and minor "actors" as a struggle for performative space on the historical stage - a struggle which was won with vision, thus aligning it with the animatic powers of the Phantasmagoria. ${ }^{22}$ Accordingly, as Castle finds, Carlyle "obsessively figures the bloody spectacle of civil insurrection as a kind of spectral drama - a nightmarish magic-lantern show playing on without respite in the feverish, ghostly confines of the 'Historical Imagination'”, 23

Given the Phantasmagoria's weight as a metaphor in heroic historiography, it is significant that Robertson occasionally featured prominent historical figures from the Revolution in his show, which premiered at a time when the uprising was still fresh in his Parisian spectators' minds. The representations of these figures anticipated the shift away from heroic vision sensed by Carlyle, their figurative power oscillating between Carlyle's Traditionalist perspective and that of the newly emancipated revolutionary crowd. Margaret Cohen explains this slippage in her analysis of Walter Benjamin's usage of the Phantasamgoria metaphor, which, contrary to Carlyle's usage,

\footnotetext{
${ }^{21}$ Mirzeoff, 57.

${ }^{22}$ Mirzeoff argues that Carlyle's visuality was "very much to do with picturing and nothing to do with vision, if by vision we understand how an individual person registers visual sensory impressions" (Mirzeoff, 67). However, Carlyle's frequent vivid invocations of the Phantasmagoria suggest otherwise, that conceptually there was a slippage between visuality and the impressionistic power of vision.

${ }^{23}$ Castle, 29.
} 
accorded the term an illuminating, demystifying power:

Robertson turns the bloody events of recent history into aesthetic apparitions, fantastic nightmares of an evening's entertainment. Divested of their material reality, however, these historical figures are more than merely entertaining. Robertson helps them to entrer dans la legende, integrating them into the pantheon of "the phantasmagoria of "cultural history," where they play the role of evil demons to the proud hero who founds Swiss bourgeois liberty. Robertson's representation thus seeks to exorcise the demonic power of the revolutionary memories haunting Parisian imagination... What better synecdoche for the ideological transposition worked by "the phantasmagoria of "cultural history" and "the phantasmagoria of civilization" than the phantasmagoria itself? ${ }^{24}$

In other words, hidden within the Phantasmagoria's lionization of famous Revolutionary tyrants was the insidious transferral of their power to their subjects, who watched these illusory figurations of historical agency materialize as ghosts. Carlyle's "spectral drama" was thus literally played out on the Phantasmagoria's stage many years earlier, as the spectator witnessed the demystification of the historical demons populating their imagination. Paradoxically, and by unintended consequence, another mystifying figure emerged from this performance: the animator, part scientist and part magician, necromancer of the past, flaunting unrivaled faculties of vision by conjuring into the material realm lifelike spectres of the imagination. This performance made possible the transferral of Heroic vision to the spectator who became their own animator, both literally through the operation of an optical device and figuratively by enacting their newfound agency as an enlightened citizen.

\section{Animating Urban Space}

In what capacity was this individual aware of her/his role as an "animator"? As noted earlier, Crafton has observed a "glissando" in nineteenth century understandings of animation between a performative action (broadly understood as effecting a change from deathly stasis to

\footnotetext{
${ }^{24}$ Cohen, 92 .
} 
lively motion) to the actual performance of an animated device. ${ }^{25}$ It was possible to view a place or object as animated, if it possessed an intangible quality of aliveness; in this sense, it was possible for places full of urban spectacle to be described as such. Consequently, this urban spectator was aware of their role inasmuch as they possessed the drive to "animate" the world around them, a prerequisite to becoming an active participant in the modern environment and thus utilize their newly-inherited powers of illuminated vision and historical agency.

Cultural commentators of the time certainly saw urban places as animated, describing the city as possessing that intangible quality of conscious life. Étienne-Gaspard Robertson was one of these commentators weighing in on the vitality of Paris, the city aptly named by Benjamin one hundred years later as the "Capital of the Nineteenth Century". In his memoirs, Robertson comments on the decline of his show as early as the 1810 s, which he attributes to the rapidly growing appetite of the Parisian crowd for new, exciting sensational entertainment:

The Parisian wants to see everything and sense everything in a day. His bright and penetrating intellect lends him a great ability to catch almost at the first sight the smallest details of the object one presents to him, and, as soon as it is comprehended, he says to you: Another! ${ }^{26}$

Robertson specifically likens this Parisian desire for a spectacular environment to the vitality of animation, writing that the city's "physionomie" is "speciale, vive, animée, et s'empreint fortement dans l'imagination". ${ }^{27}$ More than once, he attributes life to the "faces" of Paris; in one notable instance he contrasts it with the sleepy Russian city of St. Petersburg, which despite its size is lifeless and uninteresting due to its lack of an active urban crowd populating its streets with spectacle:

${ }^{25}$ Crafton, 2011: 98.

${ }^{26}$ Robertson, Vol. 1: 386.

${ }^{27}$ Robertson, Vol. 1: 66. 
...this city, of 300000 people, with its wide streets, large squares, and initially imposing appearance, soon appears monotonous, especially for a Parisian; the pedestrian movement lacks: one is not, as in our crowded streets, to be constantly jostling to find oneself at each step face to face with twenty different faces, to stroll [flâner], if I must say the word, before great shopping and elegant displays of merchandise; all of which is in Paris, and only in Paris are these lively turnings and these animated faces [physionomies animées] that give the general public an air of almost playful activity. ${ }^{28}$

What Robertson more broadly identifies here is the emergence of a collective of spectators constituted through their animation of that urban spectacle. His personal account of early nineteenth century spectacle resonates with Vanessa Schwartz' characterization of the modern Parisian crowd, which was concurrently emerging:

The crowd, and the experience of belonging to an urban collectivity more generally, did not disappear as those who stress the alienation of modern urban life suggest. Rather, their collective violence [from the Revolution] did... The visual representation of reality as spectacle in late nineteenth-century Paris created a common culture and a sense of shared experiences through which people might begin to imagine themselves as participating in a metropolitan culture because they had visual evidence that such a shared world, of which they were a part, existed. ${ }^{29}$

This visual culture was shared primarily through the growth of popular public media such as newspapers, wax museums, panoramas, and eventually the cinema, all capable of promoting and providing sensational visual experiences.

Robertson's account of his urban environment is particularly significant because he indiscriminately uses the term "animé" as a descriptor of his city as well as his magic lantern devices - such as the "Mégascope Anime", the "Fantasmagorie Vivante", and more frequently the

\footnotetext{
${ }^{28}$ Robertson, Vol. 2: 150.

${ }^{29}$ Vanessa Schwartz, Spectacular Realities: Early Mass Culture in Fin-de-Siècle Paris, Berkeley: University of California Press, 1998, 5-6.
} 
"Fantasmagorie Animée"30 The term's flexible use here, where it can refer interchangeably to the liveliness of urban space or to the technology of optical illusion, anticipates the identity of Paris in the nineteenth century as a hub of spectacular entertainment mediated by the animated activity of its citizens. Indeed, as Schwartz has noted, "life in Paris became so powerfully identified with spectacle that reality seemed to be experienced as a show - an object to be looked at rather than experienced in unmediated form". ${ }^{31}$ The city was a stage for the performance of vision.

It was on this urban stage, in the latter half of the century, that Emile Cohl honed his skills as an Incoherent caricaturist and comic strip artist, which reflected an intimate relationship with the spectacular milieu in which he worked. Across the way, the experiences of his counterpart Winsor McCay exhibited distinct parallels of spectacular immersion as a comic strip artist in the modern landscape of New York City. Their experiences were reflected in their films in an ambiguous attitude towards this shared visual culture of which they had been a part, largely due to its increasingly mechanized character. It was for this reason, as Tim Blackmore argues, that their graphic work "reflected the perverse situation of needing the machinery which was publishing them, while showing that the same machinery guaranteed the slow demise of the artform, the gradual grinding down and wearing away of the comic artist's fantastical powers". ${ }^{32}$ Their films thus reconstituted these powers, re-establishing the animator's figurative power of vision, and restoring the balance of animation with automation.

\section{Emile Cohl: The "Oldest Parisian"}

This was the title Emile Cohl apparently bestowed upon himself, citing his centuries-old

\footnotetext{
${ }^{30}$ Robertson, Vol. 1, see 333 and 416-430 respectively.

31 Schwartz, 10.

32 Tim Blackmore, “McCay's McChanical Muse: Engineering Comic-Strip Dreams,” Journal of Popular Culture, 32.1 (1998): 21.
} 
Parisian lineage. ${ }^{33}$ Unsurprsingly, his attachment to the city's spectacular environment is pronounced in much of his work. He drew cartoon strips and biting political caricatures for numerous newspapers and magazines in his lifetime, taking advantage of the newly-flourishing "age of lithography - the process that enabled images drawn by the artist's own hand to be reproduced and disseminated by the hundreds or thousands", and also a process which "made possible the spread of overtly oppositional political imagery to an extent that would have been inconceivable in the previous century". ${ }^{34}$ The mass press, as Schwartz explains, formed an integral part of Parisian visual culture:

...the newspaper served as one of the most powerful forms of modern mass cultural urban entertainments in the sense that it constituted a collective and then aimed to please it through newspaper reading... Between 1880 and 1914, the overall circulation of Parisian dailies increased 250 percent. But beyond mere circulation figures, the newspaper became an emblem of Parisian culture as its sensational reality came to stand for the best translation of the urban experience. In fact, it created the terms through which people might order and make sense of their experiences. ${ }^{35}$

The proliferation of the mass press in the 1880s corresponds with Cohl's transition from political caricature into comic strips. This move was attributed to the fact that "portrait photography was no longer a novelty; there was little motivation to celebrate heroes, as the cause of Republicanism had lost its allure; and the mores of French society were changing". ${ }^{36}$ The "portrait-charge" was replaced by "the rise of the satire de moeurs (satire of manners), or essentially non-political comments on French social life". ${ }^{37}$ Cohl thus found himself contributing to a cultural institution responsible for creating and maintaining the city's urban vitality. The newspaper, in providing the average citizen with a sensational picture of everyday events, actively reinforced the city's

\footnotetext{
${ }^{33}$ Crafton, 1990: 3.

34 Crafton, 1990: 6.

35 Schwartz, 27-28.

${ }^{36}$ Crafton, 1990: 66.

${ }^{37}$ Crafton, 1990: 66.
} 
palpable aura of visual stimulation, to which the reader was intuitively encouraged to give themselves over. The subjects of these stories were usually sensational accounts of average citizens, effectively locating this sensational subject within the same strata as its urban spectator. In other words, this artistic shift - in itself a significant move for the Republican-leaning Cohl reflected the more complete transferral of vision from Carlyle's enigmatic Hero to the urban spectator.

Further facilitating this transferral was the expansion of the sensational realities of the mass press to the exhibition space offered by museums, particularly wax displays, which vastly grew in popularity at this time. The Musée Grévin, for instance, took its subject matter from the newspapers' headlines and advertised itself as a "journal plastique", or "a newspaper molded and formed in three dimensions like other forms of the "plastic arts". ${ }^{38}$ As such, the displays at the Musée "combined the legitimacy of the museum-form with the popularity of the press and thus found and sustained its public through its spectacular depiction of reality". ${ }^{39}$ Significantly, this was the same exhibition space that, before long, would house Reynaud's Optical Theatre and the earliest cinema displays of short actualities, in which the subjects of these films "followed in the tradition of wax tableau subjects that imitated the mass press re-presentation of reality as spectacle". ${ }^{40}$ Moreover, this new re-presentation implicated the viewer as part of the urban collective being re-presented:

The Optical Theater at the Musée Grévin, as well as Edison's and Lumière's cinematographic spectacles, were based on selling tickets to the performance, not selling the apparatus or the software. The status of the consumer then becomes 'member of a social group and audience' as well as 'viewer'. ${ }^{41}$

\footnotetext{
${ }^{38}$ Schwartz, 109.

${ }^{39}$ Schwartz, 92.

${ }^{40}$ Schwartz, 190.

${ }^{41}$ Crafton, 2011: 100.
} 
Thus the museum did not merely display, but rather performed reality for its viewers, who, as the animators of the visual spectacle around them, were themselves a part of this performance. As cinematic exhibition, it internalized the performative spectacle of its urban surroundings - the sensational press, puppet theatre, magic lantern shows - and reproduced it for the viewer who, much like the patrons chez Robertson or Cohl's soused café waiter, ${ }^{42}$ saw their own thoughts and experiences externalized as a phantasmagoric exercise.

Cohl's repeated representations of this exercise in his films are where his relationship with modern Paris can be located. Unlike his satire de moeurs, he rarely directly illustrated this environment. As Crafton observes, "the world in his films is never the bright exteriors of Paris that one sees in the productions of his [Impressionist] contemporaries, but rather they are evocations of an interior universe always in flux and responding continually to the whims of the animator", ${ }^{43}$ In Cohl's work, the artist's governance over this interior universe was styled as a response to his figurative sublimation and effacement under the increasingly machinic terms by which art was being created. Cohl's response was understandably ambiguous; machines were allowing the urban vitality of Paris to thrive, as evidenced by the ubiquity of the mass press, the museums" embrace of the "plastic arts", the availability of optical devices for individual purchase, as well as the constant technology-driven upsurge and turnover in general of new public spectacles. However, these were also terms which tacitly enabled the commodification of the arts which Cohl had aggressively lampooned in the 1880s with the Incoherents, and which he more subtly resisted in his film animation, often with the narrative deployment of enchanted optical devices as vehicles for the animation. ${ }^{44}$ In these magical narratives, "Cohl developed recurring

\footnotetext{
${ }^{42}$ See the previous chapter for a description of this film.

${ }^{43}$ Crafton, 1990: 197.

44 These narratives are detailed in the previous chapter.
} 
metaphors for expressing his attitudes toward the cinema and his conception of the filmmaker as an artist, not just as a technician or producer of commodities", metaphors which isolated vision as the animation filmmaker's distinguishing trait, as "the viewing devices in his films - microscopes, X-ray machines, footprint decoders, and magic glasses - all inscribe the gaze in idealized visionary apparatuses". ${ }^{45}$ As Neupert argues, when these devices, which created a circular visual field for the animation to perform, "were exploited diegetically within the film, as in a character presenting their view to the spectator, or sharing their vision, they reinforced the revolutionary nature of the visual revolution then underway". ${ }^{46}$ Only the animator could control these enchanted machines which, representing amalgamations of shamanic mystification and scientific progress, subjected their dumbfounded subjects to carnivalesque depictions of inner realities.

Occasionally, however, Cohl's ambiguous attitude to his modern environment was allowed to surface past this subtext. Three films in particular explicitly reflect this ambivalence. The first, En Route (1910), is a mocking celebration of modern transportation. The film opens with an intertitle stating that "in the beginning, there was movement", followed by cut-out figures of celestial bodies hovering about the screen. Then, another title describes how "Man, always moving, one day grew tired", followed by images of a caveman harnessing a horse into a chariot, which then becomes a train, and finally an automobile. Other scenes depict a fish transforming into increasingly technologically-advanced ships, and birds as the precursors to hot air balloons and airships. What appears to be a celebration of modernity is humourously undercut by the final images, in which the sun and moon from the opening frames frown down upon the Earth, its surface and air chaotically populated by moving machines (Figure 3.3). This is accompanied by an intertitle which states that "Undoubtedly, man no longer exhausts himself, but the world has

\footnotetext{
${ }^{45}$ Crafton, 1990: 302.

${ }^{46}$ Neupert, 33.
} 
become quite annoyed with him". The ending of En Route can thus be read as a reflection of Cohl reacting with uncertainty to the blinding technological progress of modernity, which offered clearer pictures of the external world faster than his artisanal efforts ever could.
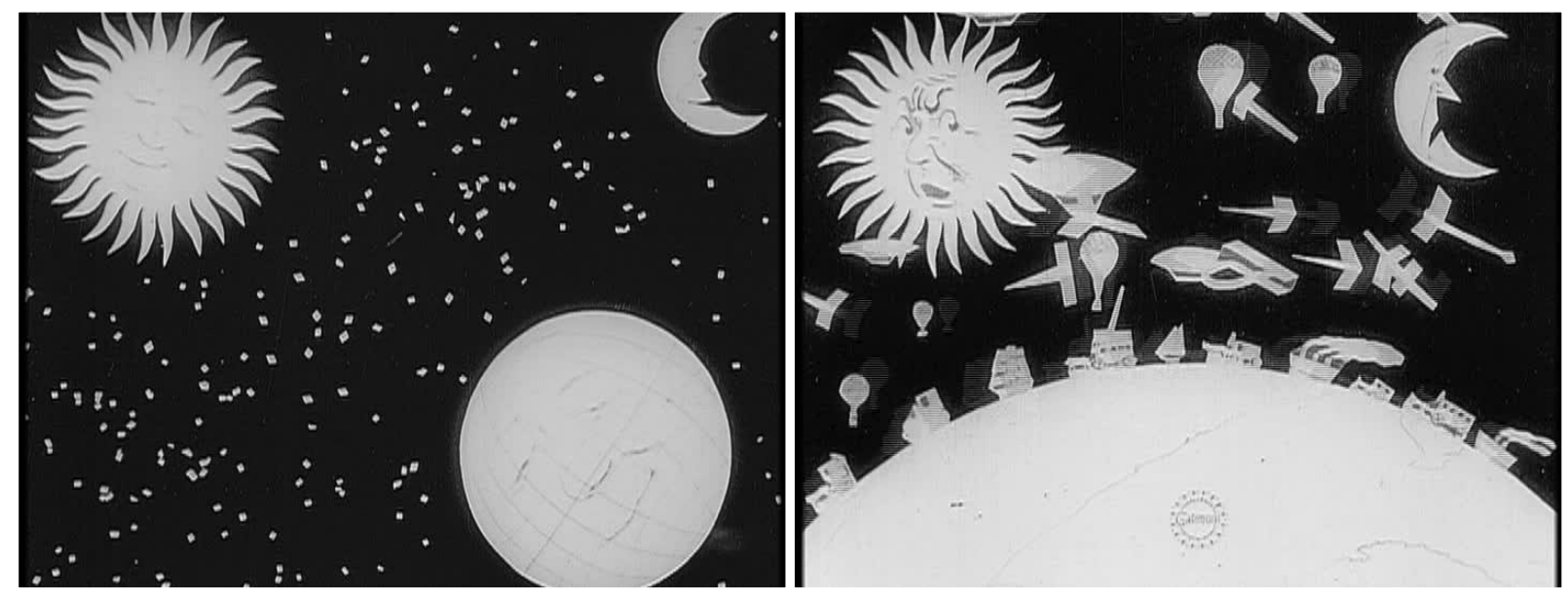

Figure 3.3. En Route (Cohl, 1910), opening and closing images.

The opening images of the second example, Rien n'est impossible à l'homme (1910), reinforces this reading of En Route, beginning with an intertitle which states that man, as "Master of the air, thanks to the airplane, he sees what once only birds had seen". Briefly, live-action footage of a primitive plane taking flight precedes a bird's eye view of a farm below, composed from miniature figurines, followed by another live-action sequence of the same perspective, apparently achieved with a camera aimed down from the rooftop of an outdoor cafe to recreate this vertical view without the use of mini-models. The film thus initially appears to celebrate the modern world, in which "the progress of science was so exhilarating that even the pessimistic influence of the Incoherents could not prevent it from being taken at face value once in a while". ${ }^{47}$ However, there are several moments of the film which subvert its surface-level celebration. Included amongst Cohl's "paeans to scientific progress", such as the ability to travel underwater,

\footnotetext{
${ }^{47}$ Crafton, 1990: 290.
} 
are the distinctly unscientific abilities to "tenderize the hardest stone" with music and "explore the deepest conscience" through hypnotism. The overblown rhetoric of these intertitles also play into Cohl's Incoherent love of satirizing seriousness. In addition, the film presents us with one of Cohl's most evocative and self-reflexive sequences, in which an intertitle celebrates the modern ability of the cinematograph to record man's favourite parts of reality for replay. This is followed by a sequence in which an animated cameraman films a comical live-action scene of a baby-snatching, both framed in the same white spatial void. The live-action scene is then shown being replayed in a dark theatre, illuminated only by the light of the projection device (Figure 3.4). The figurative power of vision here is literally given to the filmmaker, whose animated figuration once again appears to represent Cohl's self-figuration as the moving-image conjurer.
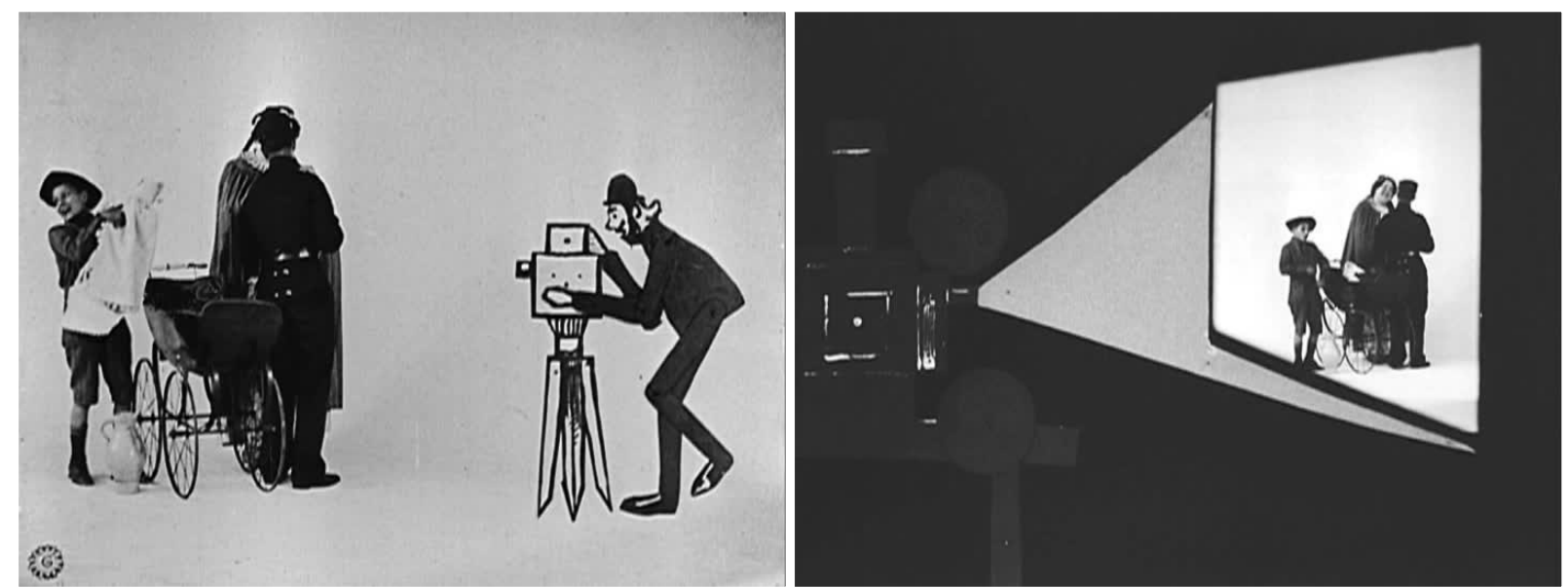

Figure 3.4. Rien n'est impossible à l'homme (Cohl, 1910).

\section{Conclusion}

A final example, Les Beaux-Arts Mystérieux (1910), in another display of self-figuration, is the film which most boldly links Cohl's depictions of interior universes to the modern exteriors of his urban world. Functioning almost as an autobiographical account of his artistic life, the film 
presents a series of sequences in which basic art materials such as pins, threads, and paintbrushes, moving about on their own, compose various images on a white surface within the black-framed background. These images then become photographs, which then become moving live-action images (Figure 3.5). As Crafton notes, “[the] order of each sequence recapitulates Cohl's own progression in the graphic arts, from the childlike drawings of his youth and Incoherent period to his eventual commitment to cinematography and animation". ${ }^{48}$ Furthermore, some of the images Cohl features here include iconic Parisian landmarks such as the Arc de Triomphe and the Eiffel Tower, signifying the grounding of his artistic roots in this urban environment; these sequences literally mark him as an animator of this urban space. Finally, the film concludes on another evocative image of self-figuration, this time featuring the animation of a clown-mask which, in reverse motion, builds itself out of paper. This image, as Crafton explains, is perhaps Cohl's ultimate statement on his art, the literal act of re-masking ironically functioning as a deliberate unmasking of the animator:

...we recognize this image as Cohl's alter ego and the hallmark of the Incoherent artist, rejecting the established world of commercial art (and cinema) with an aesthetic defiance...In this film, certainly one of Cohl's most personal and hermetic, we actually observe the unraveling of the clown's mask to reveal the vacuum inside. In his art we see the love of the grotesque and his fear of and attraction to madness as a radical alternative to the boring sameness of middle-class French society. And in his public vilification of the film industry, we do sense some measure of satisfaction derived from contemplating his career as that of the heroic martyr, the alienated artist. ${ }^{49}$

Cohl's work thus reconstituted the animator's unique powers of vision, embedding them within the Herculean labours of the artisan struggling against the mechanized world which threatened to take them away. It was this exact world, however, which characterized the modern Parisian environment and made Cohl's artistic life possible in the first place, both in his static and kinetic

\footnotetext{
${ }^{48}$ Crafton, 1990: 305.
}

${ }^{49}$ Crafton, 1990: 306. 
work. This was not a uniquely French phenomenon, however; as martyred and alienated in his art as Cohl might have felt, there was another animation artist in Winsor McCay who shouldered the same hesitance towards this world in the modern urban capital of America.

The title of this chapter thus refers not just to these films' acknowledgement of the cinematic spectator's unique position before a screen, but also the historical situatedness of those spectators and his films in an industrialized modern environment. Cohl's consistent play with the former situation was distinctly informed by the latter, with films such as The Next-Door Neighbours or Les Beaux-Arts Mystérieux visibly displaying the slippage between these two situations.
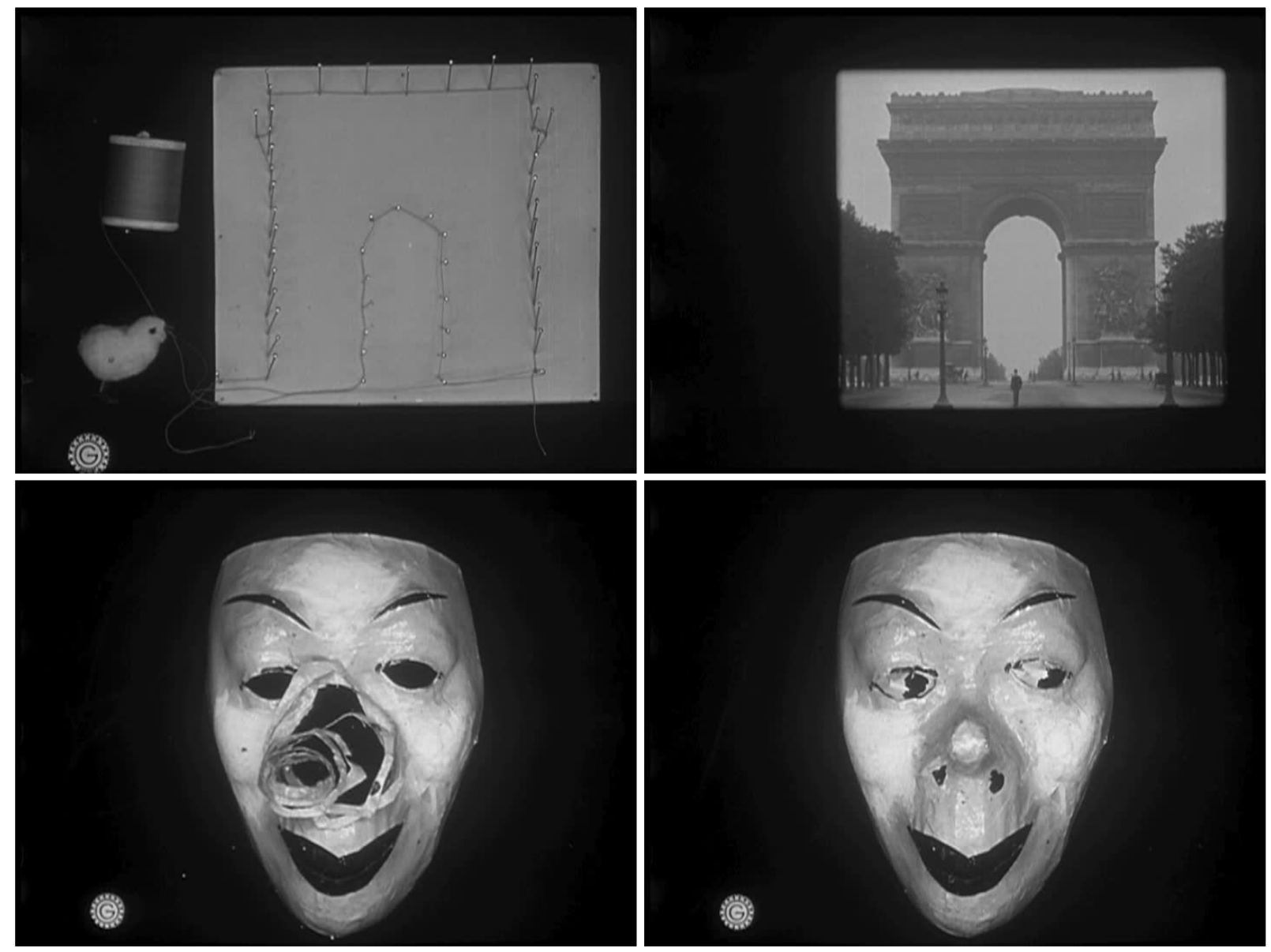

Figure 3.5. Les Beaux-Arts Mystérieux (Cohl, 1910). 


\section{Conclusion}

Each chapter thus far has analyzed an essential cinematic component of early animation. "Screen" and "Simulation" examined the performative figuration of the animator via the film frame and graphic motion, while "Situation" positioned these elements in the historical context of urban modernity which threatened to efface this performance. The question that now remains is how does this analysis contribute to contemporary understandings of animation? An example from Winsor McCay's later period of filmmaking is useful here in illuminating some of the enduring questions that continue to be put to recent animated media.

\section{Winsor McCay's Plastic Pet}

In perhaps McCay's most definitive comic strip statement on his urban world, a "Dream of the Rarebit Fiend" comic from January 7, 1905 depicts a drunk man who imagines himself as a giant milling about the city, bending skyscrapers and playing with ships and subway trains as if they were toys (Figure 4.1). The cartoon illustrates just how directly the animated environment of New York conditioned McCay's art. The comic humour of the drunk man's imagination is underscored with apprehension towards the urban universe, which is depicted as a perilous dreamscape in which machines, bodies and buildings alike are subject to physically impossible transformations, anticipating the corporeal plasticity on display in Little Nemo. As such, it is an uncanny graphic reflection of what Charlotte Nekola describes as the plastic "placelessness" of turn-of-the-century New York:

...skyscrapers, elevated railroad and electric lights created an aura of imaginary space and time. New York also gained a sense of magnitude through not only the sheer number of immigrants constantly arriving and the daily flow of commuters, but also through the sense 
of transience that this constant movement imparted...In its mix and size and aura of transience, New York exuded a sense of placelessness, with its plastic, imaginative, created spaces, its quick-study dramas, neither Europe nor America. ${ }^{1}$

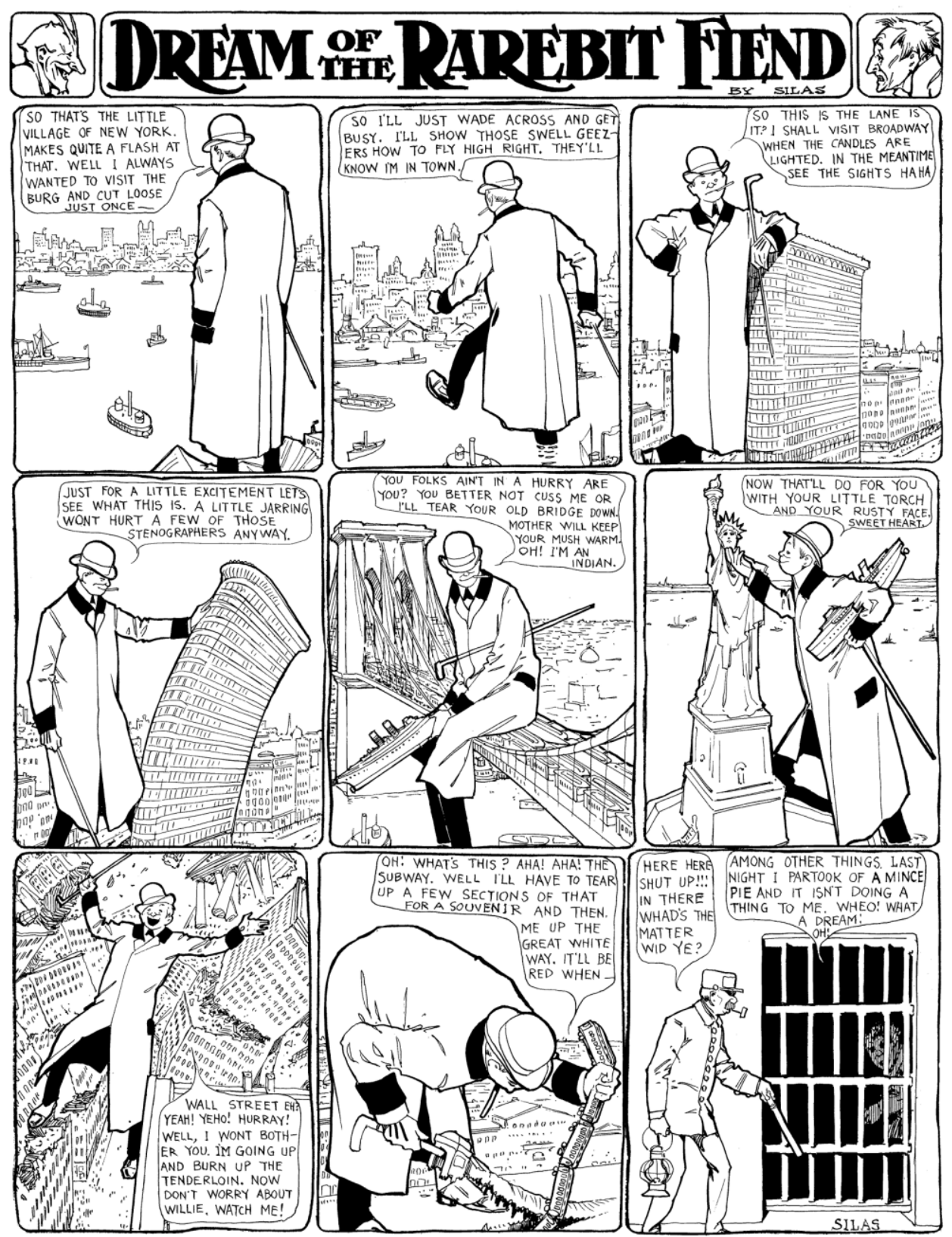

Figure 4.1. The "plastic, imaginative, created spaces" of New York in "Dream of the Rarebit Fiend" (McCay, 1905). Image taken from Merkl, DVD episode 30.

${ }^{1}$ Charlotte Nekola, “When New York Wasn't Big Enough: The Contradictions of Space, Real and Imagined, in 1890's New York", in Public Space, Private Lives: Race, Gender, Class and Citizenship in New York, 1890-1929, eds. William Boelhower and Anna Scacchi (Amsterdam: VU University Press), 2004, 265-267. 
McCay's comics absorbed the plasticity of the imaginary urban world out of a compulsive need to bring order to the physical version. The Rarebit series frequently broadcasts this compulsion through outlandish visualizations of out-of-control technology. For instance, an early episode dated October 26, 1904 depicts a man whose limbs are dismembered by the traffic on Broadway as he tries to cross the street; undeterred, he gathers them up and carries on. ${ }^{2}$ Another one from March 18, 1905 features an elevated train flying off the tracks, careening through multiple skyscrapers and landing in the water, while the driver dryly comments on his inability to swim. ${ }^{3}$ By frequently turning the city, a monumental feat of technological progress, into a carnivalesque playground for his illustrations, McCay attempted to reestablish the artist's control over this animated universe. He harnessed the constant movement of its people and the physical transformations of its landscape, and confined it within the imagined space of the comic panel. Thus in adapting his cartoons for the film screen, McCay released the pent-up dynamism contained within his static drawings created by his urban observations. The performance of framed movement in his films, most notably Little Nemo, represented a corporeal plasticity consistent with the body of the archetypal Rarebit dreamer who, like McCay himself, was in constant opposition to the mechanized world but refused to be sublimated by it.

Consequently, The Pet (1921) is McCay's most personal filmic statement on his modern world. In an adaptation of the Rarebit series' dream-narrative setup, a woman falls asleep and imagines adopting a stray pet, which arrives in the form of an unspecified dog-like creature. The pet grows into a gigantic animal and terrorizes the city; unaware of its size, it eats everything in sight, including airships and skyscrapers. Despite the innocent charm of the titular animal, the film is a dark illustration of McCay's anxiety towards the urban landscape's inundation with

\footnotetext{
${ }^{2}$ Merkl, DVD episode 9.

${ }^{3}$ Merkl, DVD episode 50.
} 
modern technology. Accordingly, near its end, the film invokes the post-apocalyptic imagery of the First World War, as the full-grown pet is bombed from the air by planes. The pet explodes, scattering the debris of the city upon the screen (Figure 4.2). The film's final image of a motionless city, devoid of life and reduced to barren ruins, starkly contrasts the kinetic vitality of the real metropolis, reminding the viewer of its destructive potential, and illustrating how, as Paul Flaig argues, "the experience of anxiety produces a spectatorial body that feels restricted, deanimated and paranoid". 4
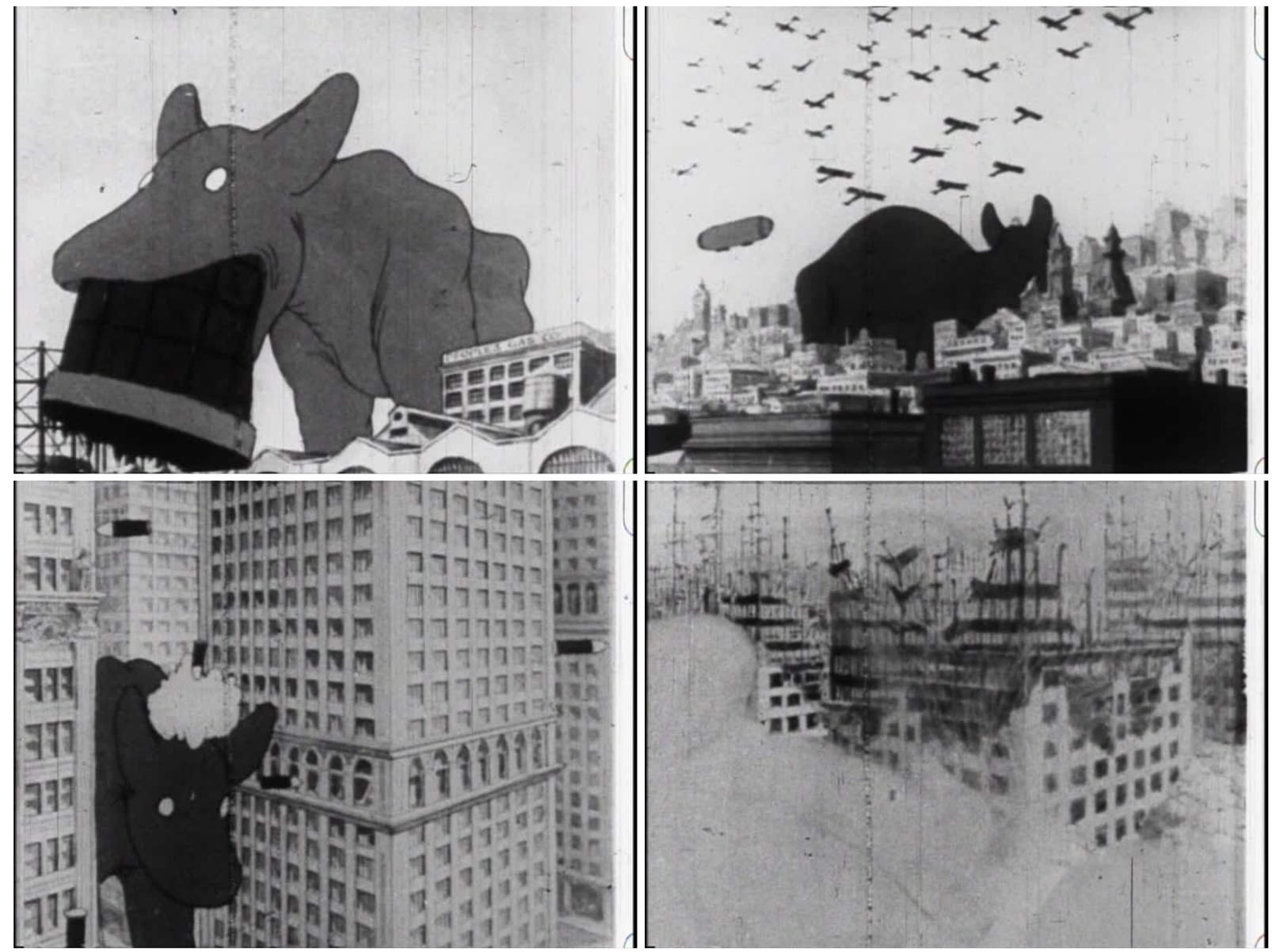

Figure 4.2. The Pet (McCay, 1921).

\footnotetext{
${ }^{4}$ Paul Flaig, "Life driven by death: animation aesthetics and the comic uncanny," Screen, 54.1 (2010): 12.
} 
For McCay, soulless automation, an effect produced through modern experience of mechanized technology, was synonymous with the potential for sudden death, which he represented in his films with sudden, deanimated stillness. Thus when the lively characters in Little Nemo cease moving, it is only logical that the following shot reveals the automated apparatus behind their movement. This motivated McCay's desire in his early films to actively assert his power over the machine producing these visions, tentatively embracing mechanized technology so long as he controlled it; he was "a modern technician", representing "the twentieth-century man ingenious enough to put the complex apparatus of animation cinematography at his service". 5 His animated self-figuration in Nemo and more overtly in Gertie further cemented McCay in this position, signifying the animator, not the film camera, as the force behind the perceptual slippage that occurs between the disparate universes of animation and live-action.

In contrast, The Pet presents no self-aggrandizing setup or flamboyant showmanship, only a defeated statement of weariness with the modern automated world; one is reminded here of Cohl's satirical remark ten years earlier in En Route that "man no longer exhausts himself, but the world has become quite annoyed with him". Indeed, as evidenced by his inebriated public scorning of his peers in 1927, McCay was displeased with those industry-minded "artists" who had pushed film animation in a direction he could not follow. As Blackmore notes, McCay had likened his own Herculean work ethic over the years "to a drawing machine, a commodified product which must be maintained in smooth working condition"; when film animation technology began to far outstrip the output of his individual faculties, he became, like Emile Cohl in Les Beaux-Arts Mystérieux, "an alien in the machine of another's devising". ${ }^{6}$ The creature in The Pet is this alien: it performs a meta-narrative of McCay's artistic career, growing ever larger to

${ }^{5}$ Crafton, 1982: 134.

${ }^{6}$ Blackmore, 34. 
dwarf its urban background and consuming scenery with machine-like persistence until its sudden death. Dark as it is, however, this meta-narrative of the artist, as J.P. Telotte writes, still testifies to the animator's power to navigate and depict on-screen the invisible space of the mind:

This unknown, unidentified and rather vaguely drawn species [the pet] simply gouges ever greater holes in the detailed and conventional landscape McCay has drawn, and in a highly ironic way, I would suggest, points towards the work of the artist, as the figure who both creates and erases, always suggesting other possibilities, always dueling with that empty space. It is also clearly a figure (both 'pet' and artist) freighted with anxiety because of its very capacity for opening up these holes, for threatening our conventional sense of space, for challenging our world view. We might even think of it as the very spectre of modernism, stalking through the animated world, reminding us of how pliable cinematic space is and how similarly malleable the real world might also prove to be. ${ }^{7}$

As Telotte suggests, the film still hints at McCay's motif of presenting a glissando between the internal phantasmic universe of animation and the external physical world, a perceptual change effected by the animator and motivated by his desire to balance the human subjectivity of animation with the mechanical indifference of automation. In its perceptual flexibility, the animated image can thus function on the same plane as the photographic image, an image which, as Gunning maintains, "opens up a passageway to its subject, not as a signification but as a world, multiple and complex". 8

\section{Return to the Present}

Contemporary media is often linked to animation by way of the use of special effects, which attempt to simulate an illusory world imagined by the animation team, located either at the core of the production (as in a CGI-produced feature) or merely on the margins (as in digital corrections to live-action shooting). Both types of productions have, perhaps too liberally, been

\footnotetext{
${ }^{7}$ Telotte, 473.

${ }^{8}$ Gunning, 2008: 35.
} 
associated with the creation of "perceptual realism", a term most notably employed by Stephen Prince in his analysis of digitally-animated special effects. Anticipating Manovich's definition of animation, Prince writes that the "flexibility" of digital imaging "frees it from the indexicality of photography's relationship with its referent", while ascribing this emphasis on the indexical relationship to Bazin's ontology of the cinema. ${ }^{9}$ In this vein, he argues that there has been a "perceptually realistic" approach to digital imaging:

A perceptually realistic image is one which structurally corresponds to the viewer's audiovisual experience of three-dimensional space. Perceptually realistic images correspond to this experience because film-makers build them to do so. Such images display a nested hierarchy of cues which organize the display of light, color, texture, movement, and sound in ways that correspond with the viewer's own understanding of these phenomena in daily life. Perceptual realism, therefore, designates a relationship between the image or film and the spectator, and it can encompass both unreal images and those which are referentially realistic. Because of this, unreal images may be referentially fictional but perceptually realistic. ${ }^{10}$

Prince makes several useful observations here, but the overall argument is porous, failing to account for the intricacies of animation spectatorship. One could argue that Winsor McCay's images were perceptually realistic, even though they did not always attempt to conform to the viewer's experience of physical worldly space. For example, how might this understanding of perceptual realism account for Little Nemo's seamless transition from re-enforced framing to three-dimensional perspective, or the wanton co-mingling of Gertie's live-action realism and animated imagination? It is appropriate to repeat here Telotte's argument that far from replicating real-world space, McCay's animation was usually implicated in a subversion of "both the organization of, and the audience's experience of, space itself". ${ }^{11}$

\footnotetext{
${ }^{9}$ Stephen Prince, "True Lies: Perceptual Realism, Digital Images, and Film Theory," Film Quarterly, 49.3 (1996): 28-30.

${ }^{10}$ Prince, 32.

${ }^{11}$ Telotte, 464.
} 
Prince further states that perceptually realistic images correspond to this experience "because film-makers build them to do so". Again, early animation is the counterpoint to the erasure of important historical details. Does the perceptual realism of The Sinking of the Lusitania solely derive from a facile imitation of real-world space? Or is it not constructed from a myriad of influences including McCay's idiosyncratic pinpoint-attention to detail, the hyperbolic propaganda of war newsreels, anxiety towards modern war technologies, and emerging conventions in narrative cinema?

This criticism is equally applicable with contemporary animation. For example, Disney's WALL-E (2008), in which a fictional future is digitally rendered in such a way that attempts to mimic photochemical technology, would be "referentially fictional" under Prince's terms. It is not, however, necessarily "unreal”, which is conflated with "referentially fictional”. Again, this assumes that a prerequisite for the indexical relationship is that which exists in the image must also exist in the world. But as animation repeatedly demonstrates, the only requirement for perception-as-real is perception itself, resonating with Gunning's assertion that "no difference exists between watching a film of a ball rolling down a hill, say, and seeing an actual ball rolling down a hill". ${ }^{12}$ Animators simply turn this fact of perception inward; Robertson's phantasms, for instance, had no external referent, but they appeared real because the spectator was able to imagine it as such. As this spectator became more enlightened, animators searched out new ways to place them in the dark again - if only briefly, as in the case of McCay and Cohl, who did not see demystification as necessarily opposed to enlightenment. Animators continue to do so with digital media, navigating and perpetuating the tension between the enlightening reveal of the automated mechanism and the mystifying power of the shamanic conjurer of self-acting images.

Therefore, in this study, I have put forward that the unique visual style and pioneering

${ }^{12}$ Gunning, 2010: 264. 
influence of these animators respectively submits the work of each as a paradigm of how to understand recent animated productions, both mainstream and experimental, through the three cinematic components named here as screen, simulation, and situation. These analyses have demonstrated that the self-reflexive tendencies of these animators' work impulsively toyed with the effacement and disclosure of the mechanisms, both human and automated, behind the projection of ostensibly self-acting animated images - an impulse, furthermore, which is rooted in archaic forms of animated displays, such as the Phantasmagoria. It is this fascination with the artifice of animation and automation which has persisted in contemporary forms of animation and moving image production more broadly. As Vivian Sobchack explains:

This contemporary emphasis on automation as 'having its motive power so concealed that is appears to move spontaneously', but doing so 'under conditions fixed for it, but not by it'...does return us to the cinematic apparatus and, even more so, to the computer, whose 'motive power' not only often appears 'spontaneous' but also seems to involve 'little labour' because we do not see its parts in automatic and serial action. ${ }^{13}$

This continuing fascination with the mystifying capacity of animation is significant as the invisible mechanisms of the digital apparatus seem to hold this portentous power. The rich parallels offered by early film animation to present-day moving image technology cannot be ignored; it is not for nothing that current virtual cinematography, like the self-figuration of the early animators, "often asserts its ability, over and above the traditional camera apparatus, to surpass physical restrictions". ${ }^{14}$

Contemporary animation, then, continues to trade in the phantasmatic pleasures of mystification and enlightenment achieved at Robertson's magic lantern show two centuries ago and brought into the cinematic medium one century ago by Emile Cohl and Winsor McCay.

\footnotetext{
13 Sobchack, 2009: 383.

14 Jones, 254.
} 
Digitally-created beings without physically tangible bodies perform for a shape-shifting screen while simulating the analog motion of life, as a result of years of building on graphic depictions of pure imagination. They are impressions and expressions of reality, or, to borrow Castle's summation of the Phantasmagoria, one's thoughts bizarrely externalized - the spectator knows they do not exist, but sees them anyway.

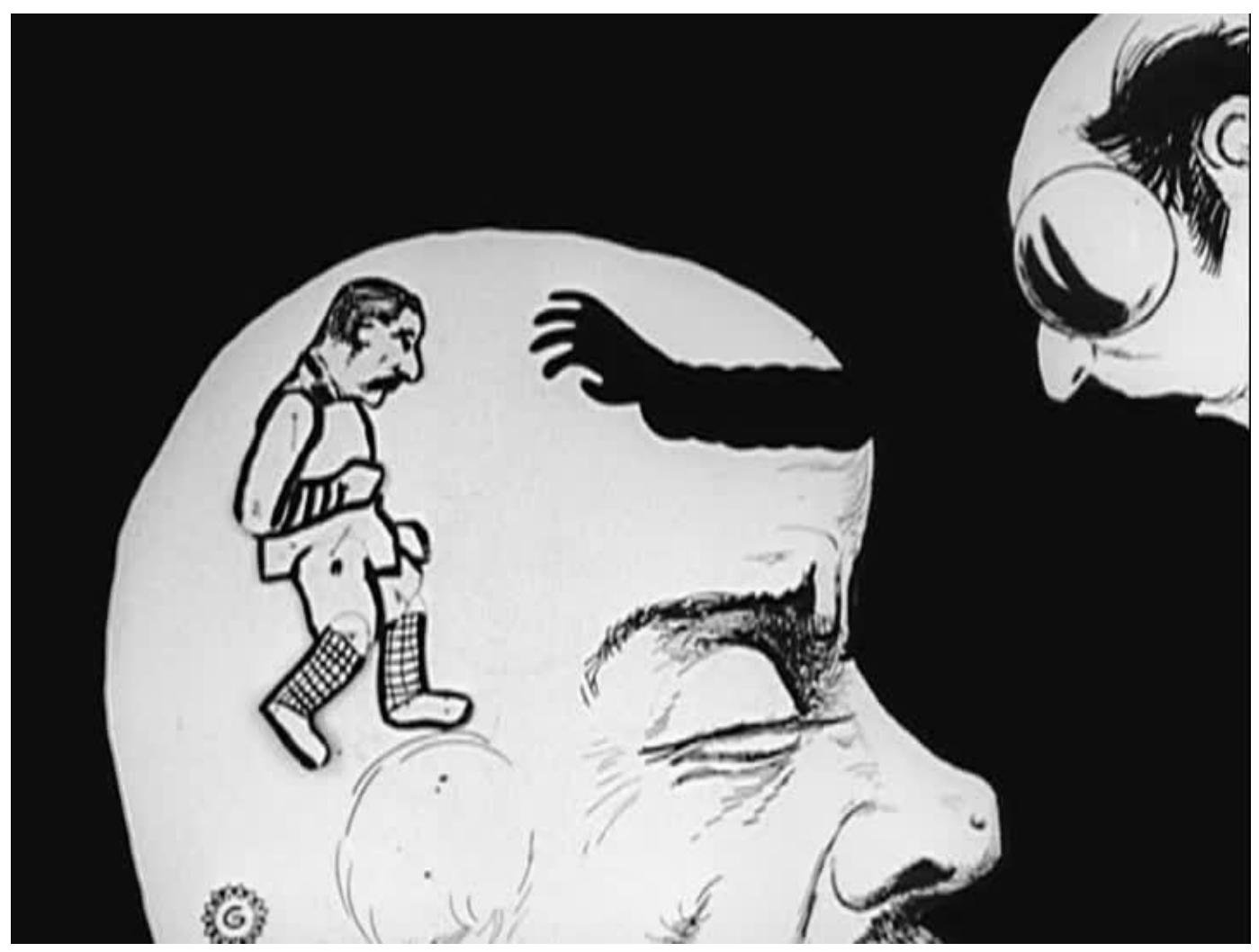

Figure 4.3. Vision reaching inwards in Rien n'est impossible à l'homme (Cohl, 1910). 


\section{Bibliography}

\section{Books and Chapters}

Bazin, André. What is Cinema? Translated by Hugh Gray. Berkeley: University of California Press, 1967.

Canemaker, John. Winsor McCay: His Life and Art. New York: Abbeville Press, 1987.

Cholodenko, Alan, ed. The Illusion of Life: Essays on Animation. Sydney: Power Publications, 1991.

Connery, Thomas B. Journalism and Realism: Rendering American Life. Evanston: Northwestern University Press, 2011.

Crafton, Donald. Before Mickey: The Animated Film 1898-1928. Cambridge: MIT Press, 1982.

_. Emile Cohl, Caricature, and Film. Princeton: Princeton University Press, 1990.

Crary, Jonathan. Techniques of the Observer: on vision and modernity in the nineteenth century. MIT Press, 1996.

Eisenstein, Sergei. “On Disney.” The Eisenstein Collection, edited by Richard Taylor, 85-175. New York: Seagull Books, 2006.

—. "Notes on Drawing." The Eisenstein Collection, edited by Richard Taylor, 186-210. New York: Seagull Books, 2006.

Friedberg, Anne. The Virtual Window: From Alberti to Microsoft. Cambridge: MIT Press, 2006.

Gunning, Tom. "Moving Away from the Index: Cinema and the Impression of Reality." In The Film Theory Reader: Debates and Arguments, edited by Marc Furstenau, 255-269. New York: Routledge, 2010.

—. "What's the Point of an Index? Or Faking Photographs." Still/Moving: between Cinema and Photography, edited by Karen Beckman and Jean Ma, 23-40. Durham: Duke University Press, 2008.

Leslie, Esther. Hollywood Flatlands: Animation, Critical Theory and the Avant-Garde. New York: Verso, 2002.

Manovich, Lev. "Digital Cinema and the History of a Moving Image." In The Film Theory Reader: Debates and Arguments, edited by Marc Furstenau, 245-254. New York: Routledge, 2010. 
McAllister, T.H. Catalogue of stereopticons, dissolving view apparatus, magic lanterns: and list of over 3000 carefully selected views for the illustration of subjects of popular interest. New York: McAllister Company, 1867. Accessed January 10, 2014.

https://archive.org/details/catalogueofstere00thmc

Nasaw, David. "Cities of Light, Landscapes of Pleasure." In The Landscape of Modernity: Essays on New York City, 1900-1940, edited by David Ward and Olivier Zunz, 273-286. New York:

Russell Sage Foundation, 1992.

Nekola, Charlotte. "When New York Wasn't Big Enough: The Contradictions of Space, Real and Imagined, in 1890's New York." in Public Space, Private Lives: Race, Gender, Class and Citizenship in New York, 1890-1929, edited by William Boelhower and Anna Scacchi, 263-272. Amsterdam: VU University Press, 2004.

Neupert, Richard. French Animation History. Malden, Oxford: Wiley-Blackwell, 2011.

Robertson, Étienne-Gaspard. Mémoires Récréatifs, Scientifiques et Anecdotiques Vol.1. Paris: Librairie de Wurtz, 1831. Accessed January 3, 2014.

https://archive.org/details/mmoiresrcratifss01 robe.

- Mémoires Récréatifs, Scientifiques et Anecdotiques Vol.2. Paris: Librairie de Wurtz, 1831. Accessed January 3, 2014. https://archive.org/details/mmoiresrcratifss02robe.

Schwartz, Vanessa. Spectacular Realities: Early Mass Culture in Fin-de-Siècle Paris. Berkeley: University of California Press, 1998.

Shapiro, Alan. "Images: Real and Virtual, Projected and Perceived, from Kepler to Dechales." Inside the Camera Obscura: Optics and art under the spell of the projected image, edited by Wolfgang Lefèvre, 75-94. Max Planck Insitute for the History of Science, 2007.

Sobchack, Vivian. "Phenomenology and the Film Experience." Viewing Positions: Ways of Seeing Film, edited by Linda Williams, [insert pages]. New Jersey: Rutgers University Press, 1995.

Ward, David and Olivier Zunz. "Between Rationalism and Pluralism: Creating the Modern City." In The Landscape of Modernity: Essays on New York City, 1900-1940, edited by David Ward and Olivier Zunz, 3-15. New York: Russell Sage Foundation, 1992, 4.

Warner, Marina. Phantasmagoria: Spirit Visions, Metaphors, and Media into the Twenty-first Century. New York: Oxford University Press, 2006.

Wells, Paul. Understanding Animation. New York: Routledge, 1998. 


\section{Journal Articles}

Barber, X. Theodore. "Phantasmagorical Wonders: The Magic Lantern Ghost Show in Nineteenth-Century America.” Film History, 3.2 (1989): 73-86.

Blackmore, Tim. “McCay's McChanical Muse: Engineering Comic-Strip Dreams.” Journal of Popular Culture, 32.1 (1998): 15-38.

Castle, Terry. "Phantasmagoria: Spectral Technology and the Metaphorics of Modern Reverie." Critical Inquiry, 15.1 (1988): 26-61.

Cohen, Margaret. “Walter Benjamin’s Phantasmagoria.” New German Critique, 48 (1989): 87-107.

Crafton, Donald. "The Veiled Genealogies of Animation and Cinema." Animation: An Interdisciplinary Journal, 6.2 (2011): 93-110.

Elsaessar, Thomas. "The New Film History as Media Archaeology." Cinémas: Journal of Film Studies, 14.2 (2004): 75-117.

Flaig, Paul. "Life driven by death: animation aesthetics and the comic uncanny." Screen, 54.1 (2010): 1-19.

Gauthier, Philippe. “A Trick Question: Are Early Animated Drawings a Film Genre or Special Effect?” Animation: An Interdisciplinary Journal, 6.2 (2011): 163-175.

Honess Roe, Annabelle. "Absence, Excess and Epistemological Expansion: Towards a Framework for the Study of Animated Documentary." Animation: An Interdisciplinary Journal, 6.3 (2011): 215-230.

Jones, Nick. "Quantification and Substitution: The Abstract Space of Virtual Cinematography." Animation: An Interdisciplinary Journal, 8.3 (2013): 253-266.

Mirzeoff, Nicholas. “On Visuality.” Journal of Visual Culture, 5.1 (2006): 53-79.

Morton, Drew. "Sketching Under the Influence? Winsor McCay and the Question of Aesthetic Convergence Between Comic Strips and Film.” Animation: An Interdisciplinary Journal, 5.3 (2010): 295-312.

Prince, Stephen. “True Lies: Perceptual Realism, Digital Images, and Film Theory." Film Quarterly, 49.3 (1996): 27-37.

Sobchack, Vivian. "Animation and automation, or, the incredible effortfulness of being." Screen, 50.4 (2009): 375-391. 
"The Line and Animorph or 'Travel is More than Just A to B'." Animation, 3.3 (2008): 251-265.

Telotte, J.P. “Winsor McCay’s warped spaces.” Screen, 48.4 (2007): 463-473.

Vermeir, Koen. "The Magic of the Magic Lantern (1660-1700): On Analogical Demonstration and the Visualization of the Invisible." The British Journal for the History of Science, 38.2 (2005): 127-159.

Whitelaw, Mitchell. "After the Screen: Array Aesthetics and Transmateriality." Column, 7 (2011): 50-57.

\section{Newspapers and Magazines}

Theisen, Earl. "The Archaeology of the Motion Picture in Three Parts - Part II." International Photographer, 8 (1936): 4-5.

“Winsor McCay gives exhibition.” The New York Times. July 20, 1927, 29.

\section{Audiovisual Sources}

Gaumont Treasures Vol. 2: 1908-1916. Kino International, 2011. DVD, 550 minutes.

Merkl, Ulrich. The Complete Dream of the Rarebit Fiend by Winsor McCay. Merkl, 2007. DVD, 820 images.

Winsor McCay: The Master Edition. Milestone Cinematheque, 2004. DVD, 105 minutes. 